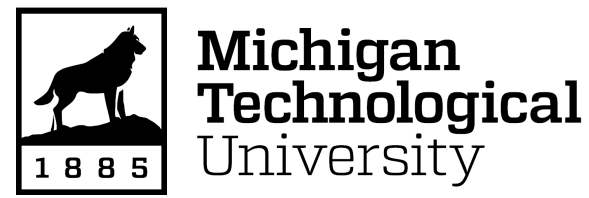

Michigan Technological University Digital Commons @ Michigan Tech

Comparison of Ignition Delays and Liquid Penetrations of JP-8, Synthetic JP-8, and a JP-8 Surrogate under Diesel Engine Conditions

Kyle Yeakle

Michigan Technological University, kjyeakle@mtu.edu

Copyright 2016 Kyle Yeakle

Recommended Citation

Yeakle, Kyle, "Comparison of Ignition Delays and Liquid Penetrations of JP-8, Synthetic JP-8, and a JP-8 Surrogate under Diesel Engine Conditions", Open Access Master's Thesis, Michigan Technological University, 2016.

https://doi.org/10.37099/mtu.dc.etdr/144

Follow this and additional works at: https://digitalcommons.mtu.edu/etdr

Part of the Energy Systems Commons 


\title{
COMPARISON OF IGNITION DELAYS AND LIQUID PENETRATIONS OF JP-8, SYNTHETIC JP-8, AND A JP-8 SURROGATE UNDER DIESEL ENGINE CONDITIONS
}

\author{
By \\ Kyle J. Yeakle \\ A THESIS \\ Submitted in partial fulfillment of the requirements for the degree of \\ MASTER OF SCIENCE \\ In Mechanical Engineering
}

MICHIGAN TECHNOLOGICAL UNIVERSITY

2016

(C) 2016 Kyle J. Yeakle 
This thesis has been approved in partial fulfillment of the requirements for the Degree of MASTER OF SCIENCE in Mechanical Engineering.

Department of Mechanical Engineering - Engineering Mechanics

Thesis Advisor: Jeffrey Naber

Committee Member: Jaclyn Johnson

Committee Member: $\quad$ David Wanless

Department Chair: $\quad$ William Predebon 


\section{Table of Contents}

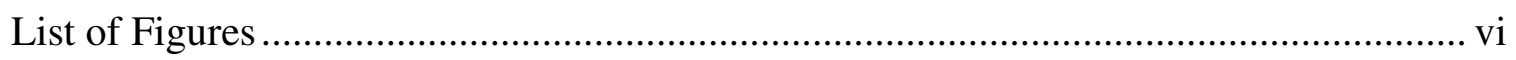

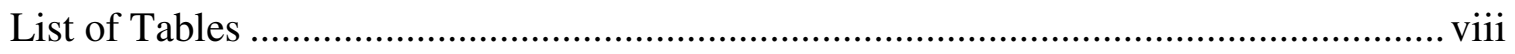

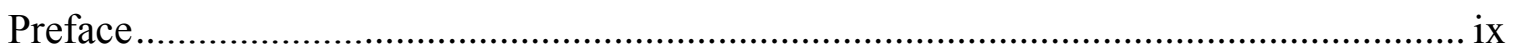

Acknowledgements ............................................................................................. $\mathrm{x}$

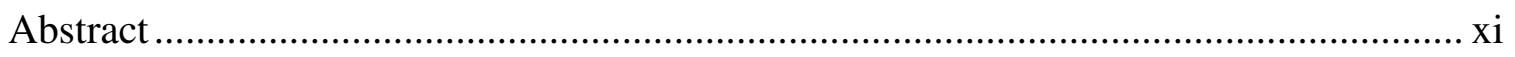

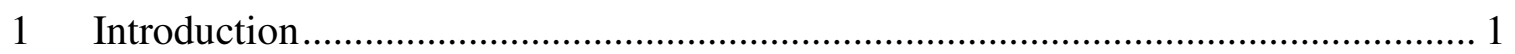

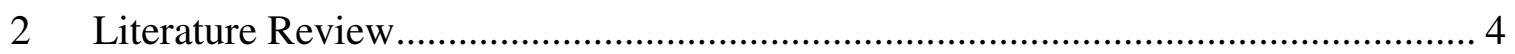

2.1 Fundamental Spray and Combustion Measurements of JP-8 at Diesel

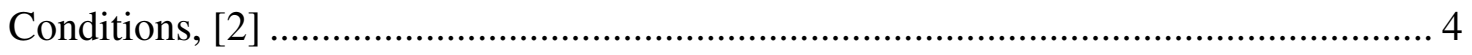

2.2 The Combustion and Ignition Characteristics of Varying Blend Ratios of JP-8 and a Coal to Liquid Fischer-Tropsch Jet Fuel in a Military Relevant Single Cylinder Diesel Engine, [6] …………………………………………………………….. 5

2.3 The Ignition Behavior of a Coal to Liquid Fischer-Tropsch Jet Fuel in a Military

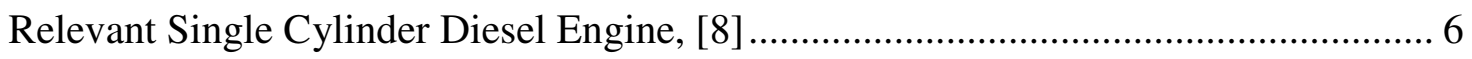

2.4 Liquid-Phase Fuel Penetration in Diesel Sprays, [9] ……………...................... 7

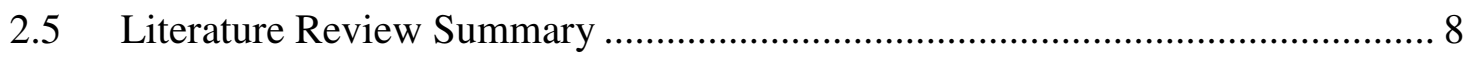

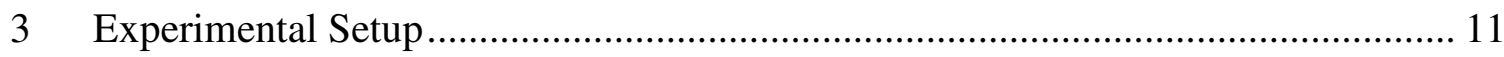

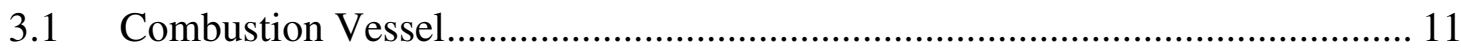

3.2 Pulse Generator's and Pulse Generator Logic..................................................... 13

$3.3 \quad$ High Speed Camera....................................................................................... 15

3.3.1 $21 \% \mathrm{O}_{2}$ Combusting Mie Scattering/Natural Luminosity Imaging Setup .. 17

3.3.2 $0 \% \mathrm{O}_{2}$ Non-combusting Mie Scattering Imaging Setup ………………...... 18

3.4 Fuel Injector, Injector Driver and High Pressure Fuel Pump System ................ 19

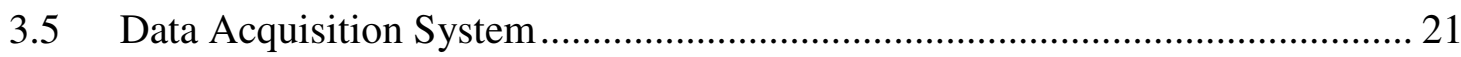




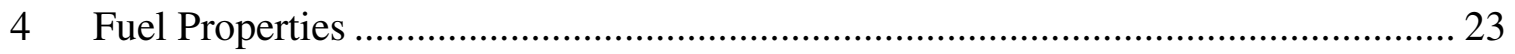

$4.1 \quad$ JP-8

4.2 Synthetic JP-8 (LCJP-8) ....................................................................... 24

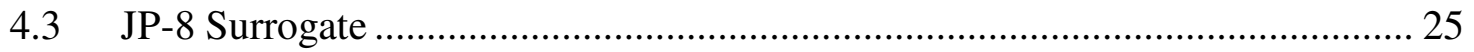

5 Test Conditions and Testing Goals .............................................................. 28

5.1 Combusting Spray Test Conditions and Testing Goals ................................ 28

5.2 Non-combusting Spray Test Conditions and Testing Goals ............................ 31

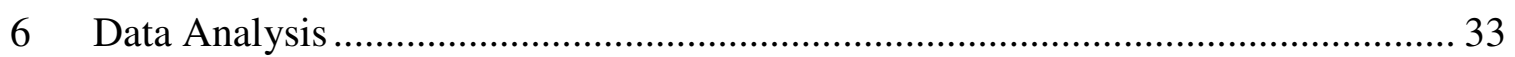

6.1 Combusting Image Processing .................................................................. 36

6.2 Non-combusting Image Processing................................................................. 39

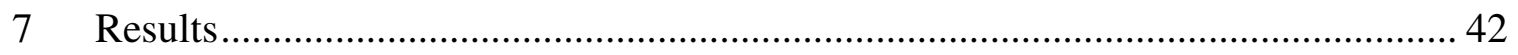

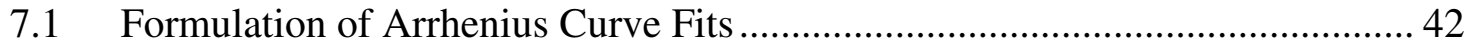

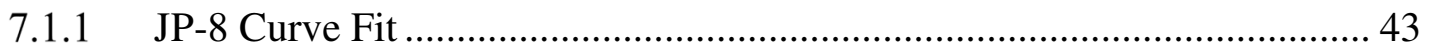

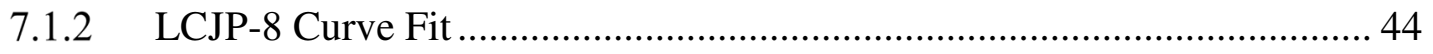

7.1.3 LCJP-8 versus JP-8 Curve Fit Coefficients .......................................... 47

7.1.4 Statistical Deviation of Ignition Delay ............................................... 47

7.2 Comparison of JP-8 Arrhenius Curve to Pickett and Hoogterp, [2] ................ 49

7.3 Comparison of JP-8 and LCJP-8 Arrhenius Curve Correlations ...................... 51

7.4 Comparison of Ignition Delays of JP-8 and JP-8 Surrogate .......................... 55

7.5 Effect of Fuel Temperature on Ignition Delay ............................................ 57

7.6 Comparison of Liquid Penetration Results ............................................. 58

7.6.1 Liquid Penetration Comparison of JP-8 and LCJP-8 ................................ 59

7.6.2 Liquid Penetration Comparison of JP-8 and JP-8 Surrogate .................... 61

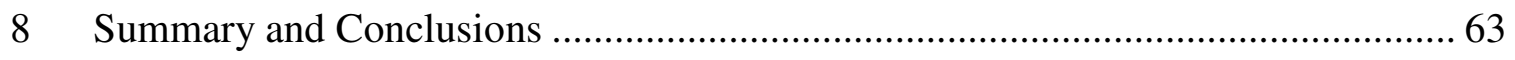




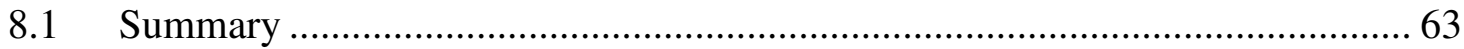

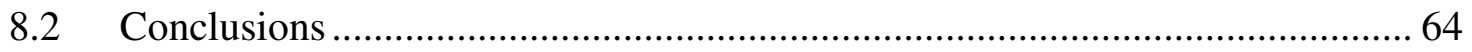

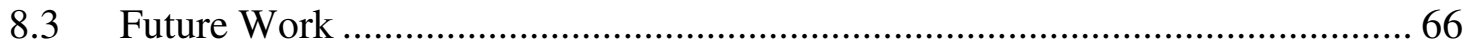

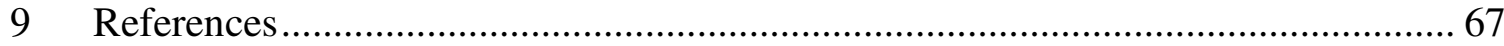

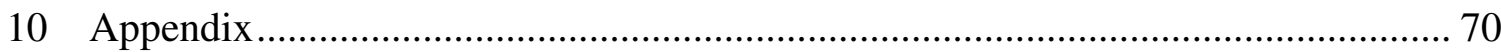

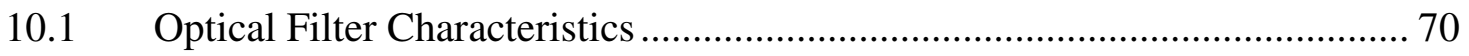

10.2 Combusting Test Matrix, JP-8 and LCJP-8 ............................................ 72

10.3 Test Matrix for the Statistical Testing of JP-8 ....................................... 77

10.4 Combusting Test Matrix, JP-8 Surrogate ................................................. 78

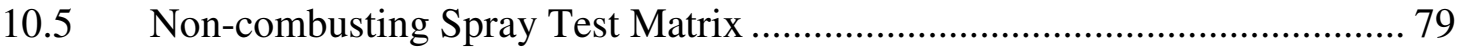




\section{List of Figures}

Figure 3-1: Combustion Vessel Schematic: Corner Ports (Upper Left), Window Ports

(Lower Left), and Assembled Cut Away (Right) …………………………..................... 12

Figure 3-2: Pulse Generator Control Schematic ............................................................ 14

Figure 3-3: Pulse Generator Timing Diagram ........................................................... 15

Figure 3-4: Combusting Spray Imaging Setup, Top View …………………………... 16

Figure 3-5: Non-combusting Spray Imaging Setup, Top View ……………………….... 17

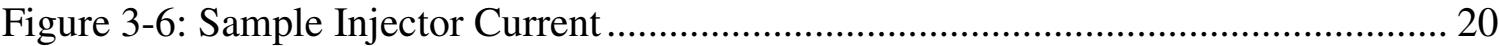

Figure 3-7: Bosch HPCR solenoid type injector with 200 micron nozzle hole diameter. 21

Figure 3-8: Fuel pump system used to pressurized injector ............................................ 21

Figure 4-1: Distillation Curve for Nominal JP-8 and the Developed JP-8 Surrogate [18]27

Figure 6-1: Initial Liquid Penetration Development. LCJP-8 @ Pinj. $=1000$ bar, $\rho_{\text {amb. }}=24$

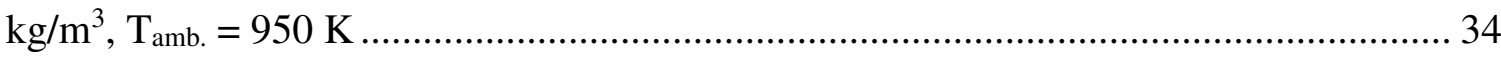

Figure 6-2: Ignition and Flame Development from Steady State Liquid Penetration.

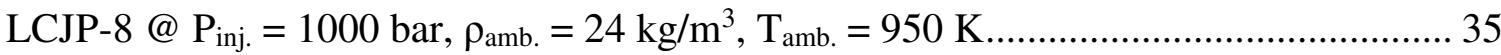

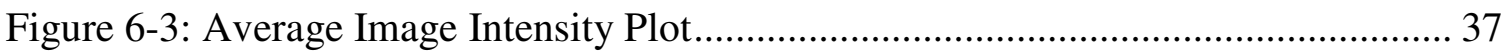

Figure 6-4: Average Image Intensity, Achieving Steady State Liquid Spray Baseline

Intensity 38

Figure 6-5: Visual on the Image Processing from Raw Image to Tracked Value. JP-8 @

$P_{\text {inj. }}=1000$ bar, $\rho_{\text {amb. }}=24 \mathrm{~kg} / \mathrm{m}^{3}, \mathrm{~T}_{\mathrm{amb}}=900 \mathrm{~K}$

Figure 6-6: Liquid Penetration Results Plot of Non-combusting Image Processing. JP-8

Surrogate @ $\mathrm{P}_{\mathrm{inj} .}=1000 \mathrm{bar}, \rho_{\mathrm{amb}}=24 \mathrm{~kg} / \mathrm{m}^{3}, \mathrm{~T}_{\mathrm{amb}}=800 \mathrm{~K}$

Figure 7-1: Arrhenius Curve Fit Results of JP-8 Overlaid on Sample Data Sets (Ambient

Density $=24.0 \mathrm{~kg} / \mathrm{m}^{3}$ ) 44

Figure 7-2: Arrhenius Curve Fit Results of LCJP-8 Overlaid on Sample Data Sets

(Ambient Density $\left.=24.0 \mathrm{~kg} / \mathrm{m}^{3}\right)$.

Figure 7-3 : Arrhenius Curve Fit Results of LCJP-8 Overlaid on Sample Data Sets

$\left(\right.$ Ambient Density $\left.=30.2 \mathrm{~kg} / \mathrm{m}^{3}\right)$ 
Figure 7-4: Average Ignition Delay with 1 Standard Deviation Error Bars Overlaid with JP-8 Arrhenius Correlation. Ambient Core Density $=24.0 \mathrm{~kg} / \mathrm{m}^{3}$, Injection Pressure $=$ 1000 bar.

Figure 7-5: Comparison of Past Ignition Delay Data with Develop JP-8 Arrhenius Curve, $\left(\mathrm{P}_{\text {inj }}=1470\right.$ bar, Ambient Core Density $\left.=30.0 \mathrm{~kg} / \mathrm{m}^{3}\right)$ 50

Figure 7-6: Comparison of JP-8 and LCJP-8 Ignition Delay Correlations, Sweeping Injection Pressure. Ambient Density: $24.0 \mathrm{~kg} / \mathrm{m}^{3}$. 52

Figure 7-7: Comparison of JP-8 and LCJP-8 Ignition Delay Correlations, Sweeping Ambient Density. Injection Pressure: 1000 bar . 54

Figure 7-8: Comparison of Ignition Delays of JP-8 Arrhenius Correlation and JP-8

Surrogate. Ambient Core Density $=24.0 \mathrm{~kg} / \mathrm{m}^{3}$ 56

Figure 7-9: Effect of Fuel Temperature on Ignition Delay of JP-8. Injection Pressure = 1000 bar, Ambient Core Density $=24.0 \mathrm{~kg} / \mathrm{m}^{3}$ 57

Figure 7-10: Effect of Fuel Temperature on Ignition Delay of LCJP-8. Injection Pressure $=1000$ bar, Ambient Core Density $=24.0 \mathrm{~kg} / \mathrm{m}^{3}$ 58

Figure 7-11: Steady State Median Liquid Penetration Comparison of JP-8 and LCJP-8. Ambient Density $=24.0 \mathrm{~kg} / \mathrm{m}^{3}$ 60

Figure 7-12: Steady State Median Liquid Penetration Comparison of JP-8 and JP-8 Surrogate. Ambient Density $=24.0 \mathrm{~kg} / \mathrm{m}^{3}$. 62

Figure 10-1: Edmund Optics, VG-9 filter transmission (From Edmund Scientific, 2014)

Figure 10-2: Edmund Optics, BG-39 filter transmission (From Edmund Scientific, 2014) 


\section{List of Tables}

Table 2-1: Summary of Literature Review, JP-8 and LCJP-8 ….................................. 9

Table 2-2: Summary of Literature Review, Liquid Sprays.......................................... 10

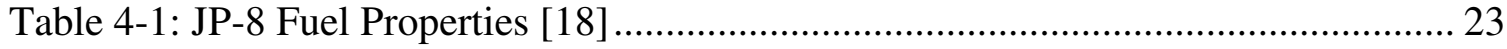

Table 4-2: Property Comparison of JP-8 and LCJP-8, [5] [7] [8] ................................ 25

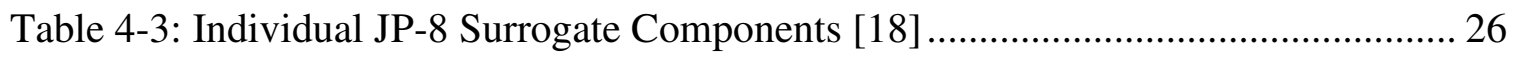

Table 4-4: Individual JP-8 Surrogate Volume Fractions [18] ..................................... 26

Table 4-5: Comparison of JP-8 and JP-8 Surrogate Properties [18]............................. 27

Table 5-1: Condensed Test Matrix for JP-8, LCJP-8 Combusting Tests ....................... 29

Table 5-2: Condensed Test Matrix of the Statistical Testing of JP-8 at Varying Ambient

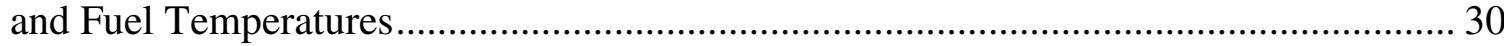

Table 5-3: Condensed Combusting Test Matrix, JP-8 Surrogate ................................. 31

Table 5-4: Condensed Test Matrix for Non-combusting Spray Testing.......................... 32

Table 7-1: Arrhenius Fit Coefficients Developed for JP-8 and LCJP-8 ......................... 47

Table 10-1: Combusting Test Matrix, $7.3 \mathrm{~kg} / \mathrm{m}^{3}$ Ambient Density ............................... 72

Table 10-2: Combusting Test Matrix, 14.8 kg/m³ Ambient Density.............................. 73

Table 10-3: Combusting Test Matrix, 18.0 kg/m³ Ambient Density.............................. 74

Table 10-4: Combusting Test Matrix, 24.0 kg/m³ Ambient Density.............................. 75

Table 10-5: Combusting Test Matrix, $30.2 \mathrm{~kg} / \mathrm{m}^{3}$ Ambient Density .............................. 76

Table 10-6: Statistical Testing of JP-8 at Varying Fuel Temperatures............................ 77

Table 10-7: Combusting Test Matrix, JP-8 Surrogate ..................................................... 78

Table 10-8: Non-combusting Spray Test Matrix ......................................................... 79 


\section{Preface}

The figures and tables included in section 4.3, specifically Figure 4-1 and Table 4-3, Table 4-4, and Table 4-5, were produced collaboratively with Meng Tang. Meng developed the surrogate fuel and matched the desired fuel properties using Chemkin, and the tables and figures were produced collaboratively for the purpose of using for this project. 


\section{Acknowledgements}

I would like to thank everyone involved with helping to ensure the realization of this thesis, both in support and in time dedicated.

Foremost, I would like to thank my research advisor, Dr. Jeffrey Naber, for the help and direction he gave me on this project and many other projects over the course of my time here. I would also like to thank my committee members, Dr. Jaclyn Johnson and Dr. David Wanless for all of their time and advice given to me.

I would also like to give thanks to TARDEC for sponsoring the project work and specifically to Peter Schihl for his guidance.

All of the members of the AERB team who helped countless times by with advice and with time donated to my work.

Lastly I would like to acknowledge all of my family and friends for their help, patience and support over the last two years. Specifically I would like to thank my parents and Olivia for their endless support and understanding throughout my time here.

Thanks to all of you,

Kyle 


\section{Abstract}

The U.S. Army and many NATO affiliates have adopted a 'one fuel forward fuel policy' (OFF). The goal of the OFF policy is reducing the logistics and cost involved with providing fuel for military vehicles. With this policy, the logical choice fuel is military grade jet petroleum, JP-8, because of the fuel constraints of turbo-jet engines. This requirement has made it necessary to run military compression ignited engines on JP-8. To reduce the Army's reliance on petroleum based fuels an alternative fuel, synthetic JP8 , derived from coal and made in the Fischer-Tropsch production method is allowed to be blended up to $50 \%$ with JP-8. The two fuels have varying cetane numbers of for 43.1 for JP-8 and 25 for the synthetic JP-8 which influence combustion characteristics. Therefore, the goal of the current work is to characterize the ignition characteristics of synthetic JP-8 as compared to the reference JP-8 under the same test conditions. A JP-8 surrogate fuel is also developed and compared against the baseline fuel in terms of both ignition behavior and liquid penetration. Testing is conducted in an optically accessible combustion vessel sweeping ambient temperatures and densities of $800-1100 \mathrm{~K}$ and $7.3-30.2 \mathrm{~kg} / \mathrm{m}^{3}$, respectively. The resultant data is used in comparison of all three fuels in ignition delay and steady state liquid penetration characteristics. Correlations are also developed for calculating the ignition delay of both the JP-8 and the synthetic JP-8 fuel and is used to compare to the surrogate fuel and to compare to a pool of data from past work on JP-8. Results of these comparisons show a 50\% increase in the ignition delay and a $10 \%$ shorter steady state liquid penetration of the low cetane value synthetic JP-8 over the baseline JP-8 fuel sample. Findings also show the surrogate matches the baseline fuel to within $10 \%$ for ignition delays but it over penetrates the baseline fuel by around $30 \%$ for liquid penetration. 


\section{Introduction}

The U.S. Army and many NATO affiliates have adopted a 'one fuel forward fuel policy' (OFF). The goal of the OFF policy is reducing the logistics and cost involved with providing fuel for military vehicles. With this policy, the logical choice fuel is military grade jet petroleum, JP-8, because of the fuel constraints of turbo-jet engines [1]. This requirement has made it necessary to run military compression ignited (CI) engines on JP-8 when they are normally designed to run on diesel fuel. Since the adoption of JP-8, work has followed to characterize its ability to run in military CI engines and has been shown to be largely able and effective [2] [3] [4]. There have been some issues with the fuel in CI engines though. Typically there has been a history of fuel injector/pump system failures and decreased output power of the engine. These issues have been largely linking to the differing fuel properties between JP-8 and diesel. These differing fuel properties have been investigated and the resultant effect they have on engine operation has been documented [2] [3] [4]. Particularly the work by Pickett and Hoogterp, [2], has explored the essential characterization of JP-8, including the spray, vaporization and ignition properties of the fuel and how it compares to diesel. From their conclusions it is shown that JP-8 is found to have lower vapor penetrations, approximately 10-15\% lower, attributed to the lower distillation curve temperatures and also have longer ignition delays of around $25-50 \%$. The latter finding is largely in effect of the lower cetane number (CN) of their sample of JP-8, being just 38 compared to a typical diesel CN of 42-45. Since the $\mathrm{CN}$ of diesel is very tightly controlled for use in CI engine design, it becomes a very important parameter when trying to substitute an alternative fuel of any kind.

Understanding how the ignition delay changes in military CI engines running JP-8 becomes the driving force for the previously mentioned studies, but also of concern is how the CN changes batch-to-batch. Since the production process of JP-8 does not regulate $\mathrm{CN}$ it tends to vary, to the extent as recorded in the 2008 report of the Petroleum Quality Information System [5] which lists the global variance of JP-8 for that year to have cetane numbers anywhere from 32.4 to 52.2. This inconsistency is reflected in the past work and needs to be taken into account in the further design of military engines. 
The testing in this experiment for the JP-8 fuel will target a comparison with the work of Pickett and Hoogterp, [2], to make direct comparisons of resultant ignition delay values and liquid penetrations. This testing will then add to the already available set of data for JP-8 fuel as used by CI engines.

To progress the initiatives of OFF, an alternative jet fuel that is synthetically derived has recently been allowed to be used and added to the official policy. To further alleviate fuel transportation logistics and to reduce the Army's reliance on petroleum based fuels an alternative fuel derived from coal and made in the Fischer-Tropsch production method is allowed to be blended up to 50\% with JP-8 [6] [7]. This synthetic jet fuel also has variance in fuel properties, particularly the $\mathrm{CN}$, and therefore the effect of this variance on CI engine combustion must be determined. The South African based Sasol Company's production version of the synthetic jet fuel is of specific interest due to it having a very low CN of just 25 [6]. This low CN synthetic jet fuel (LCJP-8) is chosen because it represents an extrema for testing the ignition characteristics and the effect of a widely varying $\mathrm{CN}$ fuel. Therefore it is pertinent to this testing to determine the ignition characteristics of the LCJP-8 and then compare to the reference JP-8 under the same test conditions. Also this testing will compare the ignition behavior of the LCJP-8 to that which was found in the work by Schihl, Hoogterp-Decker, and Gingrich, [8], to again add to the existing data pool on the LCJP-8 combustion properties and to compare their results obtained in an optical engine with the combustion vessel results.

In addition to studying LCJP-8, insight can be gained from a surrogate fuel based on the sample JP-8. This surrogate is developed in-house is tested for validity and is a possible modelling fuel. The development of this fuel is based on $\mathrm{CN}$, density, and distillation points, fuel characteristics that are pertinent to ignition and combustion within a CI engine. These fuel properties of interest can be seen in Table 4-5.

In order to characterize liquid penetration and ignition delay, testing is conducted in an optically accessible, constant volume combustion vessel. Imaging techniques employ Mie scattering and natural luminosity to characterize the liquid penetration and the ignition 
delay of each fuel. Both combusting and non-combusting testing is conducted and results and conclusions are drawn based on the above mentioned work and that which is determined from this testing.

These comparisons are made between JP-8 and LCJP- 8 and between JP- 8 and the surrogate JP-8. Correlations as developed by Siebers, [9] and Naber and Siebers, [10], are used to include further insight into the comparison of the fuels and the fuel properties. 


\section{Literature Review}

It is imperative to review and layout the relevant current and past work that is relevant to this work. To ensure that the work being done will help to add to the existing knowledge base. Below is a brief listing and summarization of the work determined to be relevant to this current work.

\subsection{Fundamental Spray and Combustion Measurements of JP- 8 at Diesel Conditions, [2]}

In this previous study, a similar sample of JP-8 fuel was studied in a combustion vessel very nearly identical to the one used for the current research work. The work looked at liquid and vapor sprays in the vessel of JP-8 with a CN of 38 as well as a \#2 diesel fuel sample with a $\mathrm{CN}$ of 46 . The work gave a property comparison of the two fuels and discussed the relative differences in the fuels including the CN, Lower Heating Value, density, and distillation curves. The injector and injection system used was a commonrail fuel system with a single-hole nozzle injector having a nozzle hole diameter of 180 microns. The fuel system was operated at a pressure difference of $138 \mathrm{MPa}$, the difference between the fuel pressure and the ambient condition of the test.

Optical diagnostics for this work included both shadowgraph imaging and Mie-scattering. The shadowgraph imaging is included to capture the vapor-phase penetration of each fuel while the Mie-scattering imaging is used for the liquid-phase penetration measurements. A high-speed CMOS camera is used to capture the diagnostics.

Results of the experiment identify the locations of averaged steady state liquid penetrations for each fuel. These results show the effects of both ambient temperature and density as each variable is swept from $700-1300 \mathrm{~K}$ and from $3.56-30.0 \mathrm{~kg} / \mathrm{m}^{3}$. The JP-8 penetration lengths are compared to the diesel sample across each variable.

Vapor penetration and spreading angle of the sprays is also resolved during the imaging diagnostic using shadowgraph imaging. Likewise these characteristics are compared 
between the JP-8 and the diesel sample in a manner similar to the liquid penetration results, sweeping both ambient temperatures and densities.

Ignition delays are also determined. The ignition delay at each condition is measured from the relative pressure raise produced by the combustion event of the fuel. A high resolution pressure transducer fixed to the vessel is used to determine the ignition delay time. The delay time of these fuels is measured and plotted across the previously mentioned sweep of both ambient temperature and ambient density. The results of both the JP-8 and the diesel sample are then compared showing 16-17\% shorter steady state liquid length penetrations and 20-25\% increase in ignition delays of JP-8 compared to the diesel at relevant ambient densities and ambient temperatures for testing.

The previous work done in this reference is used as a source of data for ignition delays to compare the baseline JP-8 in this current study to. Since the previous work of this source is done at very nearly the same ambient conditions and in nearly the same vessel, cohesion exists between experiments and experimental setups. The baseline JP-8 fuel for this work is compared against the results of this reference paper for both their sample of JP-8 and a standard diesel fuel in the area of ignition delay and liquid penetration. The data used is reproduced from plots of each comparison provided in the thesis.

\subsection{The Combustion and Ignition Characteristics of Varying Blend Ratios of JP-8 and a Coal to Liquid Fischer-Tropsch Jet Fuel in a Military Relevant Single Cylinder Diesel Engine, [6]}

The work here deals with the comparison of JP-8 and blends of JP-8 and LCJP-8 fuels. The fuels were analyzed in a single-cylinder test engine running conditions relevant to military CI engines. The work is done to reflect the current used of the LCJP-8 fuel as a supplementary fuel for displacing JP-8 produced from petroleum as a fuel source. The blending is of the two fuels with $\mathrm{CN}$ of 44 for their sample of JP-8 and a CN of 25 for the LCJP-8. The blends created are a 75-25\%, 50-50\%, and a 25-75\% blend of LCJP-8 to JP8. These blends as well as the pure fuels are run in the single cylinder test engine at low, 
medium, and high loads which represent densities of 18,24 , and $30 \mathrm{~kg} / \mathrm{m}^{3}$. This range of ambient densities is relevant to this testing and therefore the ignition delays reported for the medium and high load testing can be used to compare to. The ignition delays were determined based on cylinder pressure readings. The reported ignition delays of the LCJP-8 fuel for the high load condition are ranging from $8 \%$ to $20 \%$ increase compared to the JP-8 fuel sample across all tested engine speeds. The reported ignition delays of the LCJP-8 fuel for the medium load condition are ranging from $5-40 \%$ longer ignition delays as compared to the JP-8 fuel sample across all tested engine speeds.

This past work is cited so as to have a source of work which directly compares the two fuels of interest, JP-8 and the LCJP-8. Their sample of JP-8 has slightly differing properties than that of the sample used in this current work, but their LCJP-8 is very much the same. This work specifically looks into blend of JP-8 and LCJP-8 which reflects how the two fuels are currently being used in the field today. The ignition delays of all the fuels are going to exhibit a variance to any work done in a combustion vessel setting due to the differences in experimental devices, setup, and the data analysis. Nevertheless the relative differences in the ignition delays within the test engine gives another test point to compare the current work to.

\subsection{The Ignition Behavior of a Coal to Liquid Fischer-Tropsch Jet Fuel in a Military Relevant Single Cylinder Diesel Engine, [8]}

This past work is more specifically focused on the use of full LCJP-8 produced by the Sasol Company in a CI engine and its ignition delay characteristics as they compare to JP-8. The experimental setup, experimental apparatus, and the data analysis in this work all represent the same work as is done in [6]. The work here uses very similar samples of both JP-8 and the LCJP-8 as the work discussed in section 2.2 used, having cetane numbers of 44.9 and 25.2, respectively. The conditions of testing and the ambient atmosphere within the research engine are also relevant with conditions covering 18, 24, 
and $30 \mathrm{~kg} / \mathrm{m}^{3}$. The ignition delay values are recorded and compared to one another as well as compared to a blend and a representative diesel fuel sample.

The resultant ignition delay behaviors reflect the results of the previously mentioned work in the above section. In this reference, ignition delays at the high load condition at all engine speeds show a range of $8-20 \%$ increase in the ignition delay of the LCJP-8 fuel compared to their sample of JP-8. The medium load ignition delay data shows a range of $16-40 \%$ increase in the ignition delay as compared to JP-8, sweeping engine speeds. These ranges both lie in the same data range as is seen in the previous section, but only comparing the JP-8 to the LCJP-8 with only one blend included, rather than the whole range of blends included. In this way a more detailed look at ignition delays between the two fuels of interest is achieved.

\subsection{Liquid-Phase Fuel Penetration in Diesel Sprays, [9]}

This work characterizes the injection and spray characteristics of fuels from high pressure fuel injection systems similar to today's common rail injectors and injection systems. The tests are performed in a constant volume vessel which has optical access.

The report recorded the traits of spray formation and the effect of injector orifice diameter, injection pressure, ambient gas density and temperature, fuel temperature, and fuel volatility. The study sweeps all included variables to test the individual effects of each mentioned parameter. This is done with the use of various fuels, injector nozzles, injection pressures, and creating the different ambient conditions within the combustion vessel used. Conclusions were then drawn based on the effects of each parameter and characterized based on the relative order of each effect.

The diagnostics of the testing is a setup of simultaneous Schlieren type imaging and Miescattering type imaging. Images were taken and used to develop the necessary conclusions to characterize the portions of the spray pertinent to each parameter being studied. An ambient density sweep from $3.3-60 \mathrm{~kg} / \mathrm{m}^{3}$, ambient temperature sweep from $700-1300 \mathrm{~K}$, an injection pressure sweep from 40 - $190 \mathrm{MPa}$, an orifice diameter sweep 
from $100-500 \mu \mathrm{m}$, an orifice aspect ratio sweep from $2-8$, and a fuel temperature sweep from $375-440 \mathrm{~K}$ is performed to determine the relative effects of each.

Conclusions made based on the above described test setup include the relative effects of the variable sweeps. The important conclusions made were based on the steady state liquid penetration of the fuel and how this value relatively changed based on the variables that match the variable sweeps of the current work. This includes the effect of fuel volatility, where a lower T90 point fuel will exhibit a lower steady state penetration length. The trend of this effect is also used where the difference is greater at the lower ambient temperature of $700 \mathrm{~K}$ and less almost to the point of having no difference at the higher ambient temperature of $1300 \mathrm{~K}$.

\subsection{Literature Review Summary}

The following tables, Table 2-1 and Table 2-2, are a summary of the works discussed above and their relevant test setups and conditions covered. 
Table 2-1: Summary of Literature Review, JP-8 and LCJP-8

\begin{tabular}{|c|c|c|c|c|c|}
\hline Title & $\begin{array}{c}\text { Experiment/ } \\
\text { Apparatus }\end{array}$ & Fuels Used & $\begin{array}{c}\text { Testing } \\
\text { Conditions }\end{array}$ & $\begin{array}{c}\text { Resultant } \\
\text { Data }\end{array}$ & Conclusions \\
\hline $\begin{array}{l}\text { 'Fundamental } \\
\text { Spray and } \\
\text { Combustion } \\
\text { Measurements } \\
\text { of JP-8 at } \\
\text { Diesel } \\
\text { Conditions' - } \\
\text { Pickett and } \\
\text { Hoogterp }\end{array}$ & $\begin{array}{l}\text { Constant } \\
\text { Volume } \\
\text { Combustion } \\
\text { Vessel }\end{array}$ & $\begin{array}{c}\text { Standardized } \\
\text { Diesel, JP-8 } \\
(\mathrm{CN}=38)\end{array}$ & $\begin{array}{c}\text { Ambient } \\
\text { temperature } \\
\text { and ambient } \\
\text { density: } \\
700-1300 \mathrm{~K} \text {, } \\
3.56-30.0 \\
\mathrm{~kg} / \mathrm{m}^{3}\end{array}$ & $\begin{array}{l}\text { S.S. liquid } \\
\text { penetrations, } \\
\text { vapor } \\
\text { penetrations, } \\
\text { ignition } \\
\text { delay }\end{array}$ & $\begin{array}{c}16-17 \% \\
\text { shorter S.S. } \\
\text { liquid } \\
\text { penetration } \\
\text { and } 20-25 \% \\
\text { increased } \\
\text { ignition } \\
\text { delay as } \\
\text { compared to } \\
\text { diesel } \\
\end{array}$ \\
\hline $\begin{array}{c}\text { 'The } \\
\text { Combustion } \\
\text { and Ignition } \\
\text { Characteristics } \\
\text { of Varying } \\
\text { Blend Ratios of } \\
\text {..' - Schihl, } \\
\text { Gingrich, and } \\
\text { Decker }\end{array}$ & $\begin{array}{l}\text { Single- } \\
\text { cylinder CI } \\
\text { test engine }\end{array}$ & $\begin{array}{c}\mathrm{JP}-8 \\
(\mathrm{CN}=44), \\
\mathrm{LCJP}-8 \\
(\mathrm{CN}=25)\end{array}$ & $\begin{array}{l}\text { Fuel blends } \\
\text { and ambient } \\
\text { density: } 75- \\
25 \% \text { to } 25- \\
75 \%, 18- \\
30 \mathrm{~kg} / \mathrm{m}^{3}\end{array}$ & $\begin{array}{l}\text { Ignition } \\
\text { delay }\end{array}$ & $\begin{array}{c}8-20 \% \\
\text { increase at } \\
\text { high load, 5- } \\
40 \% \text { increase } \\
\text { at medium } \\
\text { load of } \\
\text { LCJP-8 } \\
\text { ignition } \\
\text { delay over } \\
\text { JP-8 }\end{array}$ \\
\hline $\begin{array}{l}\text { 'The Ignition } \\
\text { Behavior of a } \\
\text { Coal to Liquid } \\
\text { Fischer- } \\
\text { Tropsch Jet } \\
\text { Fuel in a } \\
\text { Military ...'- } \\
\text { Schihl, } \\
\text { Hoogterp- } \\
\text { Decker, and } \\
\text { Gingrich }\end{array}$ & $\begin{array}{l}\text { Single- } \\
\text { cylinder CI } \\
\text { test engine }\end{array}$ & $\begin{array}{c}\text { JP-8 } \\
(\mathrm{CN}=44.9), \\
\text { LCJP-8 } \\
(\mathrm{CN}=25.2)\end{array}$ & $\begin{array}{l}\text { Ambient } \\
\text { density: } 18- \\
30 \mathrm{~kg} / \mathrm{m}^{3}\end{array}$ & $\begin{array}{l}\text { Ignition } \\
\text { delay }\end{array}$ & $\begin{array}{c}8-20 \% \\
\text { increase at } \\
\text { high load, } \\
16-40 \% \\
\text { increase at } \\
\text { medium load } \\
\text { of LCJP-8 } \\
\text { ignition } \\
\text { delay over } \\
\text { JP-8 }\end{array}$ \\
\hline
\end{tabular}


Table 2-2: Summary of Literature Review, Liquid Sprays

\begin{tabular}{|c|c|c|c|c|c|}
\hline Title & $\begin{array}{c}\text { Experiment/ } \\
\text { Apparatus }\end{array}$ & Fuels Used & $\begin{array}{c}\text { Testing } \\
\text { Conditions }\end{array}$ & $\begin{array}{c}\text { Resultant } \\
\text { Data }\end{array}$ & Conclusions \\
\hline \multirow{6}{*}{$\begin{array}{l}\text { 'Liquid-Phase } \\
\text { Fuel } \\
\text { Penetration in } \\
\text { Diesel Sprays' } \\
\text { - Siebers }\end{array}$} & \multirow{6}{*}{$\begin{array}{l}\text { Constant } \\
\text { Volume } \\
\text { Combustion } \\
\text { Vessel }\end{array}$} & \multirow{6}{*}{$\begin{array}{l}\text { Standardized } \\
\text { Diesel, } \\
\text { HMN, n- } \\
\text { hexadecane }\end{array}$} & $\begin{array}{c}\text { Ambient } \\
\text { density: } 3.3- \\
60 \mathrm{~kg} / \mathrm{m}^{3}\end{array}$ & \multirow{6}{*}{$\begin{array}{c}\text { Transient } \\
\text { and steady } \\
\text { state liquid } \\
\text { penetration }\end{array}$} & \multirow{2}{*}{$\begin{array}{c}\text { Strong } \\
\text { inverse } \\
\text { relationship } \\
\text { decreasing in } \\
\text { relation as } \\
\text { either } \\
\text { condition } \\
\text { increases }\end{array}$} \\
\hline & & & $\begin{array}{c}\text { Ambient } \\
\text { temperature: } \\
700-1300 \mathrm{~K}\end{array}$ & & \\
\hline & & & $\begin{array}{c}\text { Orifice } \\
\text { diameter: } \\
\text { 100-500 } \\
\text { micron }\end{array}$ & & $\begin{array}{c}\text { Linearly } \\
\text { dependent }\end{array}$ \\
\hline & & & $\begin{array}{c}\text { Orifice } \\
\text { aspect ratio: } \\
2-8 \\
\end{array}$ & & $\begin{array}{c}\text { Small and } \\
\text { inconsistent } \\
\text { effect }\end{array}$ \\
\hline & & & $\begin{array}{c}\text { Fuel } \\
\text { temperature } \\
\text { sweep: } 375- \\
\quad 440 \mathrm{~K}\end{array}$ & & $\begin{array}{c}\text { Decreases } \\
\text { linearly with } \\
\text { increasing } \\
\text { fuel } \\
\text { temperature }\end{array}$ \\
\hline & & & $\begin{array}{c}\text { Fuel } \\
\text { Volatility }\end{array}$ & & $\begin{array}{c}\text { Lower } \\
\text { volatility } \\
\text { results in } \\
\text { longer liquid } \\
\text { lengths. }\end{array}$ \\
\hline
\end{tabular}




\section{Experimental Setup}

Testing throughout is conducted using the following systems: an optically accessible combustion vessel, multiple pulse generators used for controlling the experiment logic and timing, high speed camera, fuel injector/injection system and a high pressure common rail fuel system, a Mie scattering/natural luminosity imaging setup, and a high speed DAQ. These subsystems are all included and make up most of the typical equipment used in the AERB building located in Hancock, MI, near Michigan Tech's campus. A description of this lab and its subsystems can be found in [11]. All of the subsystem descriptions can be found in the following sections.

\subsection{Combustion Vessel}

A schematic of the combustion vessel layout can be seen in Figure 3-1. The vessel is approximately $1 \mathrm{~L}$ in volume and has 6 configurable ports, called 'windows' mounted on each surface and 8 smaller corner ports. The vessel is heated to $180^{\circ} \mathrm{C}$ and by use of a pre-mixed combustion process the ambient conditions within the vessel are increased to that which represents the proposed test conditions, in this case temperatures and pressures which are representative of a military CI engine. The pre-mixture is a combination of nitrogen, oxygen, hydrogen and acetylene mixed in the proportion necessary to obtain the desired oxygen level, once the fuels in the pre-mixture are spent. Further discussion on the pre-mix burn process can be found in [11] [12] [13] [14]. The pre-mixture is filled to the desired ambient density of the current test condition and ignited. Once ignited the pressure and temperature within the combustion vessel rapidly rises and then begins a relatively slow cool down, being on the order of 1 second. This cool down is monitored in real time through a pressure transducer mounted in a corner port of the vessel. Once the desired pressure, and therefore temperature, prescribed by the test condition is reached, the injection process is initiated. 

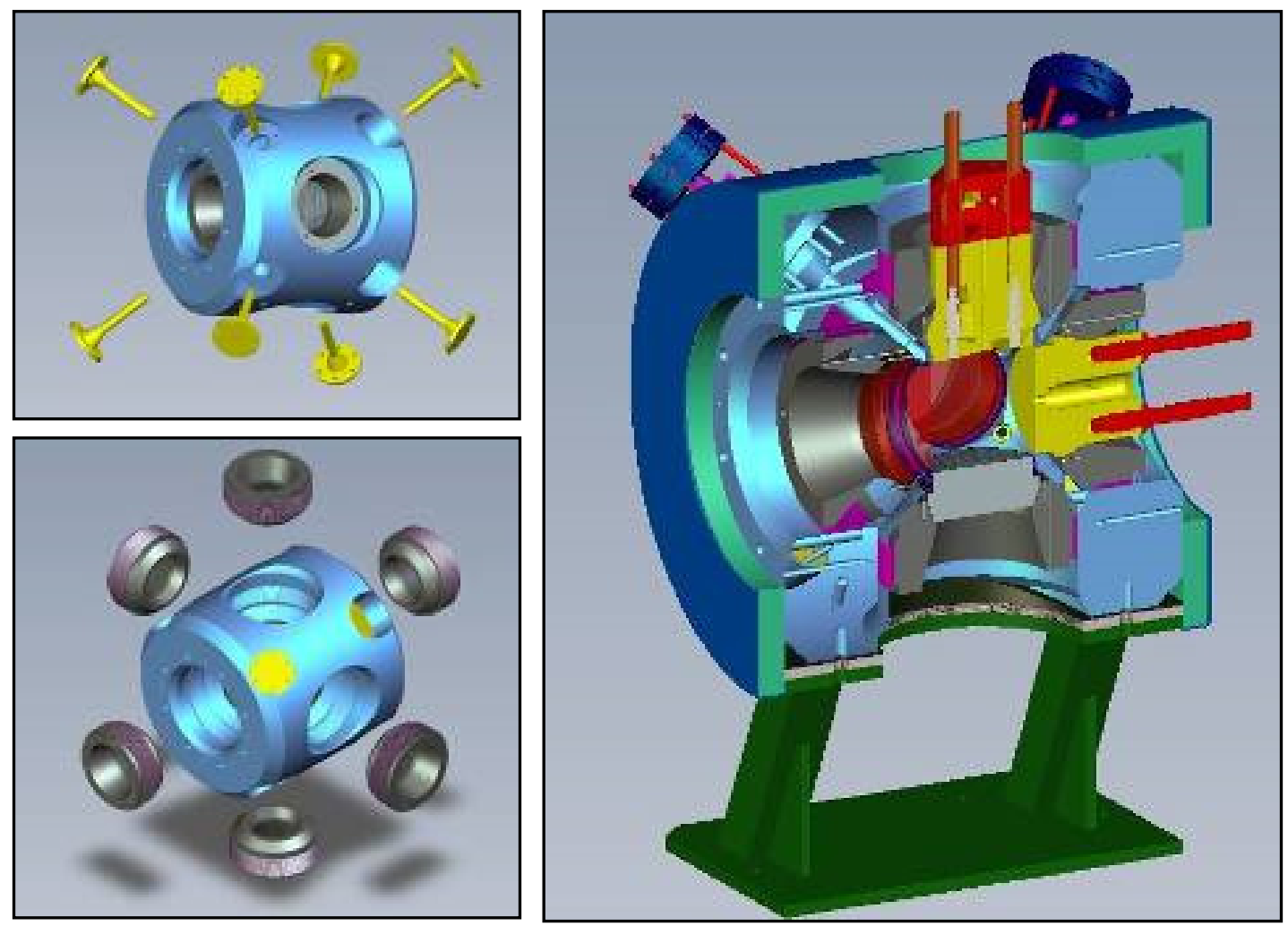

Figure 3-1: Combustion Vessel Schematic: Corner Ports (Upper Left), Window Ports (Lower Left), and Assembled Cut Away (Right)

Two of the windows are installed with the injector fixture and the pre-mix burn ignition source and the mixing fans to provide some level of turbulence inside the vessel to assist with ambient uniformity after the pre-mix burn process. The other 4 windows are free for use as an optical pathway to view the experiment. In this testing, though, only three of the windows were installed with an optical sapphire window insert (The three horizontal to the injector; one each left and right and one adjacent) with the fourth window installed as a metal 'blank' and left unused.

The window used to hold the injector also contains a cooling system. This system operates by use of an external temperature controlling device that pumps a coolant fluid through the cooling cup area in the window. This cooling cup area surrounds the mounted 
injector, controlling the injector body temperature and in this way controls the fuel temperature.

\subsection{Pulse Generator's and Pulse Generator Logic}

Due to the nature of the injection/combustion event being on the scale of only a few milliseconds, timing of all of the subsystems is critical. To control the experiment to a very precise degree of repeatability while still maintaining a great level and ease of configurability, two Stanford DG645 pulse generators (PG) are used. These PGs each have 4 output ports each with a range of 0-2000 seconds and an accuracy of 1 ns [15] although that scale of accuracy is not necessary in this testing.

Figure 3-2 shows a schematic of the PG set up. One PG is used as a 'master' and accepts the initial start signal from the DAQ system once the correct pressure is reached. Once triggered the master PG will run through its user-defined programming. For this testing the master PG is used to control, trigger, and align in time all of the sub-systems. The master pulse generator is set up to trigger the high speed camera, a secondary PG that ran a programming for the LED light sources, an injector driver system, and an oscilloscope for diagnostics. 


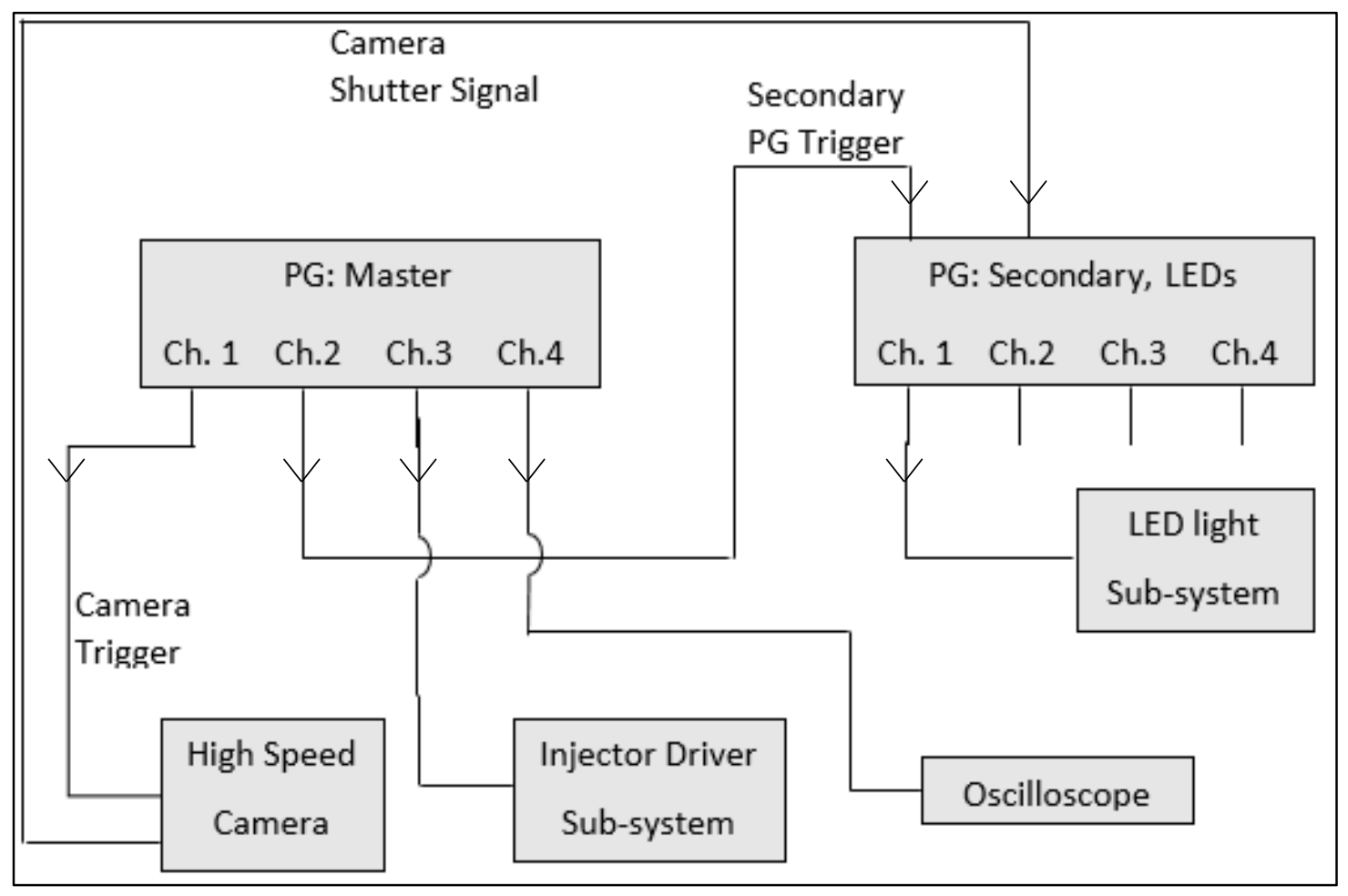

Figure 3-2: Pulse Generator Control Schematic

The secondary pulse generator is used to time the LED's used for the Mie scattering imaging technique. It is required that the LED's pulse in sequence with the camera shutter due to their design in which they can be ran at a higher output power if flashed, rather than just being left on. Therefore it is required that this second PG is used to accept a shutter open signal from the high speed camera and both align with this signal and run the LED's at the desired duty cycle.

A timing diagram of the logical processes as controlled by the PG setup from above can be seen in Figure 3-3. 


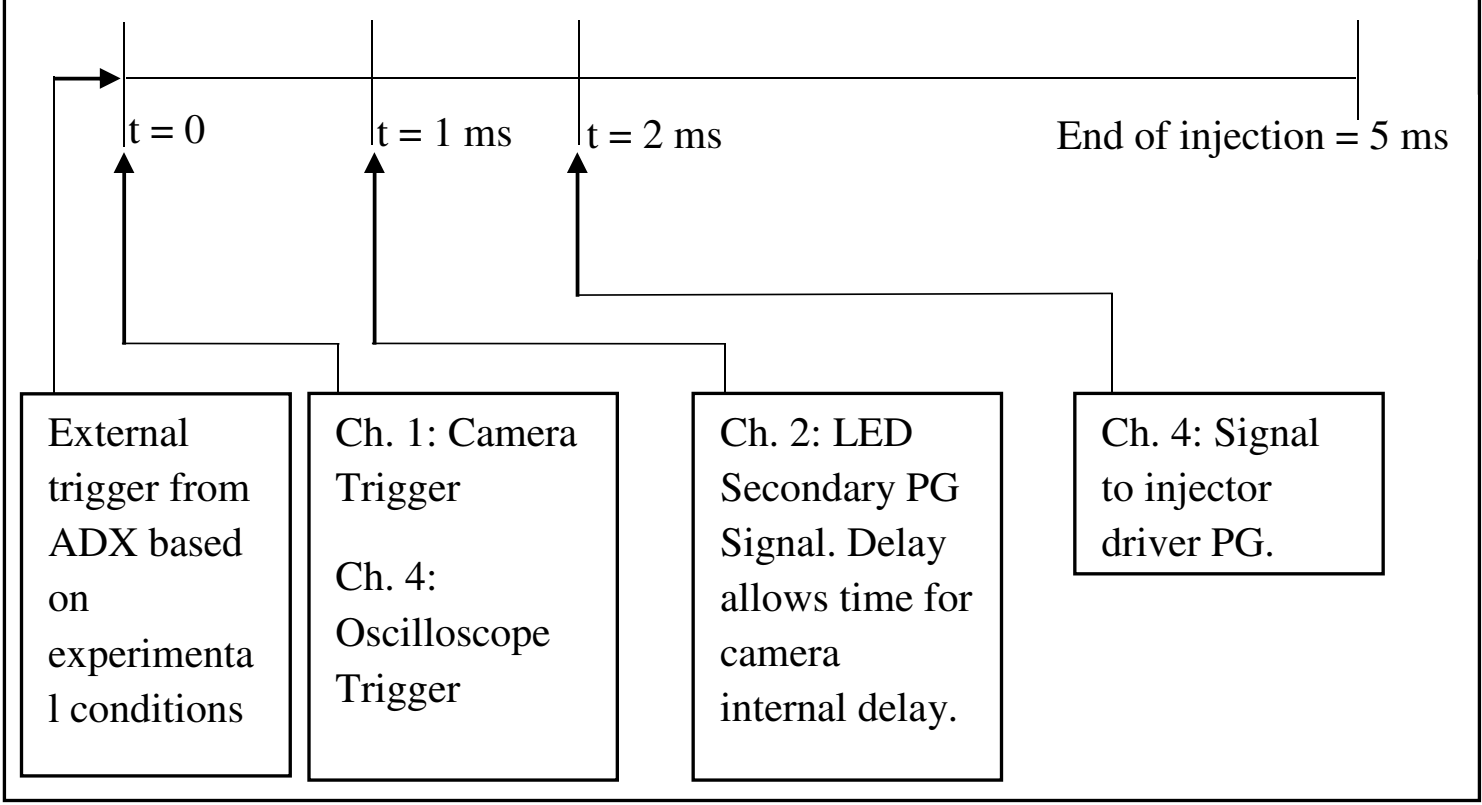

Figure 3-3: Pulse Generator Timing Diagram

\subsection{High Speed Camera}

Due to the nature of spray and combustion events it is necessary to use a high speed camera to capture video data of the experiment. A Photron FASTCAM SA1.1 is used along with an $85 \mathrm{~mm}$ Nikkor lens. The camera and lens is mounted relative to the combustion vessel as seen in Figure 3-4. The lens is focused in plane with the tip of the injector in order to clearly view the spray and proceeding combustion flame. The Photron FASTCAM is capable of imaging up to 675,000 frames per second, but with only a limited field of view. For the imaging setups during this testing the camera is operated at $30,000 \mathrm{fps}$ for combustion imaging and 100,000 fps for the non-combustion imaging. The main factor driving the determination of each frame rate was the field of view required for each particular imaging. For the combustion spray cases it was desired to capture the entire $100 \mathrm{~mm}$ width of the combustion vessel and therefor a wider field of view was needed. The non- combustion spray cases only needed to image from near the nozzle out to when the spray would be completely vaporized, and therefore was a narrower field of view. Since the camera is designed with a set amount of internal memory and processing 
capabilities, the higher resolution of the combustion imaging, being both a wider and taller image, results in a decrease in the maximum allowable frame rate. More information on this camera can be found in its operator's manual [16].

Figure 3-4 and Figure 3-5 show the overall imaging setup for both the combusting cases and the non-combusting cases, respectively.

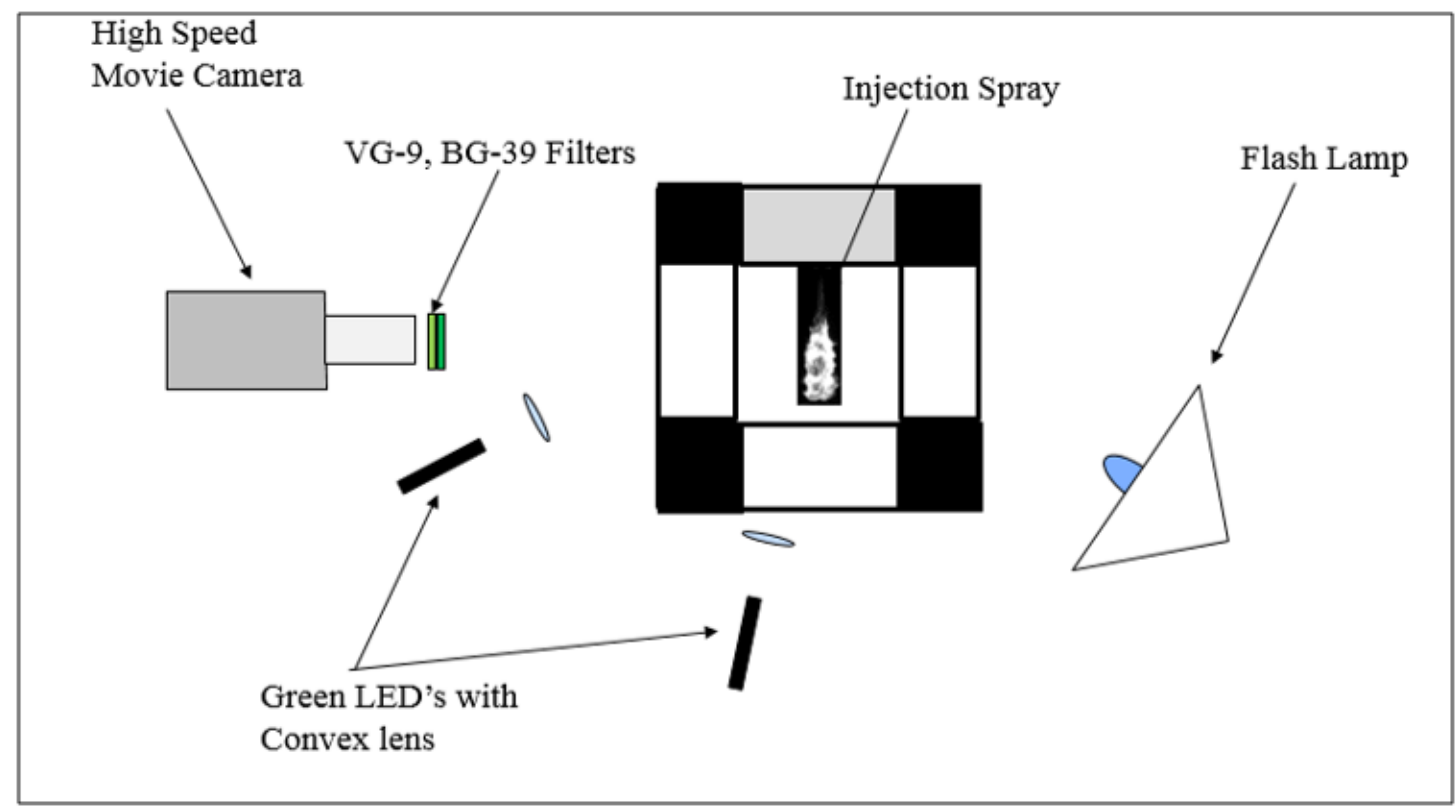

Figure 3-4: Combusting Spray Imaging Setup, Top View 


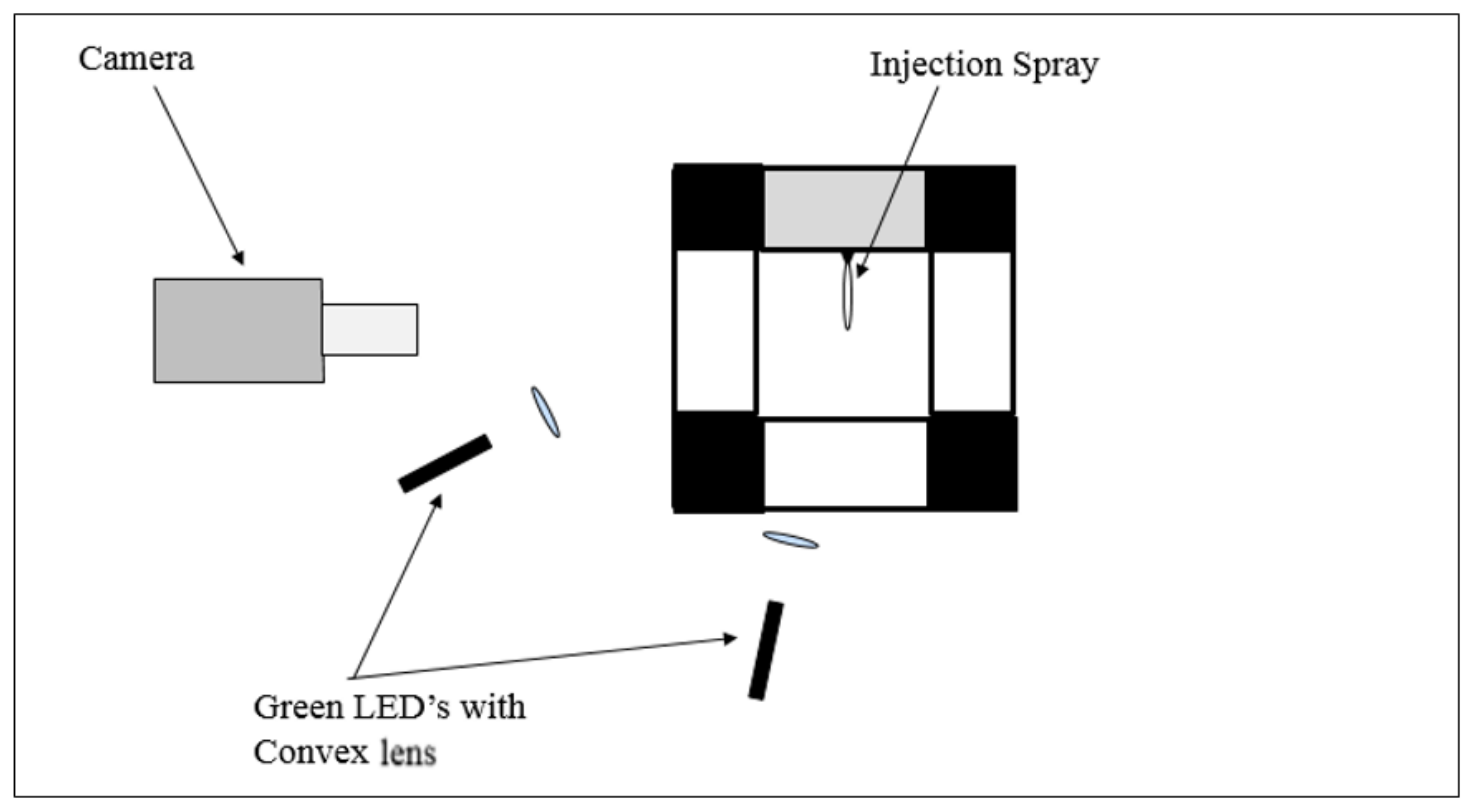

\section{Figure 3-5: Non-combusting Spray Imaging Setup, Top View}

As seen in Figure 3-4 and Figure 3-5 two imaging setups are utilized, one specifically for combusting conditions and the other for the non-combusting cases. The use and location of the camera, $85 \mathrm{~mm}$ Nikkor camera lens and the two LED setups remain unchanged in each setup. The LED's for this setup are obtained from LIGHTSPEED Technologies and are model HPLS-36AD3500 [17]. These LED's have a peak power output of $42 \mathrm{~W}$ when operated in the non-continuous, flashing mode as described above in section 3.2. They are installed with a green LED head, emitting a wavelength of $530 \mathrm{~nm}$.

\subsection{1 $21 \% \mathrm{O}_{2}$ Combusting Mie Scattering/Natural Luminosity Imaging Setup}

For the combusting imaging and lighting setup, Figure 3-4, an additional flash lamp type light source and a set of color glass filters are used. This is for the effect of adding extra light and filtering out much of the high intensity combustion luminosity in order to obtain the relatively low intensity Mie lighting being reflected off of the liquid spray, while at the same time ensuring the camera is not over saturated. The color glass filters are aligned in series in front of the camera lens and have transmission curves as seen in the appendix, section 10.1. These filters are supplied from Edmund Optics and are model 
VG-9 and BG-39, color glass filters. They are designed to allow a very high level of transmission at the wavelength produced by the LED's while also having a very favorable omission spectrum over the range of the broadband emission spectrum produced from a combustion event. In this way the green Mie scattering light is still able to be perceived among the high intensity combustion flame, once ignition occurs. With the inclusion of these filters, the green LED's, and the broad spectrum backlighting it is possible to achieve the overall goal of this imaging setup and capture both the liquid spray characteristics and the ignition and combustion characteristics.

For the combusting imaging the camera is operated at a framerate of $30,000 \mathrm{fps}$ and a resolution of $640 \times 240$ pixels. The aperture on the $85 \mathrm{~mm}$ lens is set between $\mathrm{f} / 1.8-\mathrm{f} / 4$, depending on the test case. The aperture is widened during cases were the combustion products released lower levels of light intensity and is closed down to f/4 when the combustion illumination is much stronger.

\subsection{2 $0 \% \mathrm{O}_{2}$ Non-combusting Mie Scattering Imaging Setup}

Since there is no luminosity from combustion during the non-combusting testing there is no concern for overexposure and the resultant loss of the liquid Mie scattering light.

Therefore the two color glass filters and the flashlamp are able to be removed. A diagram of this lighting/imaging setup can be seen in Figure 3-5. The two LED's are still using a green light source for testing consistency.

Due to the nature of the non-combustion spray it is possible to operate the camera at a higher framerate. Since there will be no combustion event the field of view is able to be lowered to just $448 \times 80$ pixels and therefore it is possible to operate at a framerate of $100,000 \mathrm{fps}$. This greatly increases the time resolution of the liquid imaging over that which is possible with the combusting imaging setup. This higher resolution-in-time imaging aides in the liquid penetration tracking as discussed in later sections. 


\subsection{Fuel Injector, Injector Driver and High Pressure Fuel}

\section{Pump System}

To spray the fuel into the vessel three subsystems are needed; a fuel injector, an injector driver and a high pressure fuel pump. The injector is a Bosch HPCR solenoid type injector, \#0445110243. The injector is equipped with a single hole nozzle tip with the hole being in axis with the injector body. The hole diameter of the nozzle is $200 \mu \mathrm{m}$. The nozzle discharge coefficient is manufactured to a $\mathrm{Cd}$ of 0.75 with a $\mathrm{K}$ value of 0 .

The injector is supplied with $45 \mathrm{~V}$ and is driven with MOSFET's switching the voltage to control the current. PWM signals are used to control the switching. The PWM signals are designed and sent to the driver to create a peak at $20 \mathrm{~A}$ for $200 \mu \mathrm{s}$ and a hold of $8 \mathrm{~A}$ for $2800 \mu$ s. These signals are created by a Quantum Composers Model 9614 pulse generator, which is driven by the master pulse generator. A sample injection current is seen below in Figure 3-6. 


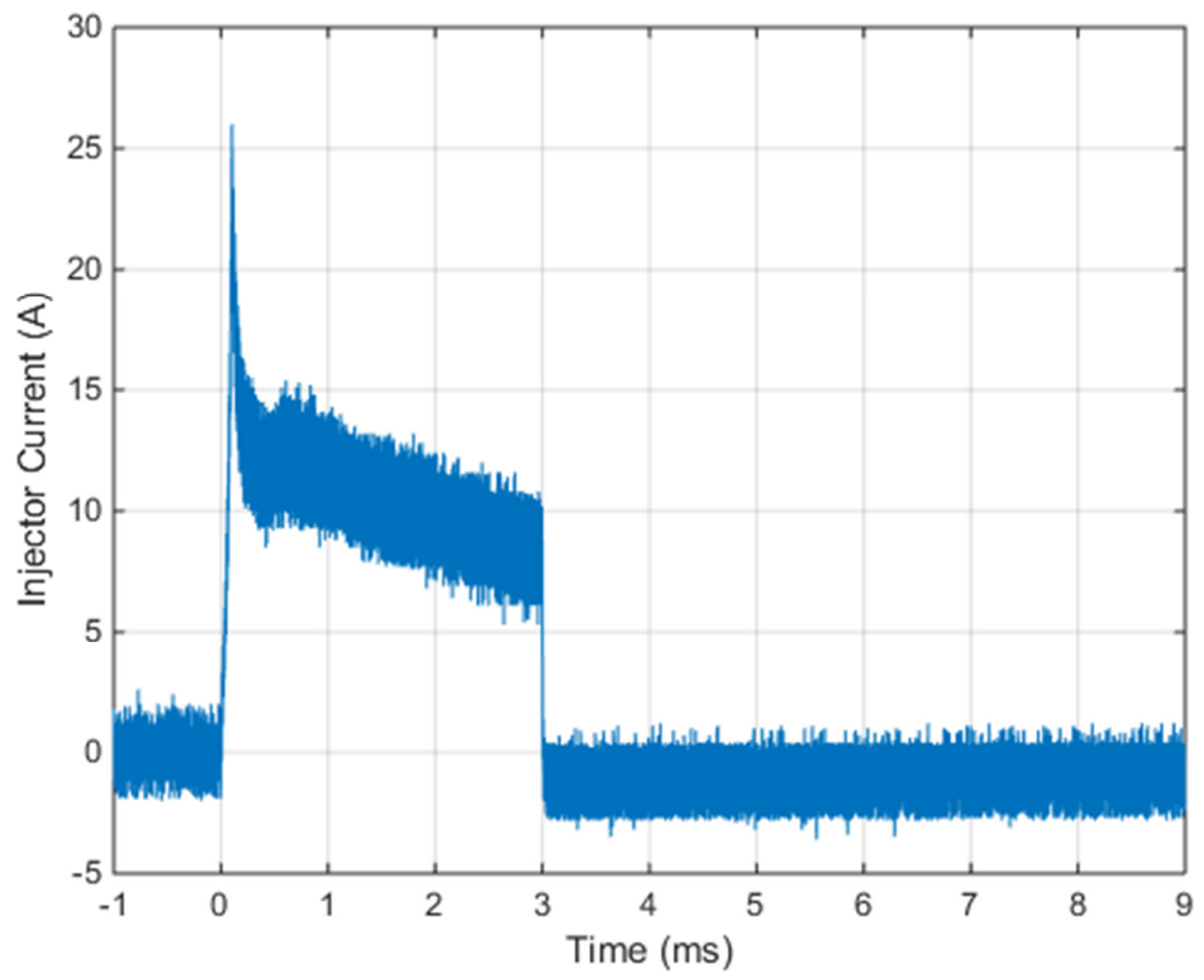

Figure 3-6: Sample Injector Current

The fuel pump system is a modular cart that is wheeled into the combustion lab. The systems is a pneumatically actuated piston type booster pump, regulated to the test injection pressure condition with high pressure accumulators inline after the pump. Both a picture of the injector and the fuel pump system can be seen in Figure 3-7 and Figure 3-8. 


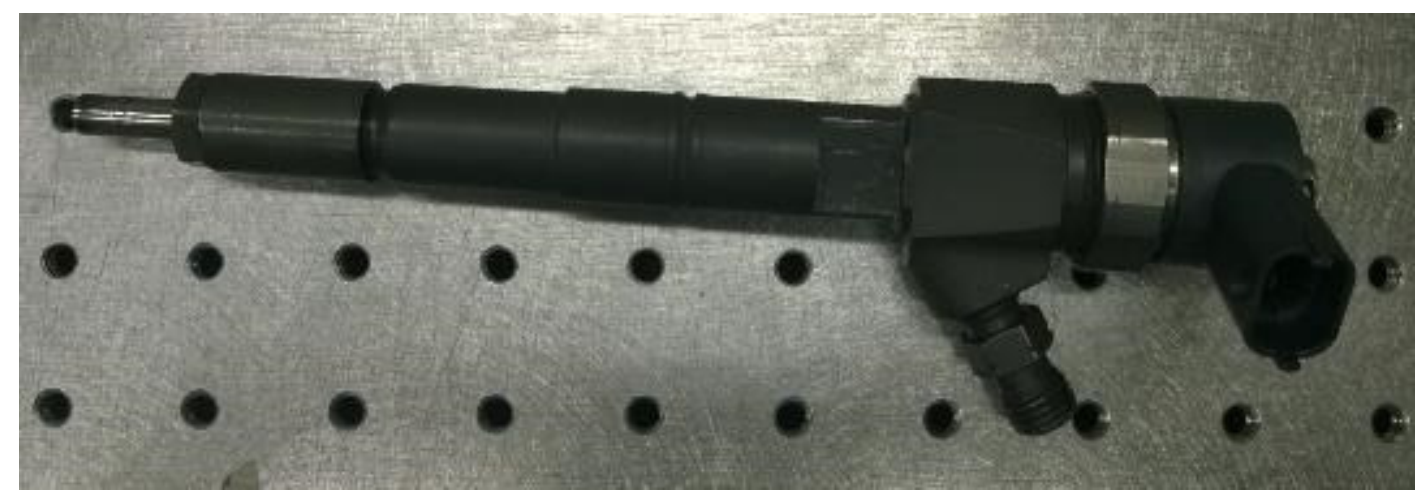

Figure 3-7: Bosch HPCR solenoid type injector with 200 micron nozzle hole diameter

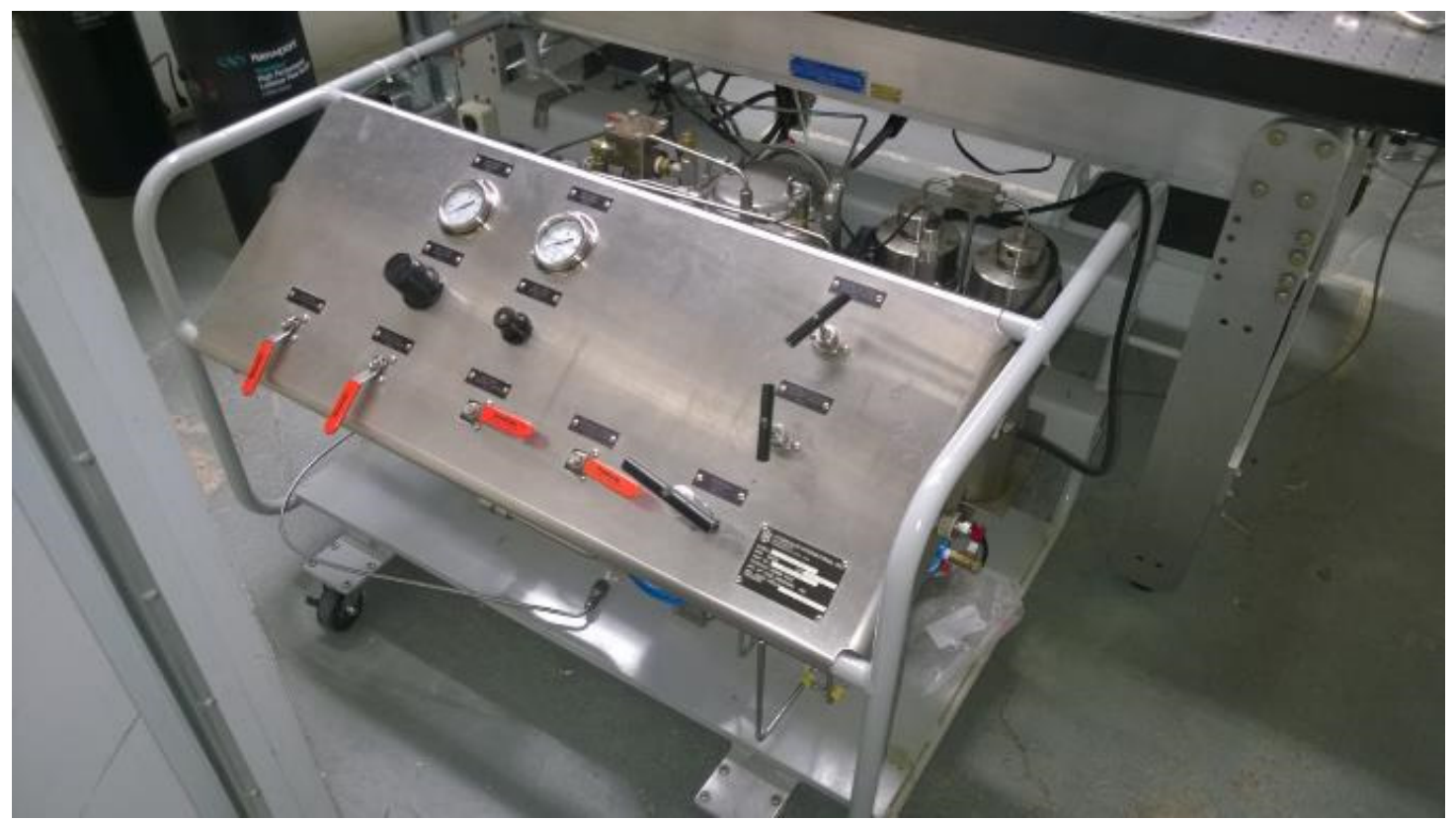

Figure 3-8: Fuel pump system used to pressurized injector

\subsection{Data Acquisition System}

Analog signals are recorded on a high speed AND Technology's ADX control/data acquisition system and high speed data recorder. An AND iTest process controller with a custom designed GUI is used to control the pre-mixture creation process, the vessel purging and filling process, the pre-mix burn ignition process and finally the start signal 
to trigger the experiment. The DAQ system records up to 8 channels at a sample rate of 100,000 samples per second with the CV pressure, injector driver current, and the fuel pressure all being monitored and recorded for this experimental setup. Once the DAQ system initiates the pre-mix burn process it begins monitoring these analog inputs and uses the $\mathrm{CV}$ pressure reading to send the output trigger signal to the PG setup as explained in section 3.2. Therefore the DAQ system is charged with aligning the experiment with the correct ambient test conditions within the combustion vessel and sends off a signal to the PG setup which correspondingly controls and triggers each subsystem as the setup prescribes. 


\section{$4 \quad$ Fuel Properties}

Extensive testing and attention has recently been placed on JP-8 as a fuel for military CI engines [2] [3] [4] [6]. The driving force for this testing has been the previously discussed OFF policy adopted by the U.S. military and many NATO affiliates. This policy has been updated to allow for the use of up to a $50 \%$ blend of a synthetically derived jet fuel, LCJP-8, with JP-8 [6] [7]. The blend ratios vary based on the rated CN of both fuels available. The blend ratio is ultimately dependent on the end resultant fuel having a $\mathrm{CN}$ of at least 40 [6]. The effect of blending has been investigated in a test engine by Schihl, $P$. et al [6] but the individual ignition characteristics of the LCJP-8 were not investigated, just the blends. Therefore this testing aims to explore these characteristics.

\section{$4.1 \quad J P-8$}

The reference fuel chosen for testing is the JP- 8 sample provided by TARDEC. This fuel is chosen as a reference fuel due to its importance in the military vehicle and previous testing completed on this fuel [2] [3] [4] [6]. The pertinent properties of JP-8 are listed in Table 4-1 and are selected for their specific effect on the injection, ignition, and combustion of a fuel in an atmosphere relevant to CI engines. These properties are pulled from the Petroleum Quality Information System (PQIS) from 2008 and based on global means [5].

Table 4-1: JP-8 Fuel Properties [18]

\begin{tabular}{|l|l|}
\hline Cetane Number & 43.1 \\
\hline Density $\left(\mathbf{k g} / \mathbf{m}^{\mathbf{3}}\right)$ & 804.4 \\
\hline Molar $\mathbf{H} / \mathbf{C}$ ratio & 1.844 \\
\hline & Straight/branched chain alkane \\
Chemical classes & Cycloalkanes \\
& Aromatics \\
\hline & $10 \%$ recovered: $171.7^{\circ} \mathrm{C}$ \\
Distillation points $(\mathbf{K})$ & $20 \%$ recovered: $179.3{ }^{\circ} \mathrm{C}$ \\
& $50 \%$ recovered: $199.6{ }^{\circ} \mathrm{C}$ \\
& $90 \%$ recovered: $243.2{ }^{\circ} \mathrm{C}$ \\
\hline
\end{tabular}


Of main importance to the ignition of a fuel is the $\mathrm{CN}$. The definition of the $\mathrm{CN}$ is based on the standardized test, ASTM D-613. This nominal value gives a characterization of the susceptibility of a fuel to compression ignite. Therefore the higher the $\mathrm{CN}$ the sooner after start of injection the fuel will begin to burn, holding all other variables constant. A slightly lower $\mathrm{CN}$, as seen in JP-8 compared to diesel (CN around 48), can be corrected for in a CI engine by advancing the start of injection. Even with this correction, though, variations in the combustion event still exist due to the other fuel properties' differences and the relative increase in the premixed burn phase of the CI combustion due to the advancement. Other changes in the ignition and combustion event can also be attributed to a difference in the fuel density and fuel viscosity and how these properties effect the fuel injector. The comparisons of JP-8 and LCJP-8 between these other properties is discussed in the next section.

\subsection{Synthetic JP-8 (LCJP-8)}

The LCJP-8 fuel is provided by TARDEC and was produced in the Fischer-Tropsch process from a coal feedstock by the Sasol Company based out of South Africa. This sample of synthetic JP-8 is selected for testing and characterization due to its very low $\mathrm{CN}$, lower than most other synthetic JP-8's produced in this method. Along with a difference in the CN, the LCJP-8 fuel also has a number of other differences that can

potentially effect the ignition characteristics under CI engine operation. A comparison of LCJP-8 and the baseline fuel, JP-8, can be seen in Table 4-2. It is important to note that besides the large difference in the $\mathrm{CN}$ between the two fuels there is only a slight difference in the densities and the viscosities with their heat of combustions being practically an exact match. The large likeliness between these fuels can be expected since the LCJP-8 is a synthetic based on JP-8. So from this comparison it may be likely that most of the difference in the ignition quality of the LCJP-8 is from the CN with the role both density and viscosity play being a secondary. 
Table 4-2: Property Comparison of JP-8 and LCJP-8, [5] [7] [8]

\begin{tabular}{|c|c|c|}
\hline Property & JP-8 & LCJP-8 \\
\hline Cetane Number & 43.1 & 25 \\
\hline 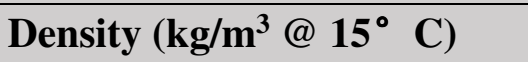 & 804 & 775 \\
\hline Viscosity $\left(\mathrm{mm}^{2} / \mathrm{s} @-20^{\circ} \mathrm{C}\right)$ & 4.279 & $\sim 5$ \\
\hline Heat of Combustion (MJ/kg) & 43.3 & 43.3 \\
\hline \multirow{4}{*}{ Distillation Points } & $\mathrm{T} 10=171.7^{\circ} \mathrm{C}$ & $173.5^{\circ} \mathrm{C}$ \\
\hline & $\mathrm{T} 20=179.3^{\circ} \mathrm{C}$ & $177.0^{\circ} \mathrm{C}$ \\
\hline & $\mathrm{T} 50=199.6^{\circ} 6$ & $185.6^{\circ} \mathrm{C}$ \\
\hline & $\mathrm{T} 90=240.5^{\circ} \mathrm{C}$ & $219.1^{\circ} \mathrm{C}$ \\
\hline
\end{tabular}

\subsection{JP-8 Surrogate}

The JP-8 surrogate is formulated in house to obtain the following target properties, with the significance of including individual properties explained. Note that the targets are selected based on applications in diesel engine injection and combustion conditions, which is quite different than the gas turbine or jet engine applications.

- Chemical classes: fuel chemical property indicator

- Cetane number: fuel ignition property indicator

- Density: important fuel parameter in fuel injection sprays, affecting the fuel mixing process

- Molar $\mathrm{H} / \mathrm{C}$ ratio: important fuel parameter in matching local equivalence ratios

- Fuel distillation temperatures: important parameter for the vaporization characteristic of the fuel

The properties of the JP8 surrogate were selected based on the PQIS Annual Report in 2008 on JP-8 and again are listed in Table 4-1.

The surrogate fuel is formulated from Reaction Design's Workbench [18]. The surrogate blend optimizer function in the software is used to blend a number of hydrocarbons from a fuel library that is comprised of chemicals from normal alkanes, iso-alkanes, ethers, cycloalkanes, aromatics, alkenes and alcohols. Thermophysical properties are from the 
fuel library. Targets to constrain the blending fractions include the aforementioned properties. The solver optimization process is a combination of global optimization and local optimization, which employs a hybrid genetic algorithm and Powell's method. A five component surrogate is chosen for this study with the individual components listed in Table 4-3.

Table 4-3: Individual JP-8 Surrogate Components [18]

\begin{tabular}{|l|l|c|c|c|c|}
\hline & $\begin{array}{l}\text { Chemical } \\
\text { Class }\end{array}$ & $\begin{array}{l}\text { Chemical } \\
\text { Formula }\end{array}$ & $\begin{array}{l}\text { Density } \\
\left(\mathbf{k g} / \mathbf{m}^{3}\right)\end{array}$ & $\begin{array}{l}\text { Cetane } \\
\text { number }\end{array}$ & $\begin{array}{l}\text { Boiling } \\
\text { point (K) }\end{array}$ \\
\hline 1-methylnaphthalene & Aromatics & $\mathrm{C}_{11} \mathrm{H}_{10}$ & 1001 & 0 & 245 \\
\hline Decalin & Cycloalkane & $\mathrm{C}_{10} \mathrm{H}_{18}$ & 896 & 44 & 187 \\
\hline hepamethylnonane & Iso-alkane & $\mathrm{C}_{16} \mathrm{H}_{34}$ & 793 & 15 & 240 \\
\hline n-decane & n-alkane & $\mathrm{C}_{10} \mathrm{H}_{22}$ & 730 & 76.7 & 174 \\
\hline n-tetradecane & n-alkane & $\mathrm{C}_{14} \mathrm{H}_{30}$ & 762 & 94 & 253 \\
\hline
\end{tabular}

The selection of these components is based on covering the distillation range, as well as covering the cetane number, density and chemical classes. Components fractions are selected such that the blend properties are optimized to replicate the target fuel properties as seen in Table 4-1. The optimization results for volume fraction are given in Table 4-4.

Table 4-4: Individual JP-8 Surrogate Volume Fractions [18]

\begin{tabular}{|l|c|}
\hline Component & Volume Fraction \\
\hline 1-methylnaphthalene & $12.12 \%$ \\
\hline Decalin & $25.19 \%$ \\
\hline heptamethylnonane & $30.39 \%$ \\
\hline n-decane & $17.06 \%$ \\
\hline n-tetradecane & $15.24 \%$ \\
\hline
\end{tabular}

A comparison of the fuel properties of the surrogate to JP8 is given in Table 4-5. As can be seen the properties and distillation are all well matched with values within $2 \%$ and the distillation temperatures within 2 to $7^{\circ} \mathrm{C}$ 
Table 4-5: Comparison of JP-8 and JP-8 Surrogate Properties [18]

\begin{tabular}{|c|c|c|}
\hline Property & JP-8 & JP-8 Surrogate \\
\hline Cetane Number & 43.1 & 43.1 \\
\hline Density $\left(\mathrm{kg} / \mathrm{m}^{3}\right)$ & 804 & 819 \\
\hline Molar $\mathrm{H} / \mathrm{C}$ ratio & 1.84 & 1.86 \\
\hline Chemical classes & \multicolumn{2}{|c|}{$\begin{array}{c}\text { Straight/branched chain alkane } \\
\text { Cycloalkanes } \\
\text { Aromatics }\end{array}$} \\
\hline $\begin{array}{l}\text { Distillation points } \\
\text { (K) }\end{array}$ & $\begin{array}{l}\text { 10\% recovered: } 171.7^{\circ} \mathrm{C} \\
\text { 20\% recovered: } 179.3^{\circ} \mathrm{C} \\
\text { 50\% recovered: } 199.6{ }^{\circ} \mathrm{C} \\
\text { 90\% recovered: } 240.5^{\circ} \mathrm{C}\end{array}$ & $\begin{array}{l}\text { 10\% recovered: } 174.2^{\circ} \mathrm{C} \\
\text { 20\% recovered: } 175.6^{\circ} \mathrm{C} \\
\text { 50\% recovered: } 200.4^{\circ} \mathrm{C} \\
90 \% \text { recovered: } 247.5^{\circ} \mathrm{C}\end{array}$ \\
\hline
\end{tabular}

Figure 4-1 shows the distillation curves for a nominal JP8 and the surrogate JP8 again showing the close match to the distillation of the surrogate.

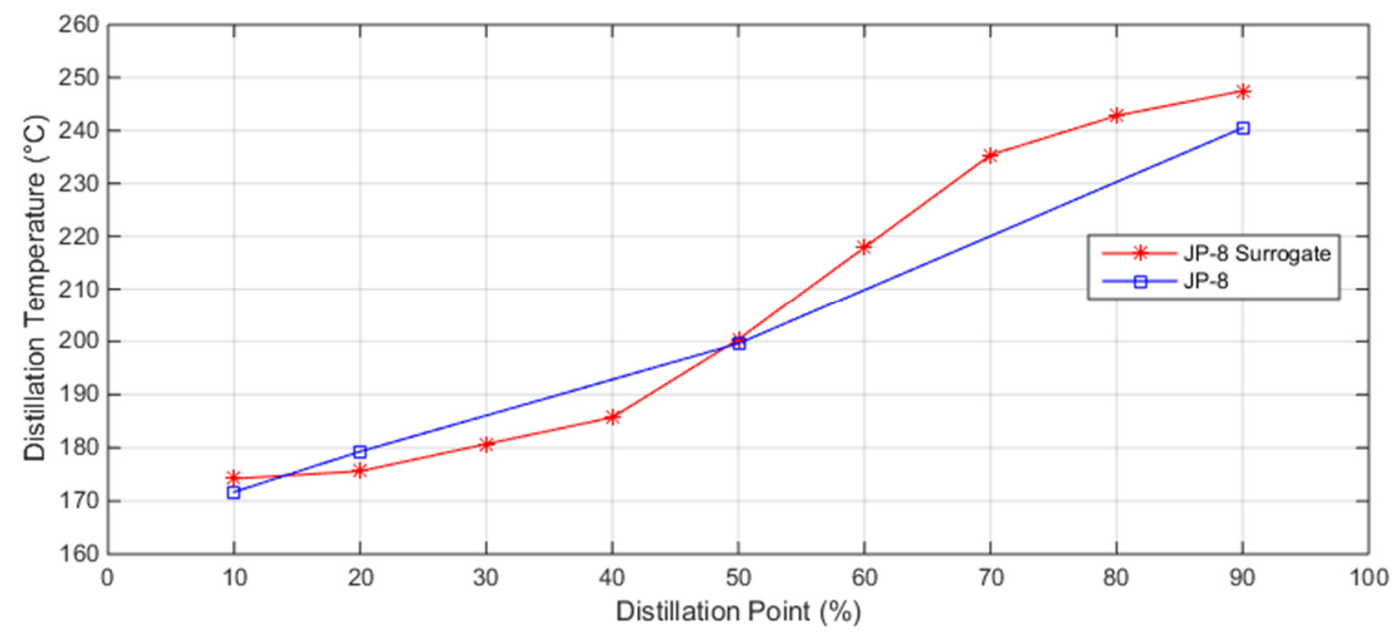

Figure 4-1: Distillation Curve for Nominal JP-8 and the Developed JP-8 Surrogate [18] 


\section{$5 \quad$ Test Conditions and Testing Goals}

To test the fuels described above and have an accurate representation of each fuel's performance, the conditions within the combustion vessel during testing must be laid out. The parameters to design the experiment include ambient density, ambient temperature, fuel injection pressure, and the fuel temperature at start of injection. These conditions are decided upon based on their effect on the overall injection and ignition processes that occur in a combustion event relative to a $\mathrm{CI}$ engine. The points of interest for each parameter are designed based on typical engine operating conditions found in military CI engines. The sweep of these variables can be found in Appendix 10.2 to Appendix 10.5 and are all prescribed from discussions between the sponsor, TARDEC, and the AERB lab affiliates, here at Michigan Tech.

Conditions that are decided to be held constant for testing are the injection duration, the injector current profile, and the nozzle dimensions. These variables are not included in the test sweep in order to create a favorable test matrix for direct comparison between JP8, LCJP-8 and the JP-8 surrogate.

\subsection{Combusting Spray Test Conditions and Testing Goals}

The approach taken during this testing was very explorative. One of the main goals was to discover the conditional limits of ignition for both the JP-8 and the LCJP-8 fuels. The sweep of testing variables was designed to locate these limits, as can be seen in how the testing is laid out in the combusting Spray test matrices for both LCJP-8 and JP-8 (Appendix 10.2: Table 10-1, Table 10-2, Table 10-3, Table 10-4, and Table 10-5). With this in mind the testing is conducted in such a way as to progress from most likely conditions for ignition towards the conditions that are less likely to initiate combustion, (i.e. working from high density, high temperature towards lower density and temperature; working backwards through the matrix).

The overall testing goals of the combustion testing is to provide a baseline test set for the JP-8 fuel in which the LCJP-8 fuel can be compared to. This is done mainly by the large overlapping of conditions as seen in Table 5-1. A sub-goal of this test set is 
to also act as an explorative test set by testing from most likely conditions to initiate combustion to the less likely, effectively finding the limits of ignition for each fuel under these conditions. For this reason the LCJP-8 testing is extended beyond the density range of the $J P-8$ up to $30.2 \mathrm{~kg} / \mathrm{m}^{3}$. A statistical sub-set of testing is also defined to provide an understanding of the effect of fuel temperature on the spray and combusting characteristics of JP-8. This set of tests are found in Table 5-2.

Then, lastly, a sub-set of testing is conducted on the spray and combustion characteristics of the developed JP-8 Surrogate. These test conditions can be found in

Table 5-3.

Table 5-1 shows a condensed version of the combusting test matrix for both JP-8 and LCJP-8. The expanded, more detailed test matrix is found in Appendix 10.2.

Table 5-1: Condensed Test Matrix for JP-8, LCJP-8 Combusting Tests

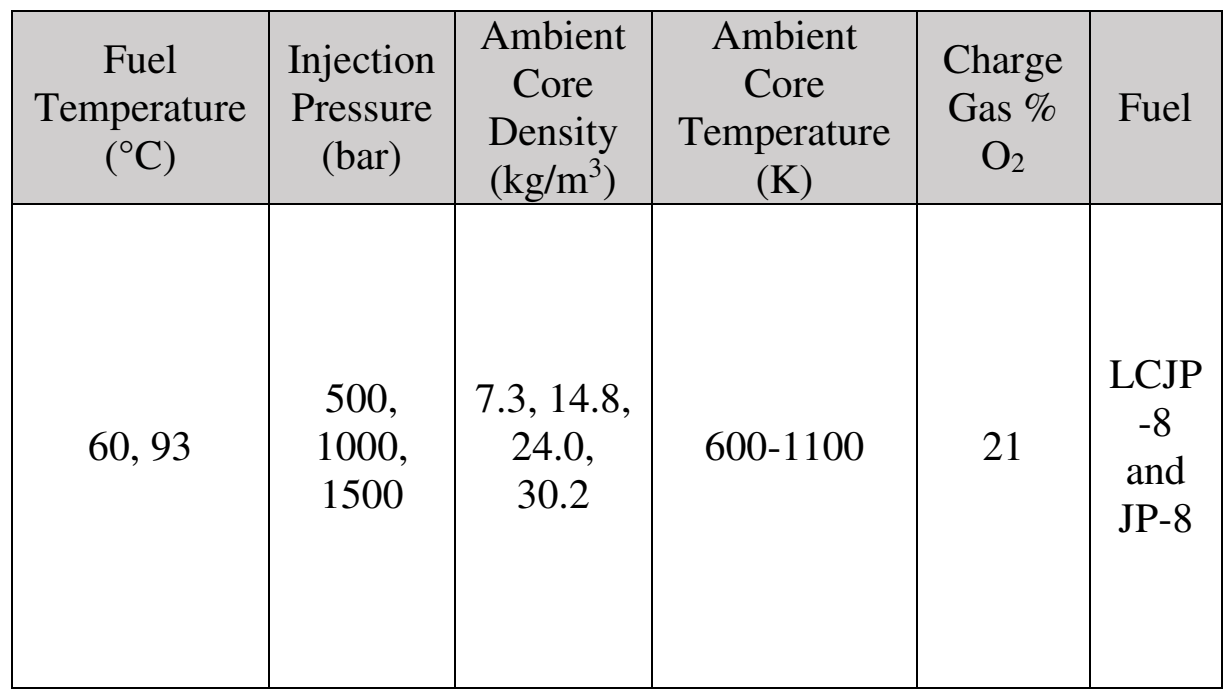

It is important to note that per the testing agreement set with TARDEC, the JP-8 fuel was not tested at the higher ambient density condition of $30.2 \mathrm{~kg} / \mathrm{m}^{3}$, only the LCJP-8 is tested at this condition. All other conditions are covered by both fuels. 
There is also a section of testing designed to cover a statistical variance in the combustion characteristics of JP-8 and the effects of fuel temperature on the JP-8 fuel. This testing is found in Table 5-2 and in Appendix 10.3 and holds the injection pressure, ambient density and charge gas $\mathrm{O}_{2} \%$ constant (at $1000 \mathrm{bar}, 24.0 \mathrm{~kg} / \mathrm{m}^{3}$, and $21 \%$, respectively) while sweeping ambient temperature from 800-1100 K at each fuel temperature.

Table 5-2: Condensed Test Matrix of the Statistical Testing of JP-8 at Varying Ambient and Fuel Temperatures

\begin{tabular}{|c|c|c|c|c|c|c|}
\hline $\begin{array}{c}\text { Fuel } \\
\text { Temperature } \\
\left({ }^{\circ} \mathrm{C}\right)\end{array}$ & $\begin{array}{c}\text { Injection } \\
\text { Pressure } \\
(\mathrm{bar})\end{array}$ & $\begin{array}{c}\text { Ambient } \\
\text { Core } \\
\text { Density } \\
\left(\mathrm{kg} / \mathrm{m}^{3}\right)\end{array}$ & $\begin{array}{c}\text { Ambient } \\
\text { Core } \\
\text { Temperature } \\
(\mathrm{K})\end{array}$ & $\begin{array}{c}\text { Charge } \\
\mathrm{Gas} \% \\
\mathrm{O}_{2}\end{array}$ & Fuel & $\begin{array}{c}\text { Number } \\
\text { of tests } \\
\text { at each } \\
\text { condition }\end{array}$ \\
\hline 93,177 & 1000 & 24 & $800-1100$ & 21 & JP-8 & 3 \\
\hline
\end{tabular}

Lastly in the combusting testing segment of this experiment is a brief matrix for testing the combusting and ignition properties of the developed fuel surrogate for JP-8. This matrix holds the fuel temperature constant at $93^{\circ} \mathrm{C}$, the injection pressure constant at 1000 bar, and the charge gas constant at $21 \% \mathrm{O}_{2}$. The ambient density and the ambient temperature is swept through a range that overlaps with a portion of the previous testing of JP-8. These test conditions are found in

Table 5-3 and in Appendix 10.4. 
Table 5-3: Condensed Combusting Test Matrix, JP-8 Surrogate

\begin{tabular}{|c|c|c|c|c|c|}
\hline $\begin{array}{c}\text { Fuel } \\
\begin{array}{c}\text { Temperature } \\
\left({ }^{\circ} \mathrm{C}\right)\end{array}\end{array}$ & $\begin{array}{c}\text { Injection } \\
\text { Pressure } \\
(\text { bar })\end{array}$ & $\begin{array}{c}\text { Ambient } \\
\text { Core } \\
\text { Density } \\
\left(\mathrm{kg} / \mathrm{m}^{3}\right)\end{array}$ & $\begin{array}{c}\text { Ambient } \\
\text { Core } \\
\text { Temperature } \\
(\mathrm{K})\end{array}$ & $\begin{array}{c}\text { Charge } \\
\text { Gas \% } \\
\mathrm{O}_{2}\end{array}$ & Fuel \\
\hline 93 & 1000 & $\begin{array}{c}14.8, \\
24.0\end{array}$ & $600-1100$ & 21 & $\begin{array}{c}\text { JP-8 } \\
\text { Surrogate }\end{array}$ \\
& & & & & \\
\hline
\end{tabular}

\subsection{Non-combusting Spray Test Conditions and Testing Goals}

To complement the combusting testing, a set of non-combusting spray testing is defined. This set of tests is more condensed than the combusting testing but is necessary in order to compare and characterize the JP-8 fuel versus both the LCJP-8 and the JP-8 Surrogate fuels without allowing combustion. This enables a better understanding of the spray development of each fuel and their relative variations based on the properties that are not strongly associated with ignition. Additionally a higher time-based resolution is possible based on a differing imaging and lighting setup in this testing than in that of the previous testing, see section 3.3.2 for more details.

This test set holds fuel temperature, injection pressure, and charge gas $\mathrm{O}_{2}$ constant at $93^{\circ}$ C, 1000 bar, and 0\%, respectively. A sweep of ambient temperature is made across two ambient densities (as seen in Table 5-4 and Appendix 10.5) that are in the range of the combustion testing described above. 
Table 5-4: Condensed Test Matrix for Non-combusting Spray Testing

\begin{tabular}{|c|c|c|c|c|c|}
\hline $\begin{array}{c}\text { Fuel } \\
\text { Temperature } \\
\left({ }^{\circ} \mathrm{C}\right)\end{array}$ & $\begin{array}{c}\text { Injection } \\
\text { Pressure } \\
(\mathrm{bar})\end{array}$ & $\begin{array}{c}\text { Ambient } \\
\text { Density } \\
\left(\mathrm{kg} / \mathrm{m}^{3}\right)\end{array}$ & $\begin{array}{c}\text { Ambient } \\
\text { Temperature } \\
(\mathrm{K})\end{array}$ & $\begin{array}{c}\text { Charge } \\
\text { Gas \% } \\
\mathrm{O}_{2}\end{array}$ & Fuel \\
\hline 93 & 1000 & $14.8,24$ & $600-1100$ & 0 & $\begin{array}{c}\text { LCJP-8, } \\
\text { JP-8 and } \\
\text { JP-8 } \\
\text { Surrogate }\end{array}$ \\
\hline
\end{tabular}




\section{Data Analysis}

Due to the nature of the raw data being in the form of high speed imaging, processing is needed to convert these images into the information needed to draw conclusions from. Pending on the type of testing conducted, a variety of processing techniques are used. All processing techniques are conducted in Matlab using codes based on previous processing procedures used by the AERB lab facility.

The following figures outline the different stages of the spray development and shows how the liquid and combusting sprays look in their raw form. Figure 6-1 shows the initial stages of the liquid penetration as the injector is actuated. The liquid fuel spray grows laterally until a steady state penetration distance is established, based upon ambient test conditions.

After a certain amount of time ignition occurs. This ignition is based on the vapor cloud that forms towards the end of the liquid spray region. The flame then develops across the vessel chamber in time once ignition happens. This process from steady state liquid formation to fuel ignition and combustion is seen in Figure 6-2.

These figures give an idea of the basis of fuel spray and the liquid formation, ignition, and flame formation process. These images are in a raw form except for a brightness correction to help distinguish the liquid spray from the background in the early images after start of injection. 


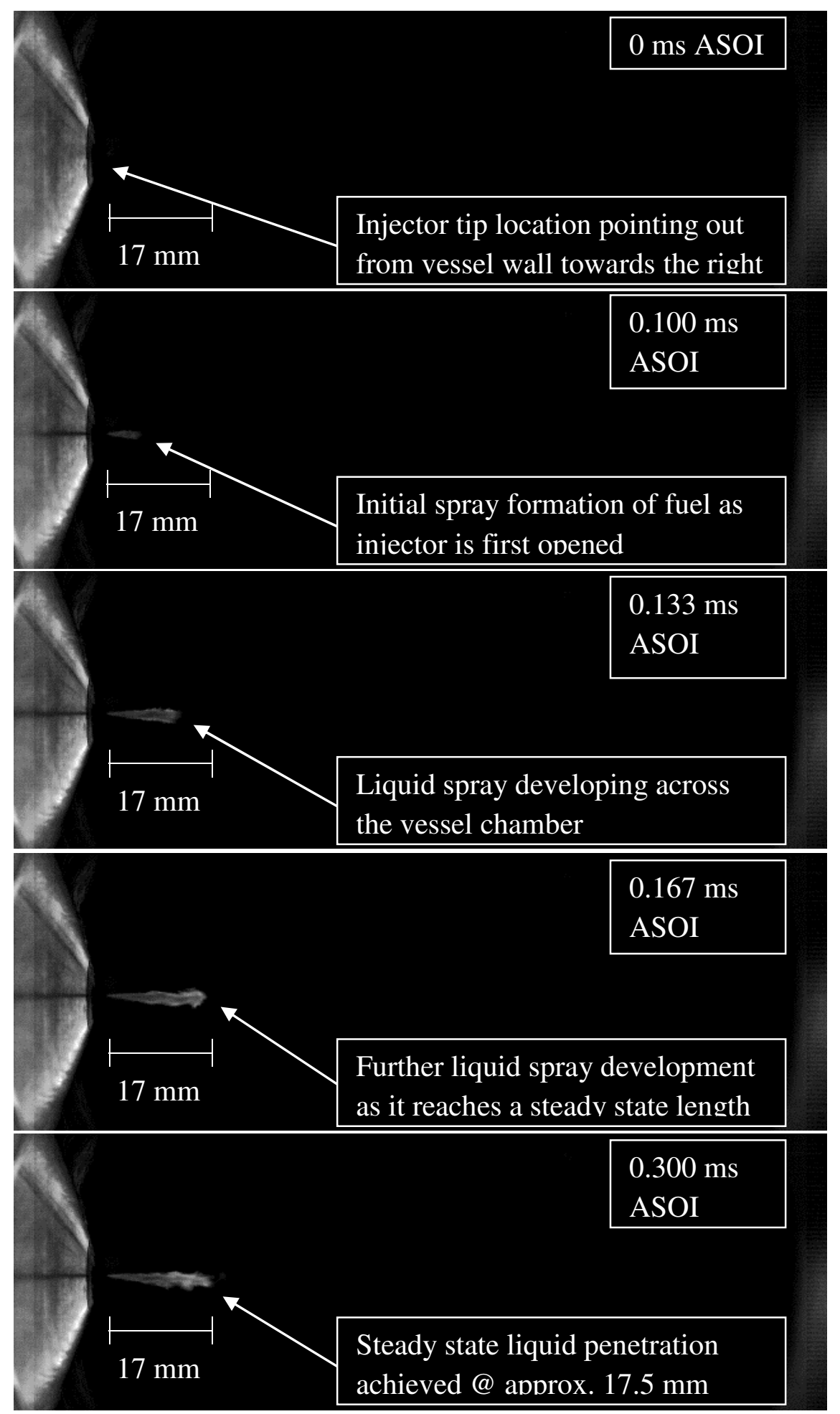

Figure 6-1: Initial Liquid Penetration Development. LCJP-8 @ Pinj.=1000 bar, $\rho_{\mathrm{amb} .}=24 \mathrm{~kg} / \mathrm{m}^{3}, \mathrm{~T}_{\mathrm{amb} .}=950 \mathrm{~K}$ 


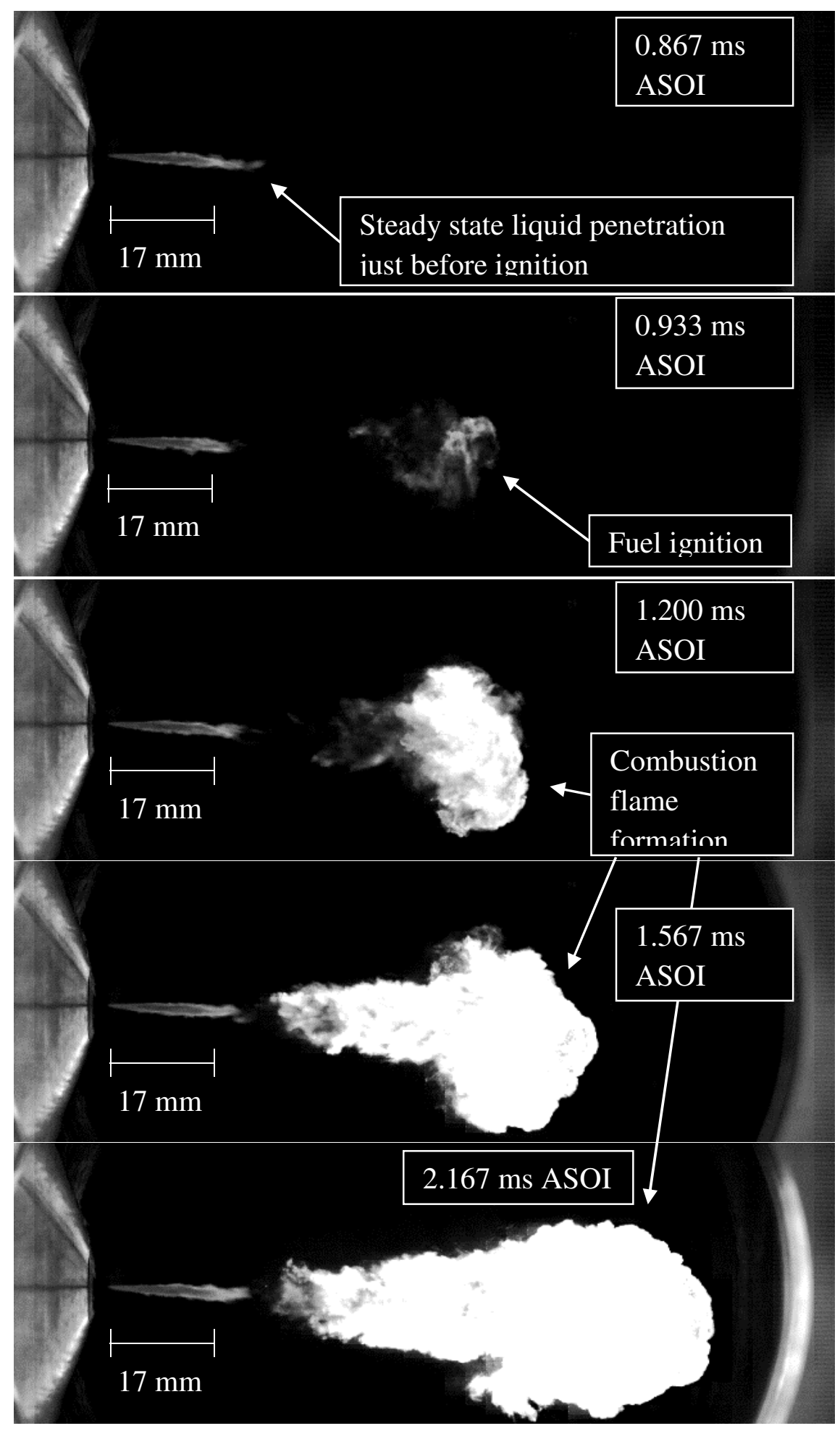

Figure 6-2: Ignition and Flame Development from Steady State Liquid Penetration. LCJP-8 @ Pinj. = 1000 bar, $\rho_{a m b . ~}=24 \mathrm{~kg} / \mathrm{m}^{3}, T_{\text {amb. }}=950 \mathrm{~K}$ 


\subsection{Combusting Image Processing}

The images produced from the combustion testing must be processed to determine the characteristics of interest involved with this study. Utilizing the imaging and lighting setup described in section 3.3.1 both the liquid spray and the flame jet can be seen. From these high speed images the property desired to be calculated is the ignition delay.

The start of ignition plays a key role in characterizing a fuel. To determine the time of start of ignition, the average intensity of the background subtracted image is calculated and compared to a baseline value. The selection of the baseline value is chosen as the average intensity of the image once the liquid spray has been fully developed. This is done to avoid a 'false ignition' calculation from being determined by just the intensity increase from the liquid portion of the spray growing. Once the baseline is calculated, ignition is defined as the point in time where the image intensity reaches $10 \%$ more than this baseline in order to avoid a false start of ignition. Due to the nature of the ignition event, this ramp up time from spray to ignition is very rapid and can very clearly be defined in this method. Figure 6-3 shows this intensity calculation and the profile of the rapid increase in image intensity once combustion begins. 


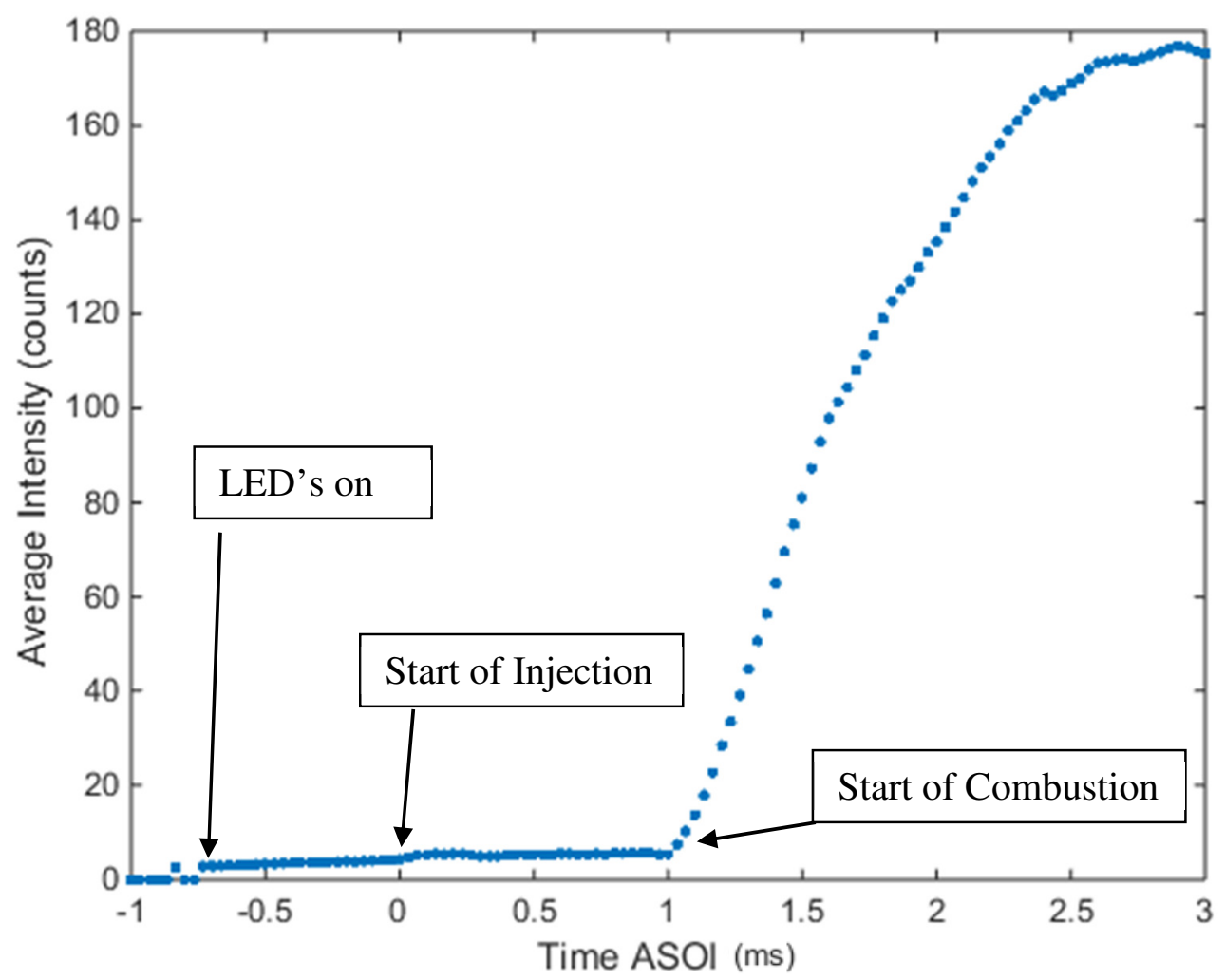

Figure 6-3: Average Image Intensity Plot

As can be seen in Figure 6-3, the average intensity of the image changes in time. The initial change occurs for this case at around $-0.75 \mathrm{~ms}$ after start of injection (ASOI). This increase in image intensity is attributed to the LED light sources turning on. Another change in the intensity occurs just after 0 ASOI. This is a result of the liquid spray developing, thus increasing the image intensity as more liquid spray reflects more light. Once the liquid spray achieves a steady state penetration condition, the image intensity likewise reaches a steady state condition and the next ramp is due to the combustion event. It is important to understand the cause of these last two changes in image intensity to be able to select an appropriate baseline value used to determine the start of ignition. The selected data points of image intensity to be averaged into a baseline value must be after the spray has reached a steady state liquid penetration and before ignition ensues. 
This becomes less trivial when the conditions are such that ignition delays are on the magnitude of $0.3 \mathrm{~ms}$ ASOI and there is very little time between when the spray reaches steady state and when combustion begins. With these issues in mind, the baseline values were chosen to work with all cases, both long and short ignition delays. Figure 6-4 below shows a magnified region of Figure 6-3, emphasizing the change of the image intensity value from the LED steady state value to the determination of the liquid spray steady state intensity value to be used as the baseline.

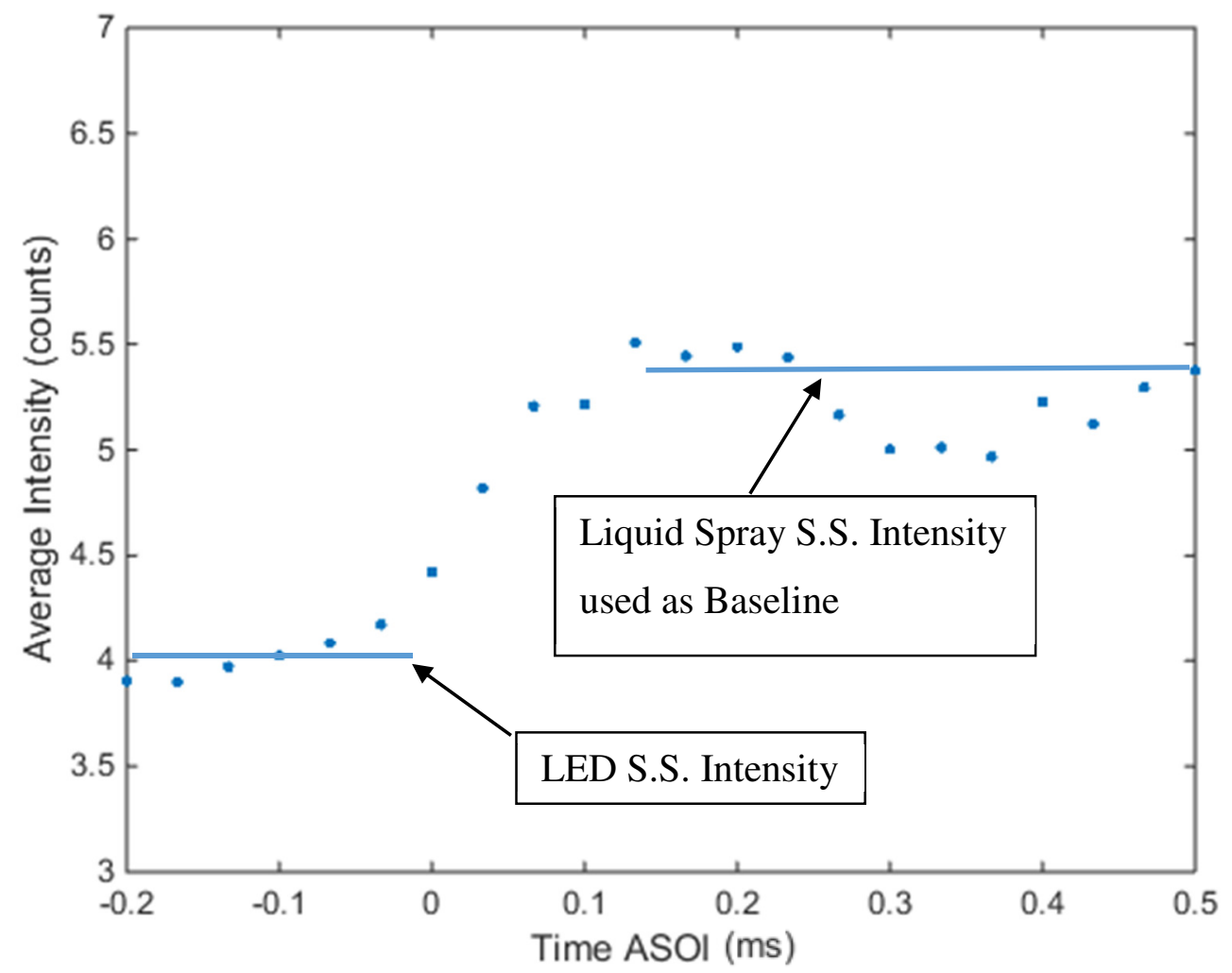

Figure 6-4: Average Image Intensity, Achieving Steady State Liquid Spray Baseline Intensity 


\subsection{Non-combusting Image Processing}

The goal of the non-combusting spray tests is to determine the liquid penetration values at a higher camera framerate (see section 3.3.2). This higher framerate allows a better time resolution of the liquid penetration through the capturing of more images per unit time.

In order to track the liquid penetration the raw images are processed in such a way as to distinguish the areas of interest apart from the rest of the image. To do this the first step is to subtract a background image and crop the leftover to an image area in which the spray will be. Once the background subtraction is complete a background thresholding process is done in Matlab based on the Otsu's method [19] as used by the Matlab command 'graythresh'. Using this thresholding value the raw image is converted into a black and white image. All pixels above the threshold value become white, all below become the black background. The edge of this white area is then smoothed out by the use of a 2dimensional median filtering technique as used by the Matlab command 'medfilt2' [20]. From this filtered edged region, the area chosen as the 'important' region is that which outlines the largest area. In this way noise that is picked up in the background away from the real spray region is ignored. From here the liquid penetration can be determined from this leftover outlined region. The liquid penetration value is calculated based on the pixel of the outline of the spray region which is furthest from the designated injector tip location. This process is visually explained in Figure 6-5. 


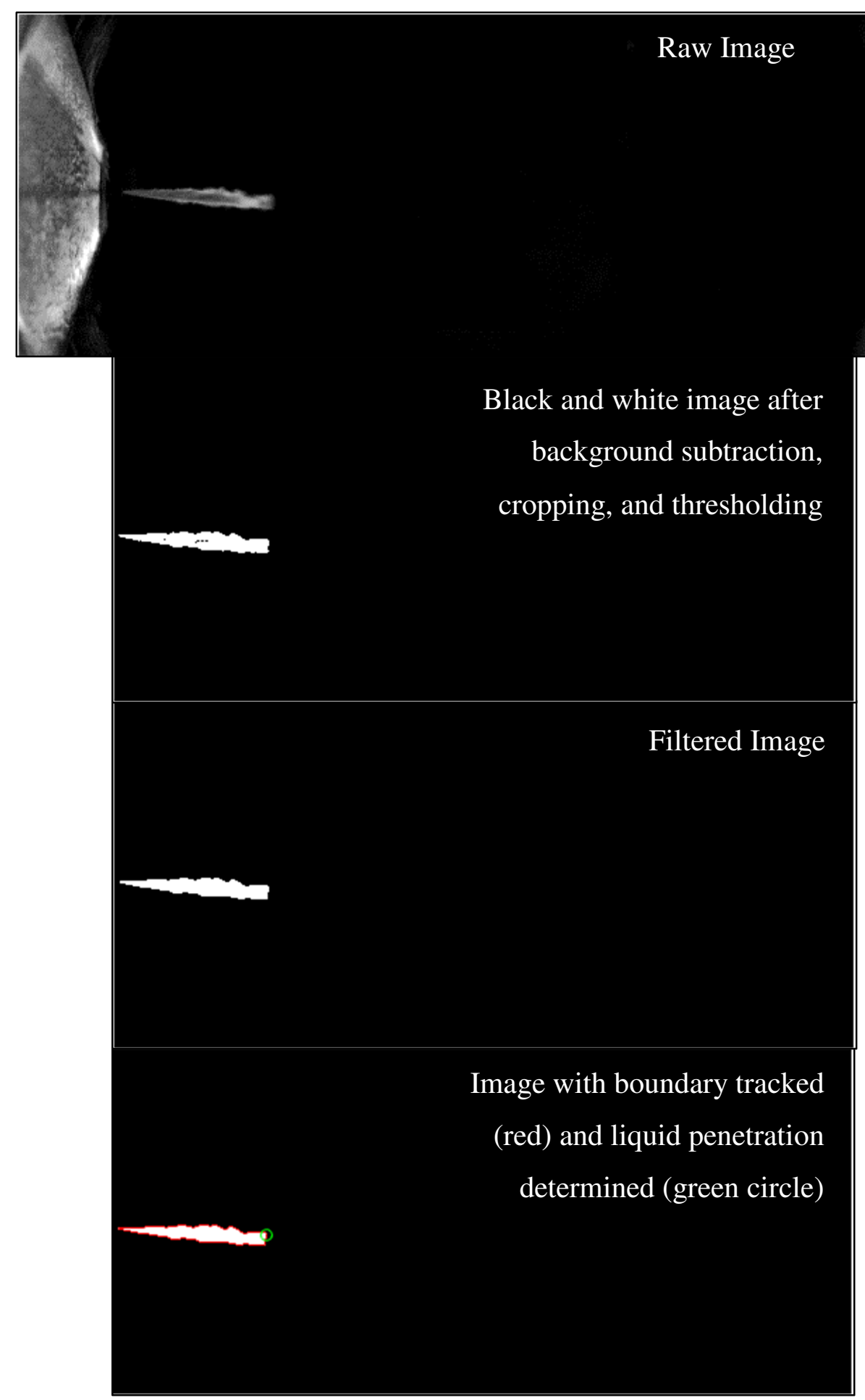

Figure 6-5: Visual on the Image Processing from Raw Image to Tracked Value. JP-8 $@$ Pinj. $=1000$ bar, $\rho_{a m b .}=24$ kg/m $/ \mathrm{m}^{3}, T_{\text {amb. }}=900 \mathrm{~K}$ 
In this way the following result is able to be determined, as seen in Figure 6-6.

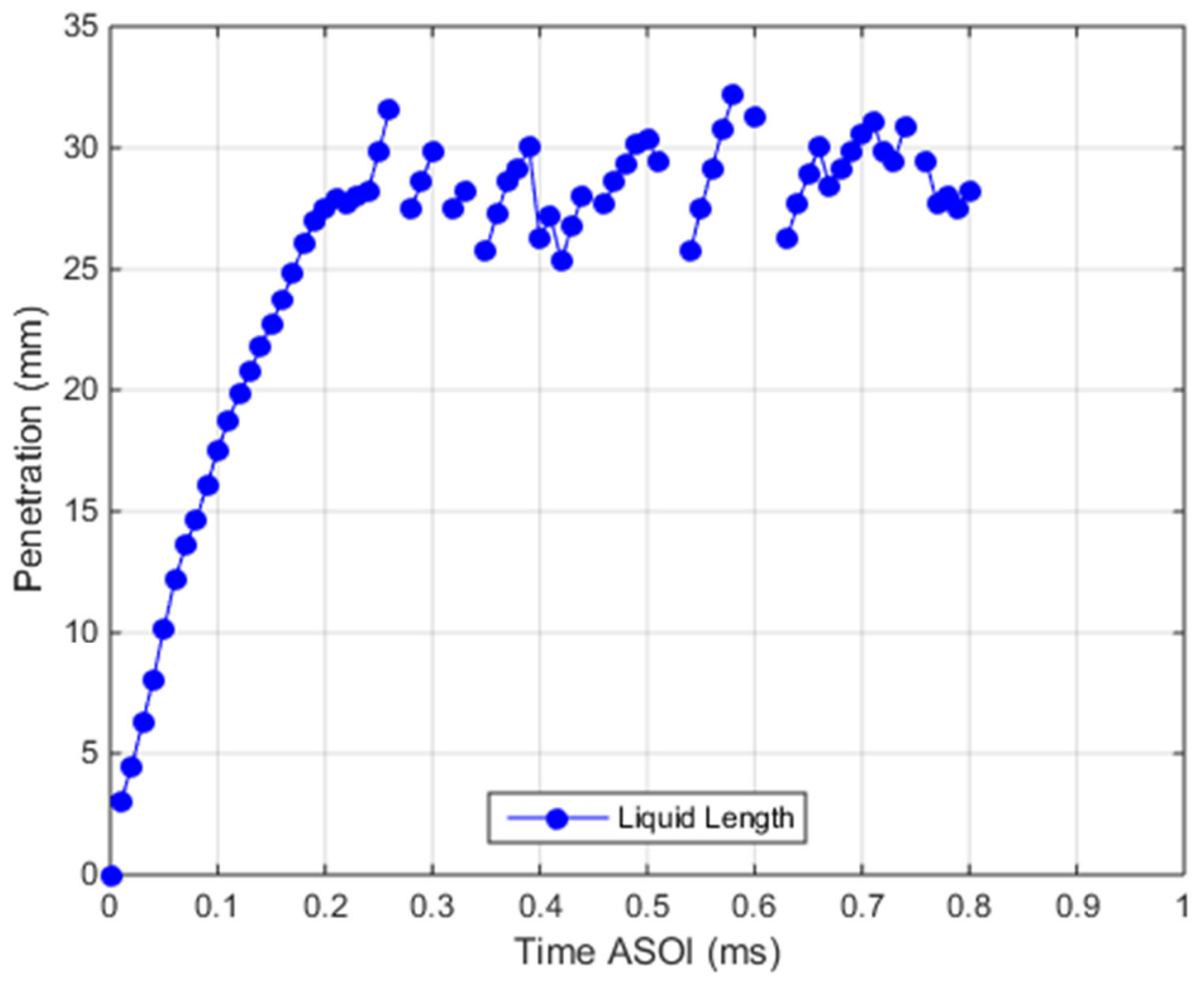

Figure 6-6: Liquid Penetration Results Plot of Non-combusting Image Processing.

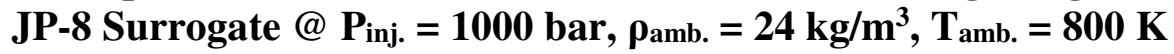




\section{$7 \quad$ Results}

After obtaining the high speed images and processing them, as described in the previous section, ignition delays and steady state liquid penetration values are determined. These results can therefore be compared both fuel to fuel, being JP-8 versus LCJP-8, and can be compared individually to past work. Of particular interest of the combustion testing is the ignition delay of each fuel at varying ambient conditions. To compare and to consolidate the determined ignition delays, Arrhenius based curve fit equations are developed for each fuel.

\subsection{Formulation of Arrhenius Curve Fits}

The Arrhenius curve fit is a standard used for developing an equation for the temperature dependence of various reaction rates. When applied to CI engines it can be formulated in terms of the delay time for the start of combustion. In its general form, the Arrhenius equation is as follows:

$$
\tau_{I D}=A e^{\frac{E_{a}}{R T}}
$$

where $\tau_{I D}$ is the ignition delay time, in miliseconds, $\mathrm{A}$ is the pre-exponential factor, $E_{a}$ is the activation energy, $\mathrm{R}$ is the universal gas constant and $\mathrm{T}$ is the reaction temperature. Using this base equation a modified version is created to be specifically relative to ignition reactions within CI engines. This form is found in Heywood, [21], and is as follows:

$$
\tau_{I D}=\frac{A}{P} e^{\frac{E_{a}}{R T}}
$$

where $P$ is the ambient pressure. Since this work is done relative to the variables of ambient temperature and ambient density, where $\mathrm{P}$ is directly related to $\rho$, the ambient density, the ambient density is used instead. Lastly there is also the need to add in an offset in order to account for the physical delay of the injection process. This offset is a function of the square root of injection pressure and represents the theoretical time it 
takes to inject the minimum amount of fuel needed to initiate combustion no matter the extent of the ambient conditions. It can be viewed as a physical delay of the system, taking into account the time of fuel delivery, mixing and all other processes required before combustion can be initiated. Adding in this offset and relating the density gives:

$$
\tau_{I D}=\frac{K}{\sqrt{P_{\text {inj. }}}}+\frac{A}{\rho_{\text {Core }}} e^{\frac{E_{a}}{R T \text { Core }}}
$$

The offset value meant to model the minimum amount of time required to inject is based off the works of Naber, Siebers, and Julio [22] and is modified to include the varying injection pressure and its effects on the theoretical minimum ignition delay. Also included in the coefficient, $K$, is chemical reaction properties that play a significant role in the theoretical minimum ignition delay. All encompassed the entire term of $\frac{K}{\sqrt{P_{\text {inj. }}}}$ can be seen as accounting for the minima of injector delay, fuel delivery rate, and fuel mixing kinetics that all go into the physics of ignition and the value of an absolute minimum time value. This term is thought of as being the physical delay of the system.

The right side of the term, $\frac{A}{\rho_{\text {Core }}} e^{\frac{E_{a}}{R T} \text { Core }}$, then is left to account for the effect of ambient density and ambient temperature on the chemical reaction that occurs for ignition.

\subsubsection{JP-8 Curve Fit}

Due to the nature of the testing being an exploratory look at the ignitability of each fuel not all test conditions in the combusting test matrix experienced ignition. After sweeping through all proposed test variables for the prescribed testing of JP-8, only one ambient density produced combustion. Because of this, the influence of ambient density on the Arrhenius curves is not explicitly determined. Instead a coefficient is calculated for the total of $\frac{A}{\rho}$ and the density is divided out. Therefore in this way ambient temperature, ambient density, and injection pressure are still the three criteria used for fitting the curve. With this in mind a least squares curve fitting is done on the data sweeping 
ambient temperature while holding injection pressure constant to determine the best fit for individual injection pressure data sets. In Figure 7-1 the results of this curve fitting can be seen with the individual curve for each injection pressure overlaid on the ignition delay data sets for the injection pressure of 500, 1000, and 1500 bar.

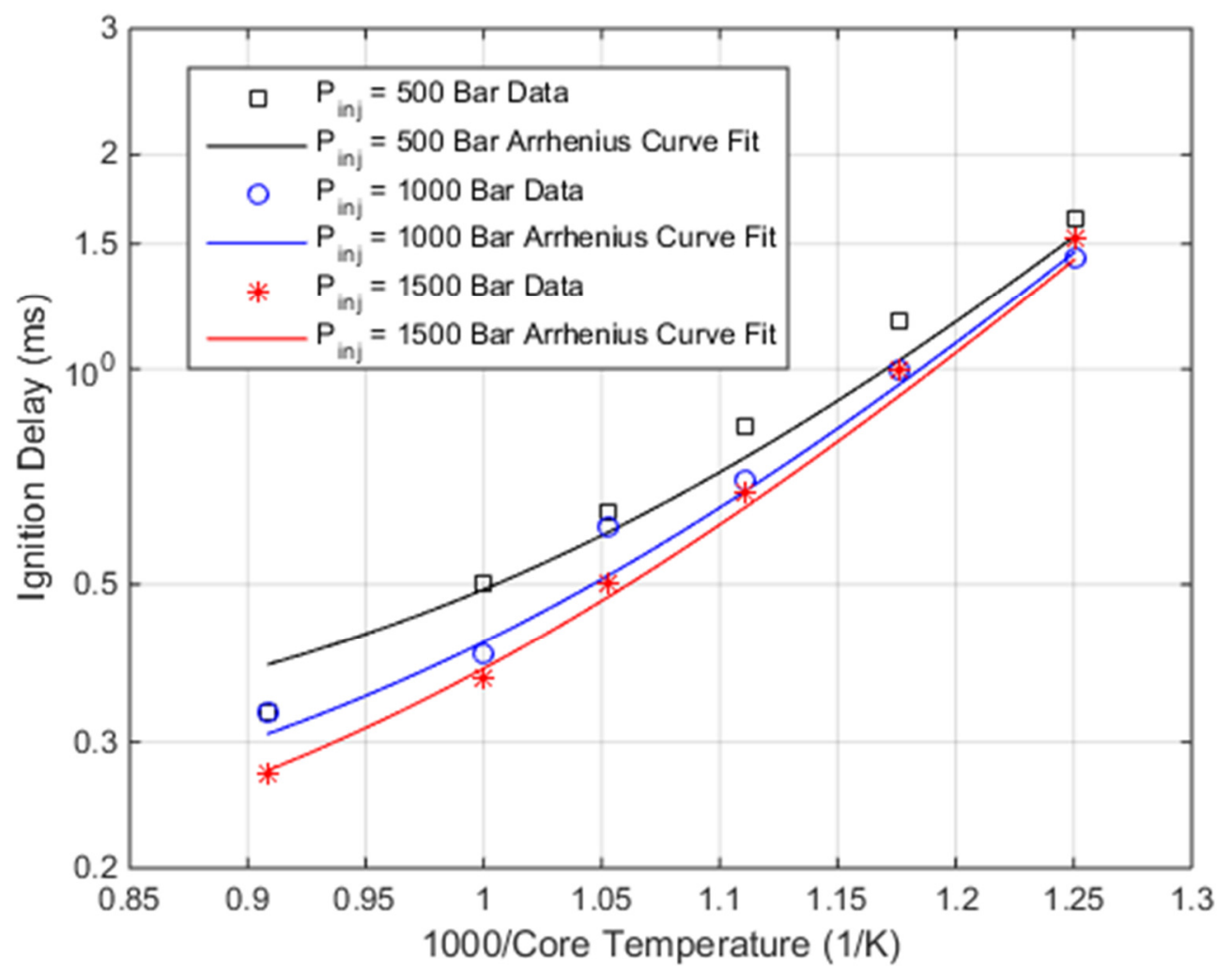

\section{Figure 7-1: Arrhenius Curve Fit Results of JP-8 Overlaid on Sample Data Sets $\left(\right.$ Ambient Density $\left.=24.0 \mathrm{~kg} / \mathrm{m}^{3}\right)$}

It can be seen that the developed correlation matches the experimental data with a deviation of less than $15 \%$ for the 1000 bar case and less than $10 \%$ for the other two injection pressures. The coefficients of this curve fit can be seen in Table 7-1.

\subsubsection{LCJP-8 Curve Fit}

In the same way as is developed for JP-8, Arrhenius curve fit coefficients are created to describe the ignition delay of LCJP-8. For this set of testing the ambient density went up 
to a maximum of $30.2 \mathrm{~kg} / \mathrm{m}^{3}$, rather than just the $24.0 \mathrm{~kg} / \mathrm{m}^{3}$ of the testing for JP-8.

Because of this, ignition is observed with the LCJP-8 in both the 24.0 and $30.2 \mathrm{~kg} / \mathrm{m}^{3}$ test sweeps. This allowed for a larger range of variable testing and enabled the ability to examine how well the developed equation predicts ignition delay when ambient density is not a constant, as was the case with the ignition testing results of the JP-8 test fuel. Figure 7-2 shows the developed Arrhenius curve with a sample data set of the $24.0 \mathrm{~kg} / \mathrm{m}^{3}$ results overlaid.

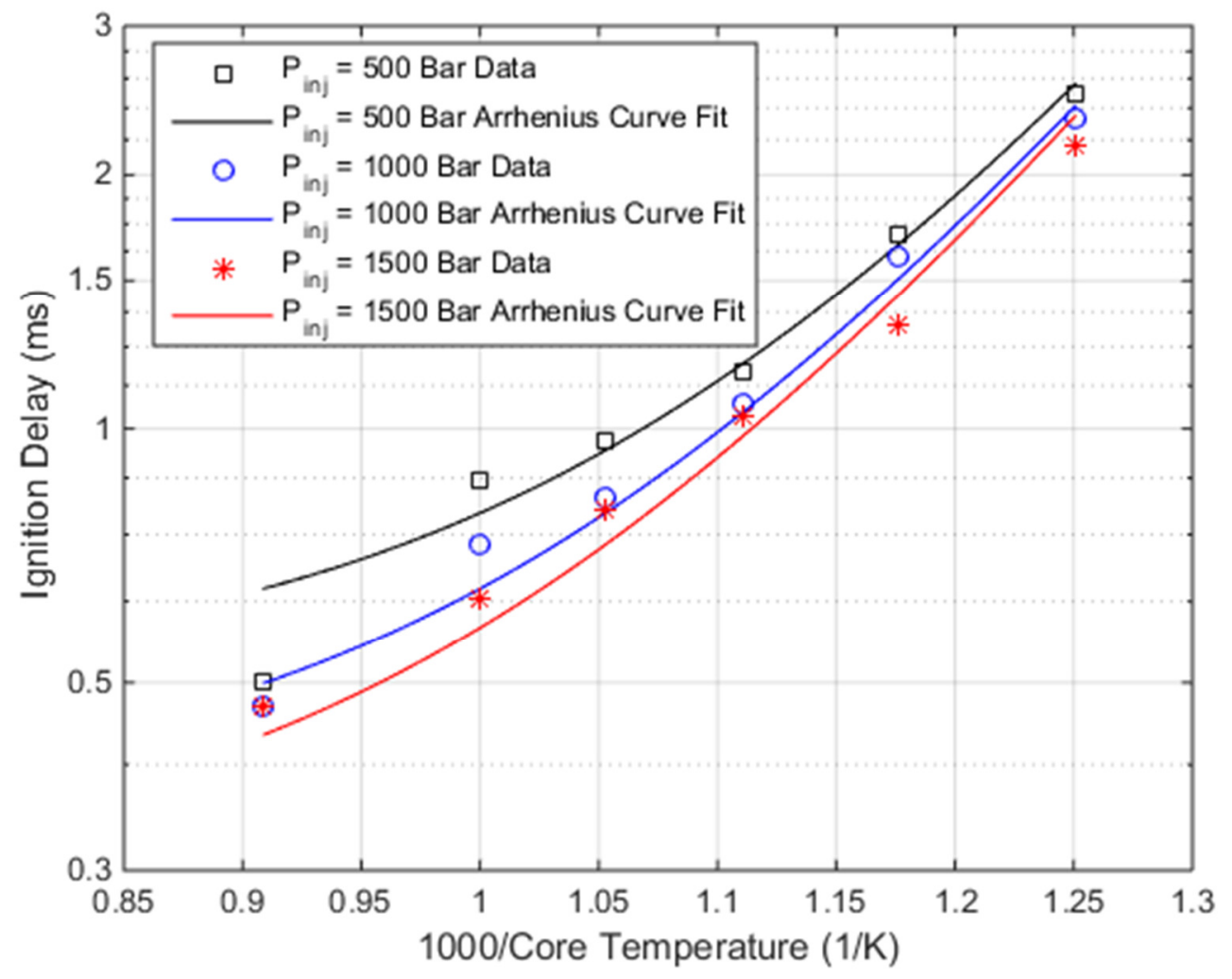

Figure 7-2: Arrhenius Curve Fit Results of LCJP-8 Overlaid on Sample Data Sets $\left(\right.$ Ambient Density $=24.0 \mathrm{~kg} / \mathrm{m}^{3}$ )

Again the developed correlation shows good agreement with the experimental data. A maximum deviation between data and correlation is less than $15 \%$, 
These same Arrhenius coefficients were then used in the calculation of the ignition delay at the higher ambient density case, the $30.2 \mathrm{~kg} / \mathrm{m}^{3}$ condition. Data results are overlaid to determine how well this correlation adapts to the changing of this testing variable. Figure 7-3 shows the result of the $30.2 \mathrm{~kg} / \mathrm{m}^{3}$ Arrhenius correlation with experimental data set overlaid.

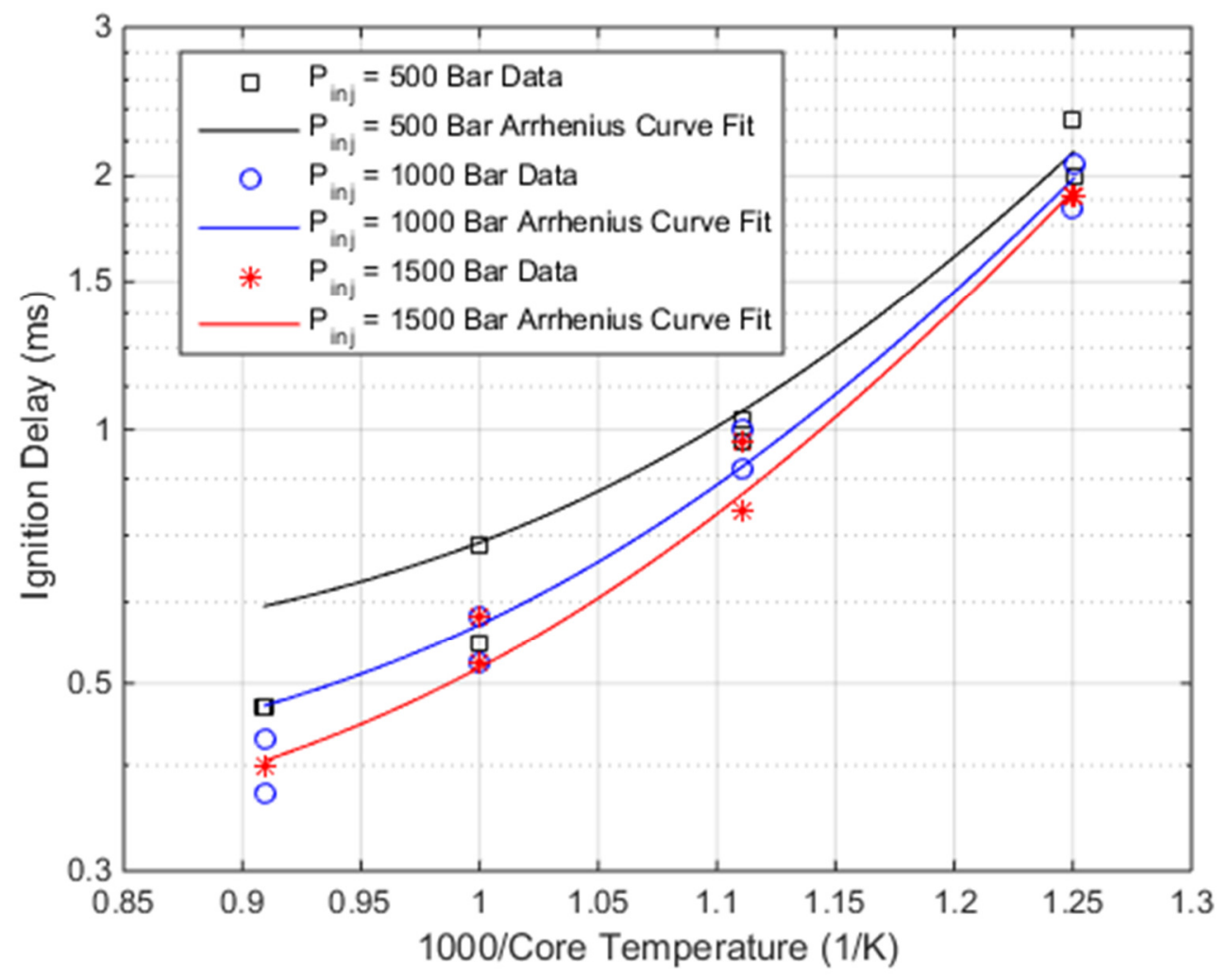

\section{Figure 7-3 : Arrhenius Curve Fit Results of LCJP-8 Overlaid on Sample Data Sets $\left(\right.$ Ambient Density $=30.2 \mathrm{~kg} / \mathrm{m}^{3}$ )}

As seen in Figure 7-3 the correlation follows the trend set by the experimental data set.

The observed fit between the correlation and the data set shows a larger deviation at 500 bar injection pressure and the higher temperature conditions of 1000 and $1100 \mathrm{~K}$ with a $20 \%$ and a $23 \%$ deviation respectively. At the 1000 bar injection pressure a maximum of $21 \%$ deviation is seen at the $1100 \mathrm{~K}$ condition. At the rest of the conditions less than a $13 \%$ difference between experimental data and the correlation is seen. The region which 
shows the largest deviation is at the high temperature conditions. This could show that the developed correlation coefficients do not represent the injection and injector characteristics as well as the physical delay of the correlation, the $\frac{K}{\sqrt{P_{\text {inj. }}}}$ term, is more dominate at these higher core temperatures and higher core densities.

\subsubsection{LCJP-8 versus JP-8 Curve Fit Coefficients}

Table 7-1, summarizes the curve fit values determined in the previous sections. Note that for the LCJP-8 there are two plots above, one for each ambient density of 24.0 and 30.2 $\mathrm{kg} / \mathrm{m}^{3}$ while the JP-8 fuel was only tested at the densities of $24.0 \mathrm{~kg} / \mathrm{m}^{3}$ and lower. Each fit line for the LCJP-8 was developed using the same coefficients in the table below, only changing the value of the variable $\rho$ to match the testing condition of the overlaid data.

Table 7-1: Arrhenius Fit Coefficients Developed for JP-8 and LCJP-8

\begin{tabular}{|c|c|c|c|}
\hline \multirow{2}{*}{ Equation } & \multicolumn{3}{|c|}{$\tau_{I D}=\frac{K}{\sqrt{P_{\text {inj. }}}}+\frac{A}{\rho_{\text {Core }}} e^{\frac{E_{a}}{R T_{\text {Core }}}}$} \\
\hline Fuel & $\mathrm{K}$ & $\mathrm{A}$ & $\mathrm{E}_{\mathrm{a}}$ \\
\hline JP-8 & 5.90 & $5.69 \mathrm{E}-03$ & $5.71 \mathrm{E}+04$ \\
\hline LCJP-8 & 11.30 & $2.80 \mathrm{E}-03$ & $6.50 \mathrm{E}+04$ \\
\hline
\end{tabular}

Again the representation of each term in the Arrhenius correlation developed represent the different characteristics of ignition. $\frac{K}{\sqrt{P_{i n j} .}}$ represents a physical delay of the system, account for rate of injection and mixing physics. $\frac{A}{\rho_{\text {Core }}} e^{\frac{E_{a}}{R T} \text { Core }}$ represents the chemical reaction that takes place for ignition to occur and its temperature and pressure dependence.

\subsubsection{Statistical Deviation of Ignition Delay}

Part of the designed test matrix includes a section for testing the test variance of the JP-8 ignition delays at a single ambient core density and single injection pressure of 24.0 $\mathrm{kg} / \mathrm{m}^{3}$ and 1000 bar respectively. The result of this testing is able to show how the 
ignition delay values change test-to-test and can be seen in Figure 7-4. Here it is shown that the calculated values of the ignition delay for the higher temperature lay within the 1 standard deviation bars but the two lower temperature conditions lay just outside of it.

This figure also shows that the deviation of the ignition delay is slightly greater at the higher temperature conditions with coefficients of variations of 5.7, 6.0, 8.9, and 8.2\% for the respective temperatures of $800,900,1000$, and $1100 \mathrm{~K}$. Therefore up to a $9 \%$ deviation in the ignition delay data can be expected at these test conditions. 


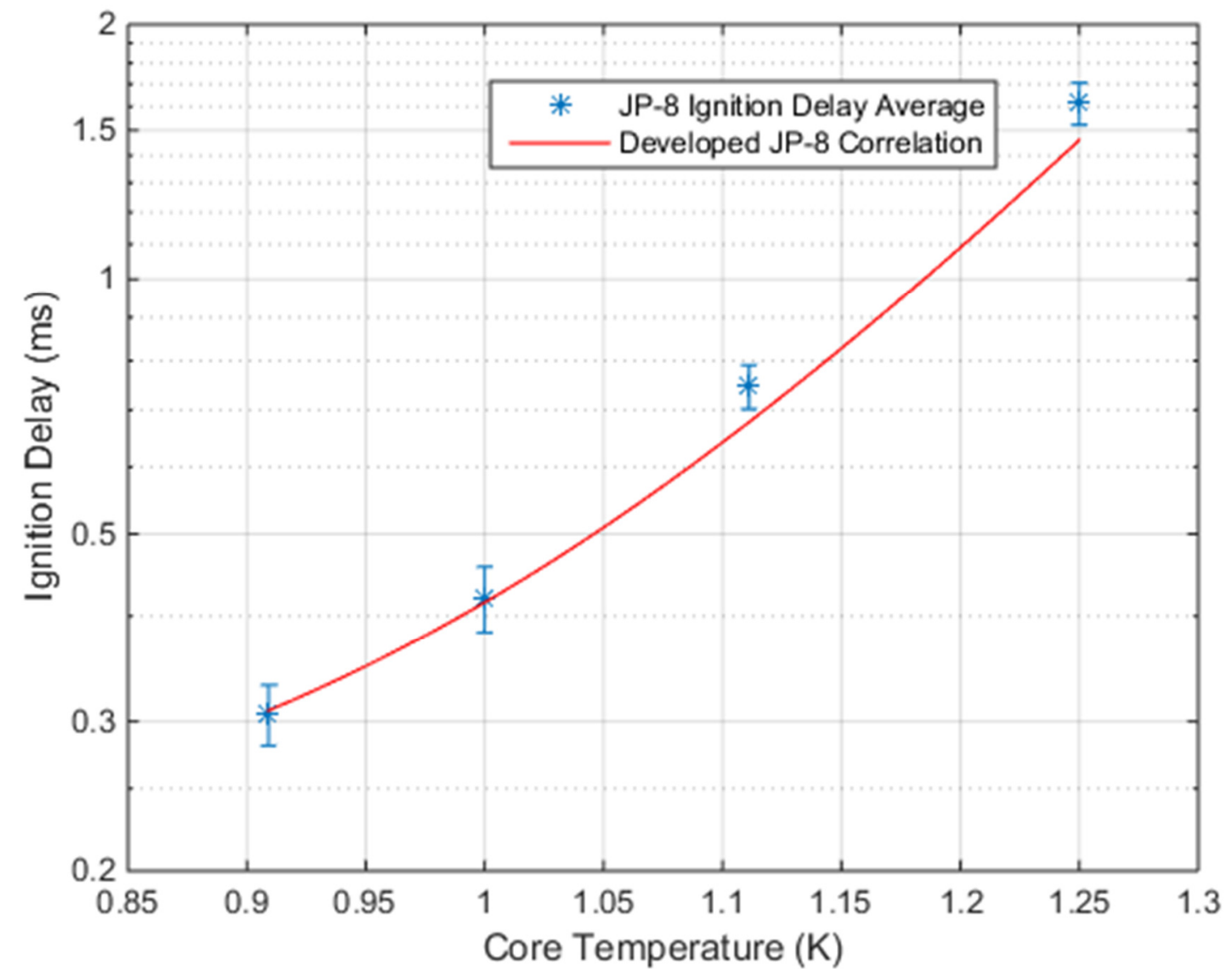

Figure 7-4: Average Ignition Delay with 1 Standard Deviation Error Bars Overlaid with JP-8 Arrhenius Correlation. Ambient Core Density $=\mathbf{2 4 . 0} \mathbf{~ k g} / \mathrm{m}^{3}$, Injection Pressure $=1000$ bar.

\subsection{Comparison of JP-8 Arrhenius Curve to Pickett and}

\section{Hoogterp, [2]}

A comparison is made between the JP- 8 data of this testing with the results of previous work. The comparison is done between the developed Arrhenius curve for JP-8 and the reference data from Pickett and Hoogterp [2]. Here it can be determined how comparable the results of this testing and experimental setup are to the pool of data available on JP-8. Then it can be known how well this sample of JP-8 performed and how well the results derived from this sample act as a baseline for testing. Also included is a set of data points 
on the performance of diesel at the same test conditions as the JP- 8 testing conducted by Pickett and Hoogterp [2] as seen in Figure 7-5.

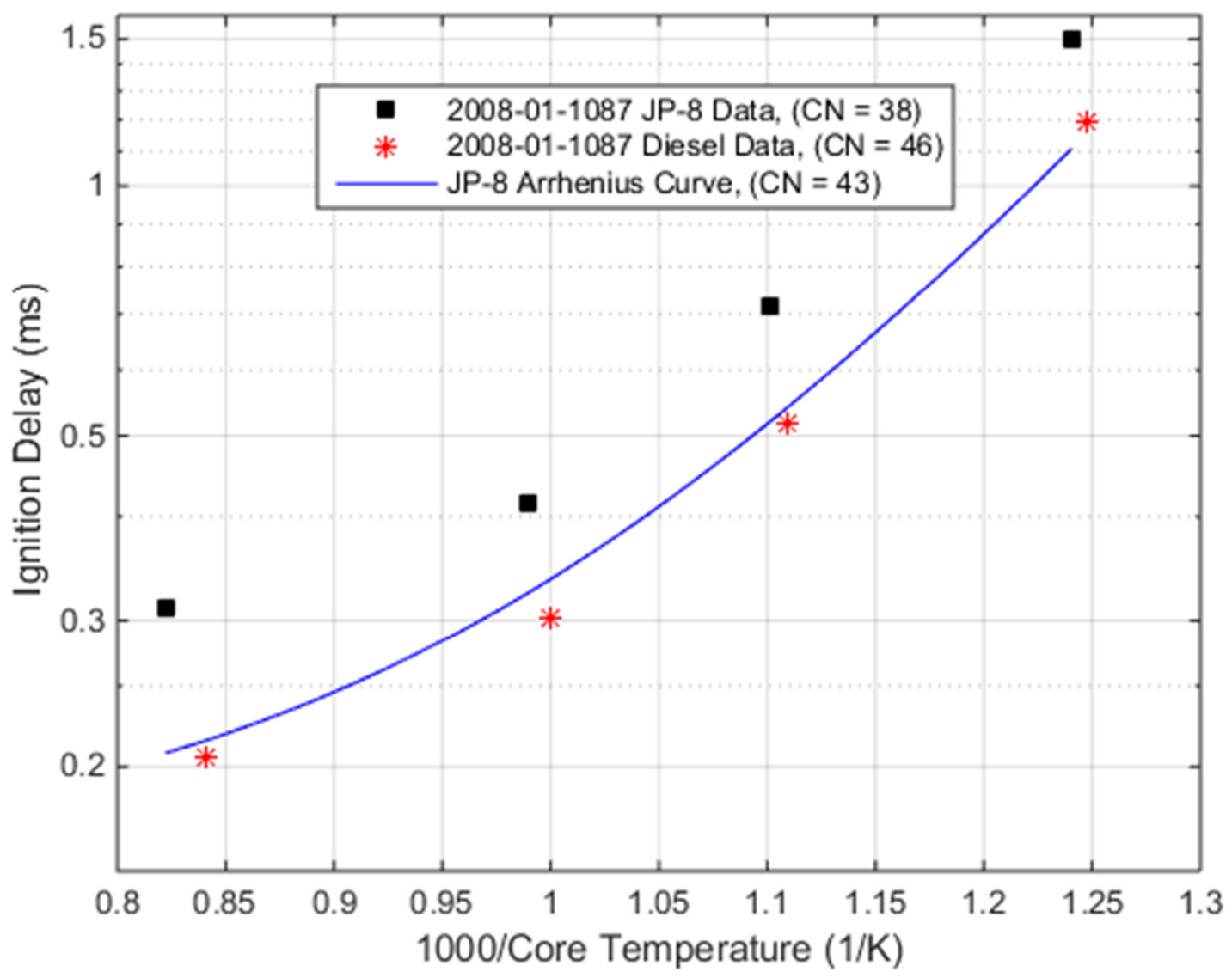

Figure 7-5: Comparison of Past Ignition Delay Data with Develop JP-8 Arrhenius Curve, $\left(P_{\text {inj }}=1470\right.$ bar, Ambient Core Density $\left.=30.0 \mathrm{~kg} / \mathrm{m}^{3}\right)$

As is expected the developed Arrhenius curve for this sample of JP-8 is predicting ignition delays in between the past work on the measured ignition delays of JP-8 and of diesel. Note that the conditions of the test data being compared to is at an injection pressure and an ambient density not covered by this testing. That fact considered with how the trend of the curve compares to the past data gives further credibility to the developed Arrhenius curve for JP-8 in its ability to predict ignition delays outside of the 
tested variable ranges of injection pressure and ambient density, over which it was developed.

Also of interest is how the predicted ignition delay lies closer to the higher $\mathrm{CN}$ diesel fuel than the 38 value CN JP-8. This is partly due to the sample of JP-8 used for this testing has a $\mathrm{CN}$ of 43 , closer to that of diesel. In complement to that rational is also the difference that the correlation curve is generated using data obtained from a single hole injector of nozzle diameter equal to 200 micron, while the comparative past data points were gathered using a 180 micron nozzle diameter. This would result in shifting the predictive values even closer towards the lower end of ignition delays due to a higher fuel flowrate that is not accounted for in the development of the curve. A less than $10 \%$ increase in ignition delay is seen between the CN 43 JP-8 compared to the diesel sample where greater than a $23 \%$ increase is seen between the CN 43 JP-8 and the CN 38 JP-8 samples.

\subsection{Comparison of JP-8 and LCJP-8 Arrhenius Curve}

\section{Correlations}

A comparison of the JP-8 and LCJP-8 fuels can be made. From the above section the JP8 ignition delay curve looks to predict delay times within a very acceptable and expected region and can be accepted as a valid correlation for this type of combustion work. Also of merit is that the trend of the equation follows the apparent data trend of the past work across a temperature sweep. This lends confidence to the ability of the curve and its capacity to operate successfully at injection pressures and ambient densities that are both covered and not covered by this testing. Accepting the JP-8 curve as a valid correlation, relative differences can then be examined at various injection pressures and ambient densities between the two fuels by comparing the results of each curve. Figure 7-6 shows such a comparison of the two developed correlations as injection pressures are swept. 


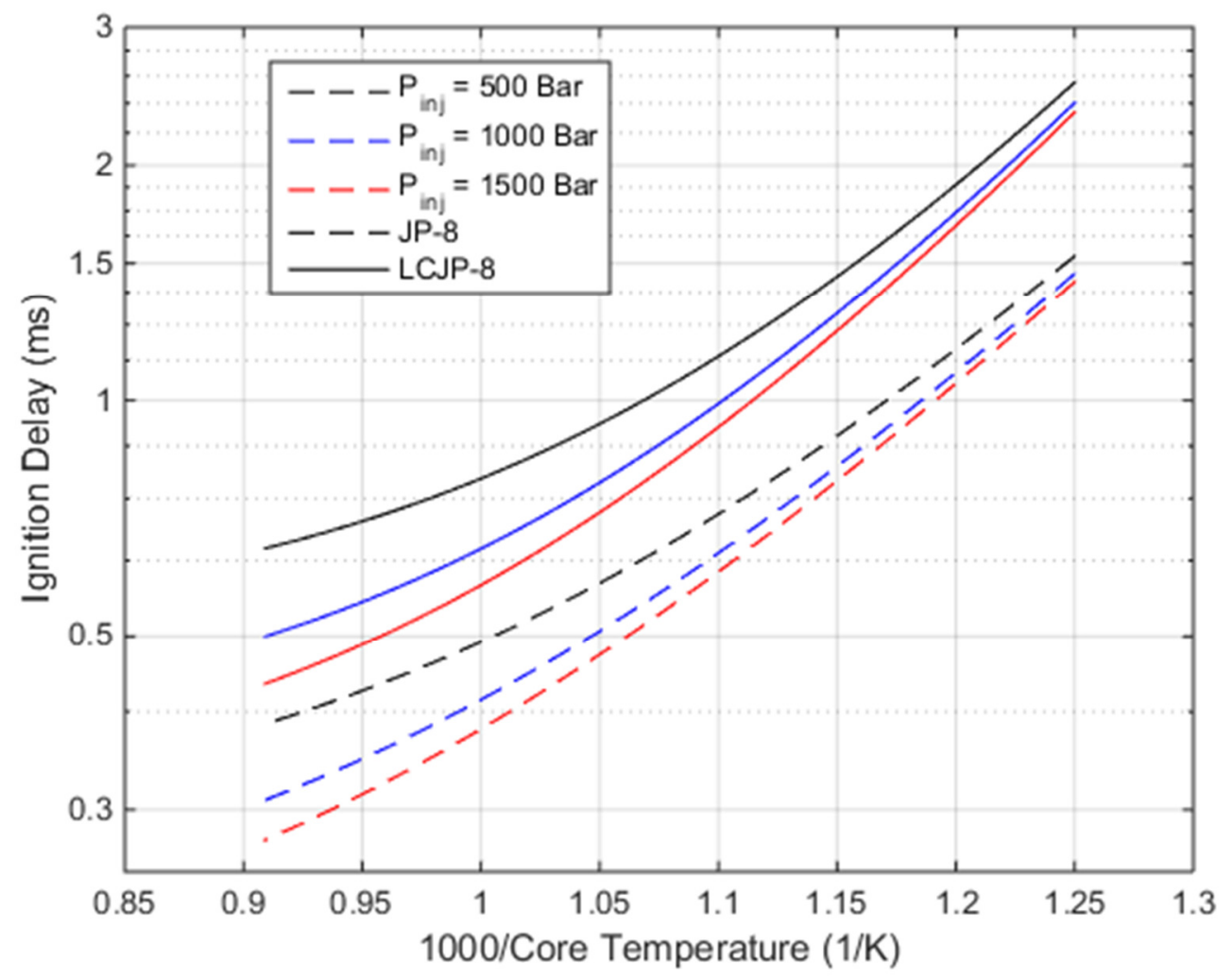

Figure 7-6: Comparison of JP-8 and LCJP-8 Ignition Delay Correlations, Sweeping Injection Pressure. Ambient Density: $24.0 \mathrm{~kg} / \mathrm{m}^{3}$

Figure 7-6 shows the comparison of these two correlations as ambient temperature is swept from $800 \mathrm{~K}$ to $1100 \mathrm{~K}$ and the ambient density is held at $24.0 \mathrm{~kg} / \mathrm{m}^{3}$. The plot shows the results of the developed correlations at the three injection pressure tested in this work. In this data set the ignition delay times of the LCJP-8 fuel show an increase of approximately 50-60\% over this sample of JP-8. This relative difference between JP-8 and LCJP-8 is slightly higher than the work done by Schihl, Hoogterp-Decker, and Gingrich [8] which reports ignition delays of the LCJP-8 at approximately 5-40\% longer than JP-8 at this ambient core density. The difference between this past work and the finding here cannot be attributed to differing $\mathrm{CN}$ since their sample of both JP-8 and LCJP-8 have nearly the same values at 44.9 and 25.2 respectively, but the high end of the difference between ignition delays is almost in range of findings here. At the higher 
ambient temperature end of the figure the delays show a higher relative difference, being about $60 \%$ different at the $1100 \mathrm{~K}$ condition while at around 50\% through the rest of the temperatures. At the higher ambient temperature the ignition delay is more largely determined by the minimum time it takes to get fuel into the vessel, rather than the time it takes the fuel to reach activation energy. Because of this it can be concluded that the differences between the injector operations when running each fuel is a slightly stronger factor than the fuel $\mathrm{CN}$ at the higher ambient temperatures. At the moderate to low end of the ambient temperature sweep this is not necessarily the case since the relative differences between ignition delays of the two fuels holds constant at about 50\%. Another important comparison that can be made between the two correlations is the relative differences across various ambient densities, keeping injection pressure constant. This comparison can be seen in Figure 7-7. 


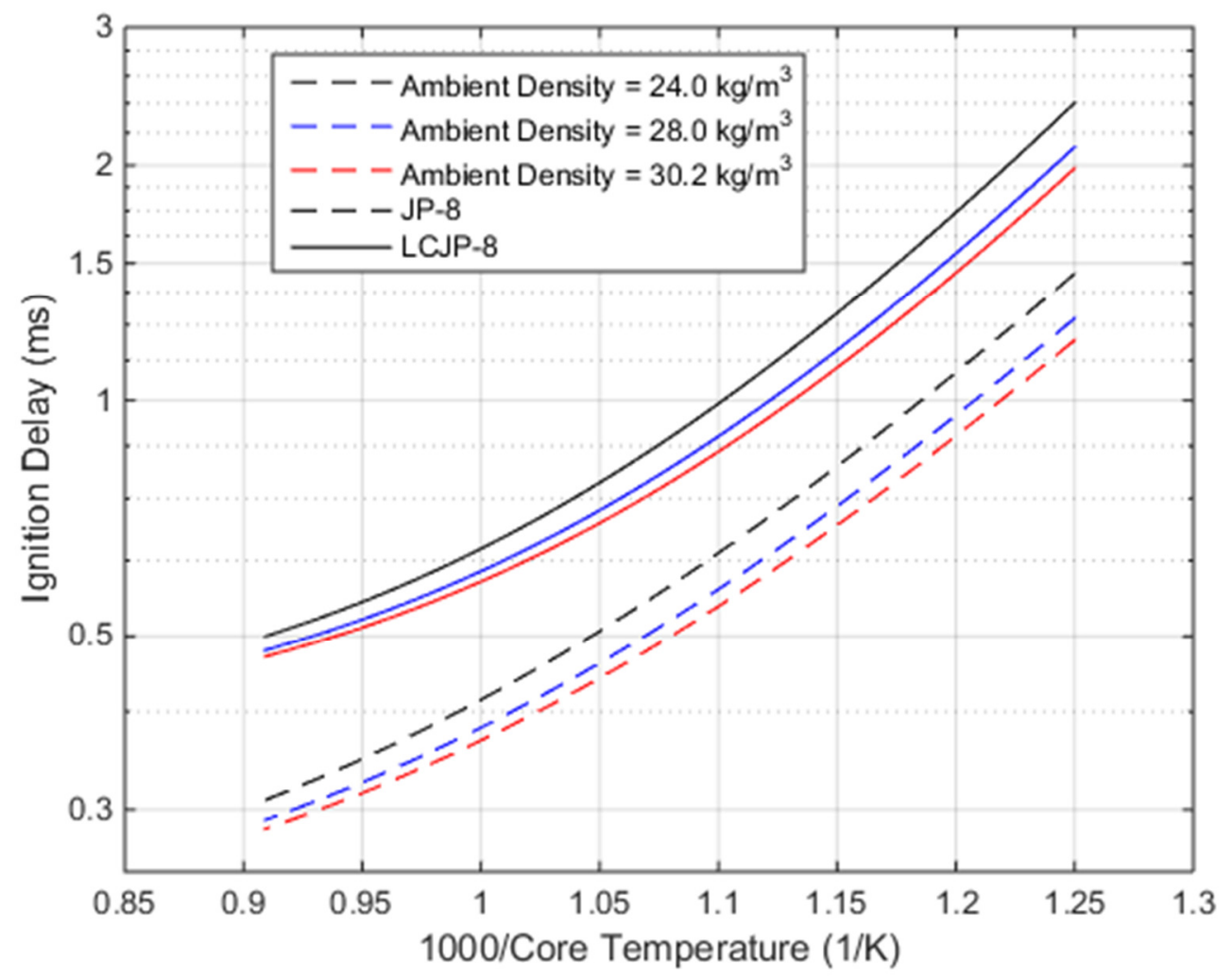

Figure 7-7: Comparison of JP-8 and LCJP-8 Ignition Delay Correlations, Sweeping Ambient Density. Injection Pressure: 1000 bar

Figure 7-7 shows another comparison between the calculated ignition delays of the JP-8 sample and the LCJP-8. In this comparison the developed correlations are used to create an ignition delay curve at a specific ambient densities not tested in this experiment, but at which is still within the bounds of the scope of this work. The JP-8 fuel sample was not tested at core densities higher than $24 \mathrm{~kg} / \mathrm{m}^{3}$, but here the correlation is used to calculate a theoretical ignition delay curve to compare to the LCJP-8. Also note that neither fuel was tested at the $28 \mathrm{~kg} / \mathrm{m}^{3}$ condition but both were calculated to provide another theoretical ignition delay to compare between the two fuels. The injection pressure is held constant at 1000 bar. In this comparison it is shown that the relative ignition delays scale with ambient density since the percent change between the JP-8 and LCJP-8 remain fairly constant at about $50-60 \%$ difference across the temperature sweep. 
It is important to note that the predictive equations will calculate an ignition delay at conditions where the fuel does not ignite during this testing. It is therefore beneficial to only use the equations at ambient densities above $24.0 \mathrm{~kg} / \mathrm{m}^{3}$ and above ambient temperatures of $800 \mathrm{~K}$.

\subsection{Comparison of Ignition Delays of JP-8 and JP-8 Surrogate}

Another important portion of this experiment is the development of a surrogate fuel for JP-8. This fuel is developed to match the properties relevant to combustion and spray injection with in a CI engine. Therefore it is important to compare the results of the ignition delay testing of the surrogate fuel with the developed correlation of the JP-8 fuel. This comparison is necessary to determine the validity of the surrogate fuel as a fuel that can be used to model JP-8 combusting sprays with in a computer modeling program. Figure 7-8 below shows this comparison and how well the surrogate matches the ignition delay of the JP-8 baseline fuel. 


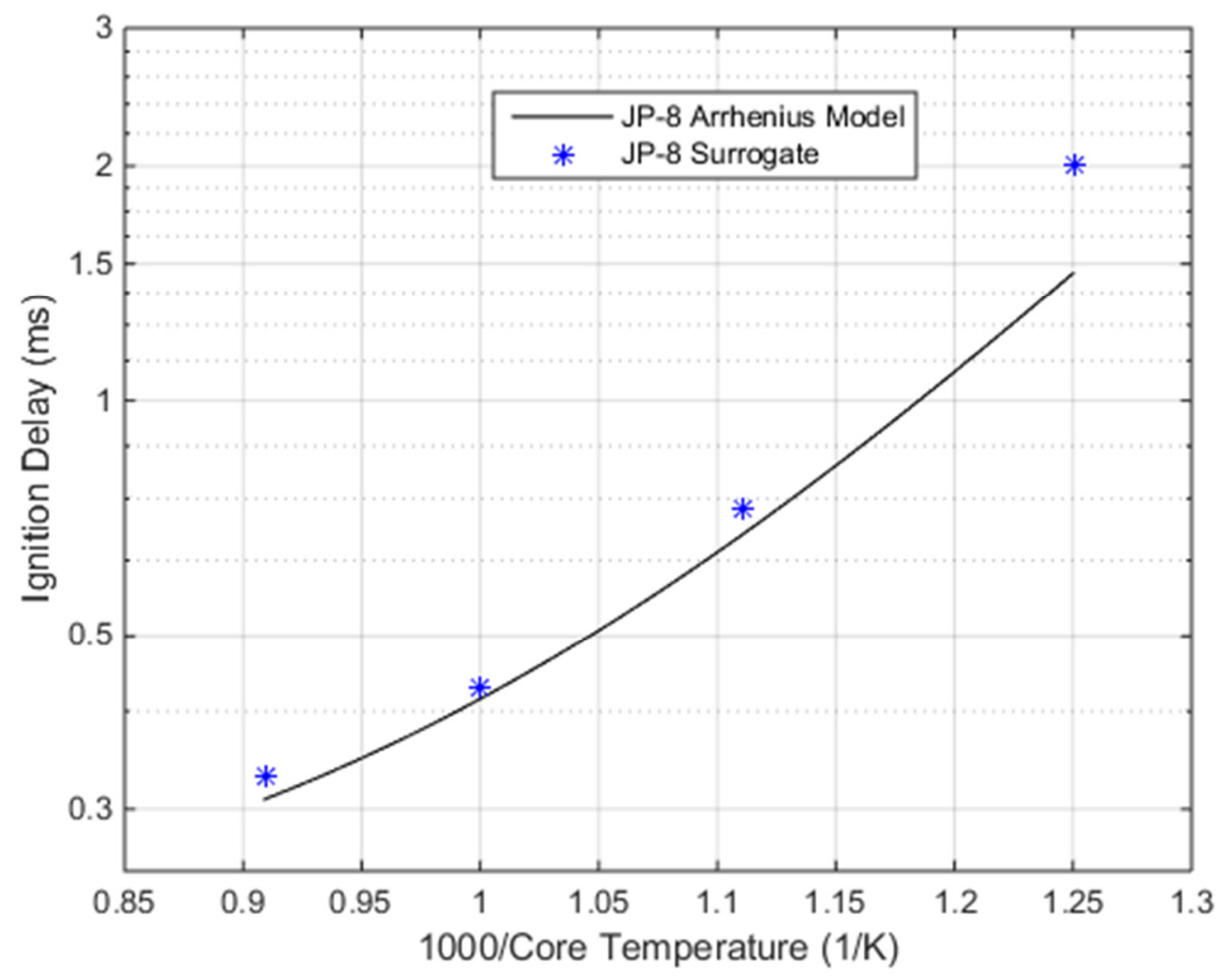

Figure 7-8: Comparison of Ignition Delays of JP-8 Arrhenius Correlation and JP-8 Surrogate. Ambient Core Density $=24.0 \mathrm{~kg} / \mathrm{m}^{3}$

As seen the ignition delays predicted by the JP-8 correlation and the experimental data match well, especially at the higher ambient temperatures. The results of the ignition delay at all ambient temperatures of the surrogate show times that are less than $10 \%$ greater than the predicted JP-8 curve except at the lowest temperature data point, which exhibits about a 30\% increase in the surrogate's ignition delay time. This outlier is likely due to test variation and could be a maximum ignition delay time for this condition. If multiple tests were conducted at this condition and averaged a better fit would likely be possible. Therefore with the exception of this outlier, it is shown that for ignition delay purposes this surrogate matches very well with the baseline JP-8 fuel. 


\subsection{Effect of Fuel Temperature on Ignition Delay}

The effect of fuel temperature on the ignition delays for each fuel is also explored during this testing. As seen in Figure 7-9 and Figure 7-10 the JP-8 fuel sample is tested at three fuel temperatures of 60,93 and $177^{\circ} \mathrm{C}$ while the LCJP-8 sample is tested at just the lower two temperatures. These comparisons show no strong relation between ignition delay and fuel temperature for these fuel samples. Because of this the fuel temperature is chosen to not be a term used to develop the correlations from section 7.1.

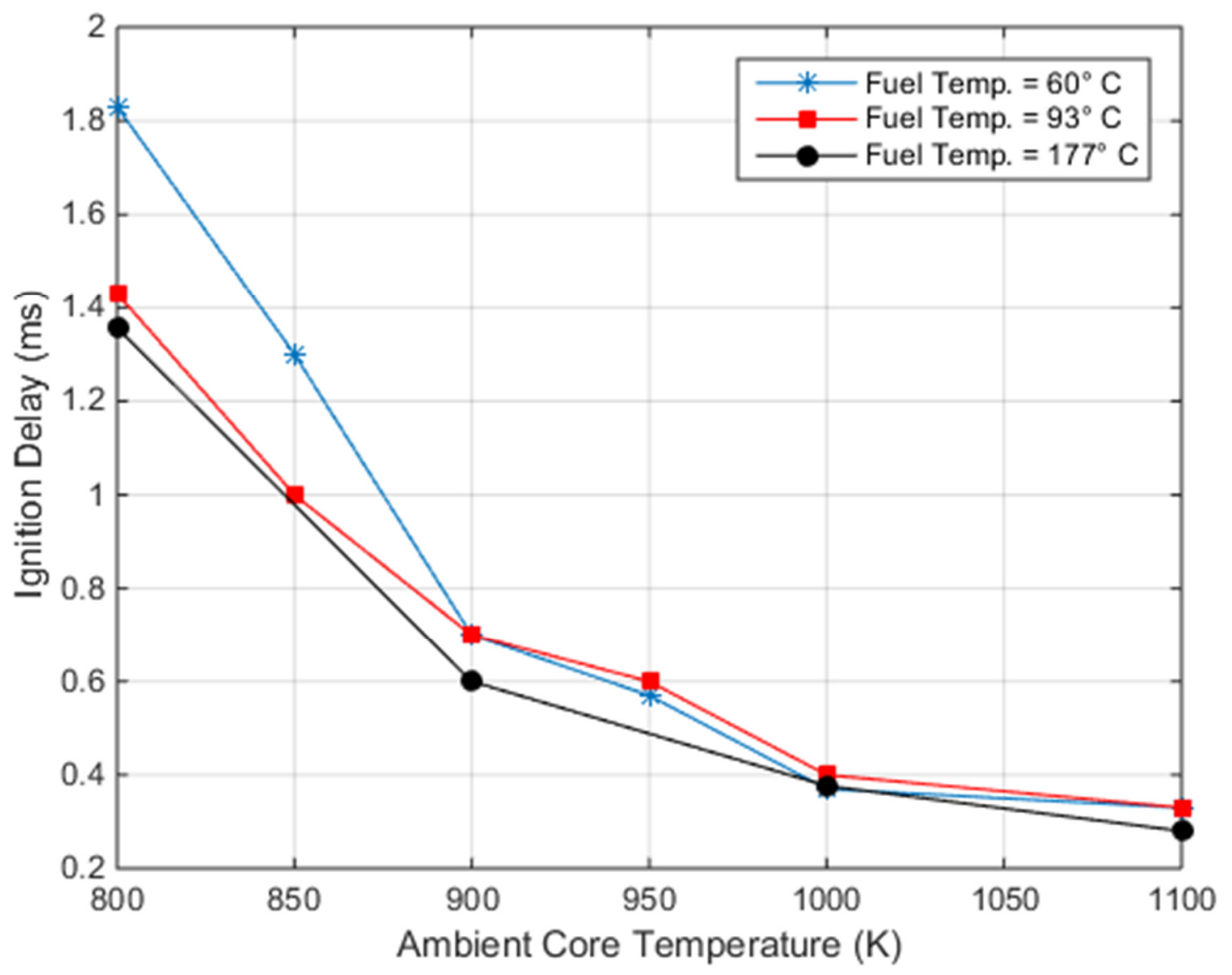

Figure 7-9: Effect of Fuel Temperature on Ignition Delay of JP-8. Injection Pressure $=1000$ bar, Ambient Core Density = $24.0 \mathrm{~kg} / \mathrm{m}^{3}$ 


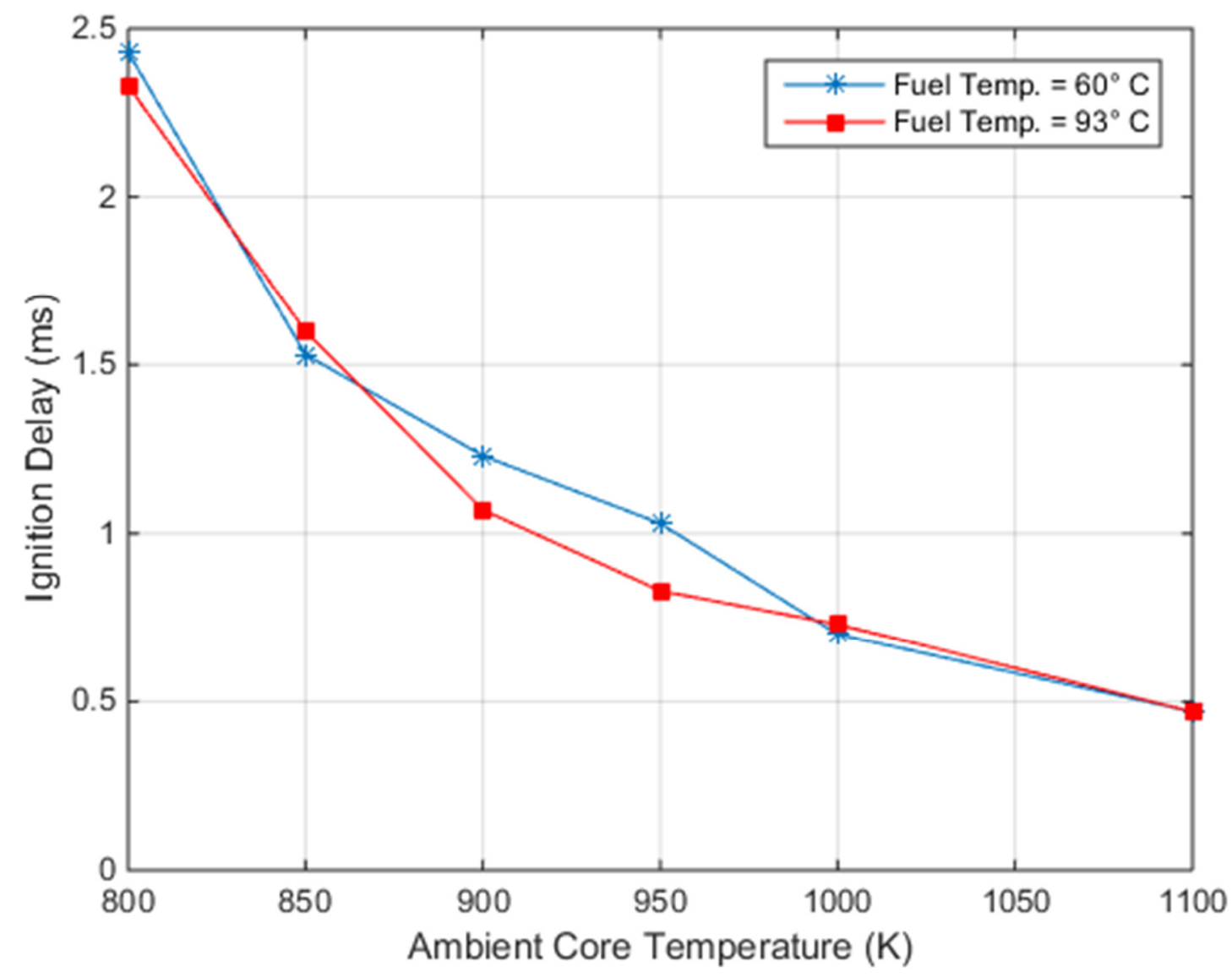

Figure 7-10: Effect of Fuel Temperature on Ignition Delay of LCJP-8. Injection Pressure $=1000$ bar, Ambient Core Density $=24.0 \mathrm{~kg} / \mathrm{m}^{3}$

\subsection{Comparison of Liquid Penetration Results}

Also of importance to this study is the understanding of how the liquid penetration of the fuels compare to one another. Two comparisons are made on this characteristic, between the JP-8 fuel and the LCJP-8 fuel, and another between the JP-8 fuel and its developed surrogate. The first comparison will highlight the differences between the two fuels and how much the synthetically derived jet fuel differs from the baseline fuel. The second 
comparison is needed in order to verify that the developed surrogate fuel matches the baseline fuel in the properties that are relevant to liquid sprays.

\subsubsection{Liquid Penetration Comparison of JP-8 and LCJP-8}

To determine the differences in the fuels and how these fuels effect engine operation, non-combusting spray tests are also conducted. These tests are targeted at looking into how the liquid phase sprays differ in liquid penetration distances at various ambient conditions. Important fuel properties for this testing no longer are dominated by the ignition and combusting properties of the two fuels, now spray and vaporization properties are highlighted. How a liquid penetrating spray develops in time can be seen in section 6.2 in Figure 6-6. As is apparent in that figure the spray has a period of transition from start of injection to a steady state penetration value. This ultimate steady state value is important in determining differences in injector/engine design that need to be made to help CI engines run similarly on a different fuel. Therefore the steady state values are determined from a median penetration value once steady state is achieved. These steady state penetration distances can then be used to analyze the effect of ambient temperature on liquid penetrations and how these penetrations change fuel-to-fuel. This comparison can be seen below in Figure 7-11. 


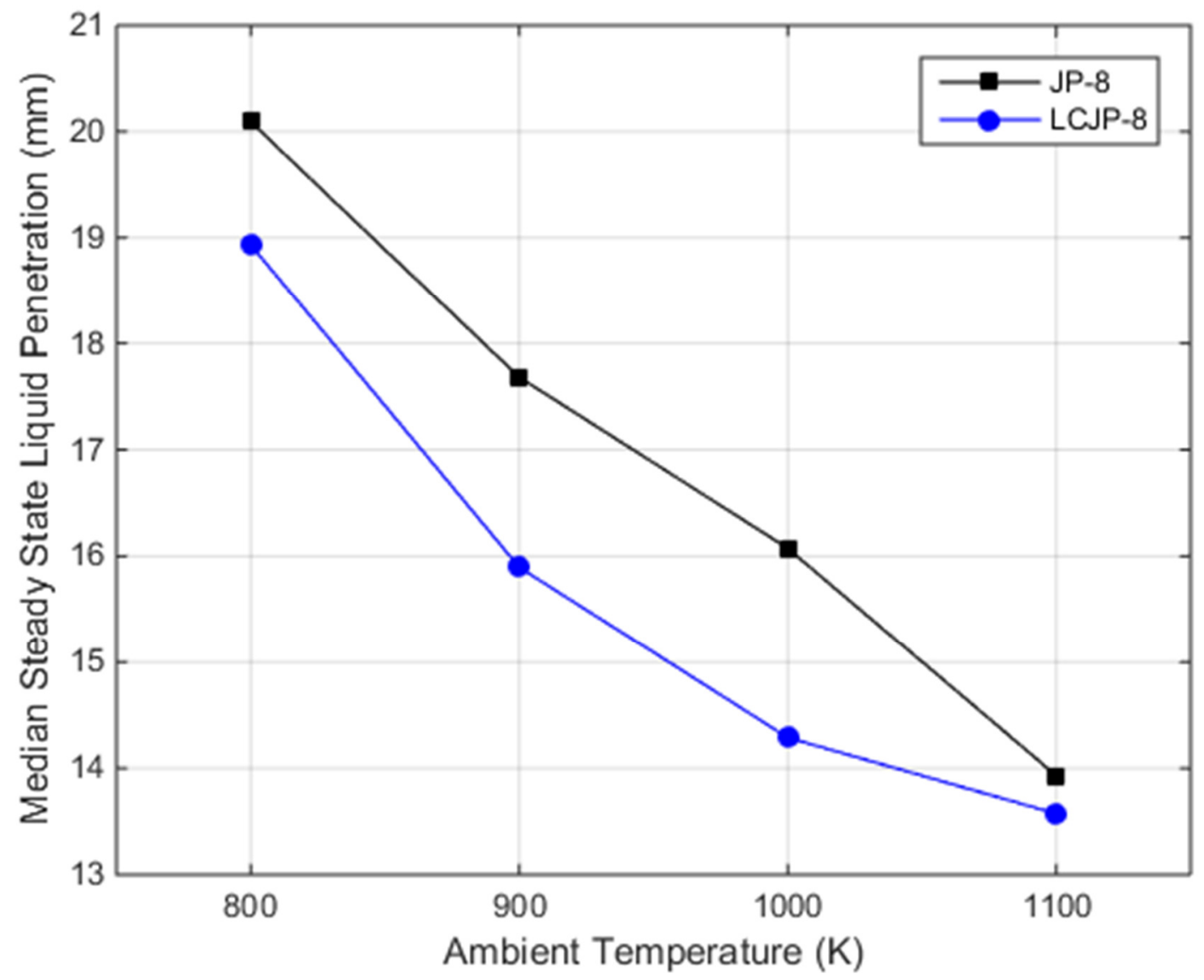

\section{Figure 7-11: Steady State Median Liquid Penetration Comparison of JP-8 and LCJP-8. Ambient Density $=24.0 \mathrm{~kg} / \mathrm{m}^{3}$}

In the figure above the effect ambient temperature has on each fuel's steady state liquid penetration can be compared. As the ambient temperature increases the value of the median steady state liquid penetration decreases, as is expected [9]. But, important to note, the penetration value of the LCJP-8 fuel is $10 \%$ less than that of the JP- 8 fuel at the lower temperatures. As seen, though, the LCJP-8 fuel under-penetrates the JP-8 fuel sample ranging from about $10 \%$ at the lower temperatures to only $2 \%$ at the highest test condition of $1100 \mathrm{~K}$.

This figure shows how the steady state liquid penetrations differ between the JP-8 and LCJP-8 fuels. As the ambient temperature increases the value of the median steady state 
liquid penetration of each fuel decreases, as is expected. Furthermore it is observed that as the ambient temperature increases the difference between the steady state liquid penetrations decreases. This behavior can be attributed to a difference in the T90 temperatures, or the point at which a fuel is $90 \%$ distilled. The T90 temperatures can be found in Table 4-2 where it is shown that there is approximately a $40^{\circ} \mathrm{C}$ lower T90 temperature value for the LCJP-8 compared to the JP-8 fuel. This behavior of the steady state liquid trends in how they collapse to the same value with increasing ambient temperatures is observed in Siebers [9], where the same observation is made and attributed to differences in T90 temperatures.

\subsubsection{Liquid Penetration Comparison of JP-8 and JP-8 Surrogate}

The comparison of the liquid penetrations is also an important aspect in determining the validity of the JP-8 surrogate developed for this testing. The surrogate was developed as a modelling fuel for JP-8 with properties matched as seen in Table 4-5. Properties of interest in this table for the liquid penetration would be the comparisons of the fuel densities and the distillation curve of each fuel. The resultant of the testing and data analysis for the JP-8 fuel surrogate and its median liquid penetration values compared to that of the JP-8 baseline fuel is seen in Figure 7-12. 


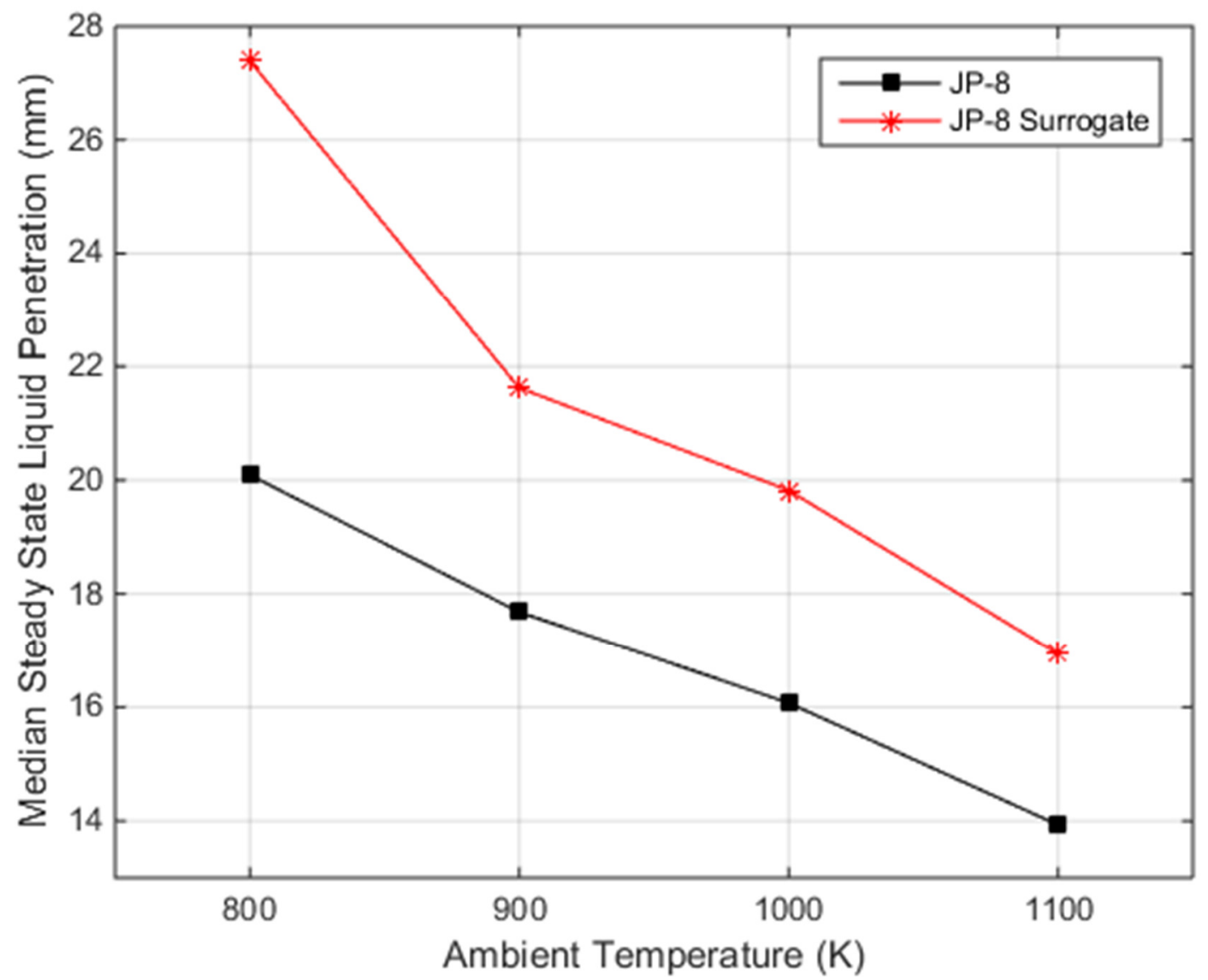

Figure 7-12: Steady State Median Liquid Penetration Comparison of JP-8 and JP-8 Surrogate. Ambient Density $=\mathbf{2 4 . 0} \mathrm{kg} / \mathrm{m}^{3}$

As seen in the above figure the developed surrogate over-penetrates the baseline fuel by a constant 15 to $17 \%$. Some of this over-penetration can be attributed to the $90 \%$ distillation temperature of the surrogate being 3\% higher than the baseline JP-8 fuel but this likely does not account for the entire difference.

Again the same attribute of steady state liquid penetrations collapsing together as the ambient core temperature increases as is discussed in the comparison between the liquid penetrations of JP-8 and LCJP-8 in the previous section. 


\section{Summary and Conclusions}

The goal of this study is to compare and contrast the supplied sample of JP- 8 to the other two fuels used in this study. This comparison was done with both the ignition delays and the steady state liquid penetrations. A sweep of injection pressure, ambient temperature, and ambient density is used to compare both the combusting and non-combusting characteristics of each fuel and how they compare. These conditions sweeps are as follows:

- $\quad$ Injection Pressure: 500 - 1500 bar

- $\quad$ Ambient Temperature: $600-1100 \mathrm{~K}$

- $\quad$ Ambient Density: $7.3-30.2 \mathrm{~kg} / \mathrm{m}^{3}$

Below is a summary of work completed and conclusions made based upon the above variable testing sweeps.

\subsection{Summary}

One fuel used to compare against is the synthetically derived JP-8 (LCJP-8) fuel produced by the Sasol Company out of South Africa. This fuel is of interest in this study for both its potential use as an alternative fuel to JP-8 (used both as a blending agent and on its own) and as an outlying extrema of low CN of the various LCJP-8 samples produced in the same Fischer-Tropsch method by other companies [7].

The first step in this comparison was to develop correlations based on the ignition delay times of each fuel. The development and results of this correlation is discussed in section 7.1. Specifically Figure 7-1, Figure 7-2, and Figure 7-3 show good agreement between the developed correlations and the experimentally determined ignition delay values with differences of less than $15 \%$ between the data and correlation, excluding outliers. 
Next, it is important to compare and validate these correlations against the past work on JP-8 produced by Pickett and Hoogterp, [2]. As seen in Figure 7-5 the ignition delays of this sample of JP-8 perform within the expected bounds of past work laying between the measured ignition delays of the diesel sample and their sample of JP-8 which had a lower CN.

Since the Arrhenius fit shows good correlation with data they are used to compare the two fuels of interest to each other. Figure 7-6 shows the comparison of these two correlations as ambient temperature is swept from $800 \mathrm{~K}$ to $1100 \mathrm{~K}$ and the ambient density is held at $24.0 \mathrm{~kg} / \mathrm{m}^{3}$.

Another task of this work was to develop an in house surrogate for the purpose of use as a modelling fuel. The information that is pertinent to the development of the surrogate and the goals of this surrogate development can be seen in section 0. Table 4-5 shows the relevant properties used to design the surrogate for this study. This surrogate is tested for ignition delay and then compared to the ignition delay times of the JP-8. Figure 7-8 shows this comparison.

Besides ignition delay testing, this work also looks into the differences in the liquid penetrations of the fuels and how these steady state penetration values compare. Section 7.6 has the results of the liquid penetration testing and shows the comparison between both the JP-8 and the LCJP-8 fuels and the JP-8 and the developed JP-8 surrogate fuels. The steady state liquid penetration can be seen in Figure 7-11 and Figure 7-12.

\subsection{Conclusions}

The following lists a summary of the conclusions made in the results section.

- The developed ignition delay predictive curves for both the JP-8 baseline fuel and the LCJP-8 fuel match well with the experimental data to within 10-15\% for JP-8 and $15 \%$ for LCJP-8. 
- $\quad$ At the test conditions of $24.0 \mathrm{~kg} / \mathrm{m}^{3}$ and 1000 bar injection pressure for the JP-8 fuel sample it is shown that up to a $9 \%$ variance can be expected, as seen in Figure 7-4.

- $\quad$ The JP-8 ignition delay predictive curves match well with the past work done by Pickett and Hoogterp [2] showing a fit between their lower CN JP-8 sample and the results of their diesel sample.

- The LCJP-8 fuel correlation shows ignition delays that are 50-80\% longer than that of the ignition delay of the baseline fuel over the range of ambient temperatures and densities covered by this testing.

- The experimental data on the ignition delay of the developed JP-8 surrogate shows less than a $10 \%$ difference with the JP-8 correlation at all tested ambient temperatures expect the lowest temperature of $800 \mathrm{~K}$ where a $30 \%$ deviation is seen.

- The effects of fuel temperature on the ignition delay of each fuel is found to be insignificant and is therefore not included in the development of the Arrhenius correlations.

- The LCJP-8 under-penetrates the JP-8 steady state liquid penetration values by approximately $10 \%$ at lower ambient temperatures and only by $2 \%$ at higher ambient temperatures. This behavior where the steady state liquid penetrations converge onto each other as ambient temperature increase is observed by Siebers, [9], and is attributed to the lower penetration fuel having a lower T90 distillation temperature.

- $\quad$ The developed JP-8 surrogate shows a longer steady state liquid penetration than the JP-8 baseline fuel by about $15-17 \%$. The $90 \%$ distillation temperature of the surrogate is slightly higher than the baseline JP-8 fuel, approximately $3 \%$ higher, attributing to some of this over-penetration but it is likely that another 
unaccounted for difference also plays a significant role such as differences in fuel properties that were not part of the surrogate design criteria.

\subsection{Future Work}

Recommendations for future work include the following.

- $\quad$ Further explore JP-8 and LCJP-8 at the ambient core densities of 14.8, 24.0 and $30.2 \mathrm{~kg} / \mathrm{m}^{3}$ to confirm finds with more repeats of test condition.

- Redevelop correlation coefficients based on averaged values of ignition delay at the repeated test conditions.

- $\quad$ Include pressure based and photodiode based ignition delay diagnostics to confirm with the imaging based findings.

- Develop a new surrogate which matches both ignition/combusting properties as well as spray characteristics. 


\section{References}

[1] T. Moran, "The logistics battle: U.S. wages a one-fuel war," Automotive News, 2003.

[2] L. M. Pickett and L. Hoogterp, "Fundamental Spray and Combustion Measurements of JP-8 at Diesel Conditions," SAE International, vol. 1, no. 1, pp. 108-118, 2008.

[3] P. Schihl, L. Hoogterp and H. Pangilinan, "Assessment of JP-8 and DF-2 Evaporation Rate and Cetane Number Differences on a Military Diesel Engine," SAE International, vol. 1549, no. 01, 2006.

[4] R. G. Papagiannakis, P. N. Kotsiopoulos, D. T. Hountalas and E. Yfantis, "Single Fuel Research Program Comparative Results of the Use of JP-8 Aviation Fuel versus Diesel Fuel on a Direct Injection and Indirect Injection Diesel Engine," $S A E$, vol. 1673, no. 01, 2006.

[5] "Petroleum Quality Information System," 2008.

[6] P. Schihl, E. Gingrich and L. Decker, "The Combustion and Ignition Characteristics of Varying Blend Ratios of JP-8 and a Coal to Liquid Fischer-Tropsch Jet Fuel in a Military Relevant Single Cylinder Diesel Engine," SAE International, vol. 9073, no. 01, pp. 501-514, 2015.

[7] C. A. Moses and P. N. J. Roets, "Properties, Characteristics, and Combustion Performance of Sasol Fully Synthetic Jet Fuel," Journal of Engineering for Gas Turbines and Power, ASME, vol. 131, 2009. 
[8] P. Schihl, L. Hoogterp-Decker and E. Gingrich, "The Ignition Behavior of a Coal to Liquid Fischer-Tropsch Jet Fuel in a Military Relevant Single Cylinder Diesel Engine," SAE International Journal of Fuels and Lubricants, vol. 5, no. 2, pp. 785802, 2012.

[9] D. L. Siebers, "Liquid Phase Fuel Penetration in Diesel Sprays," SAE, vol. 08, no. 09, pp. 1-23, 1998.

[10] J. D. Naber and D. L. Siebers, "Effects of Gas Density and Vaporization on Penetration and Dispersion of Diesel Sprays," SAE, no. 960034, pp. 59-88, 1996.

[11] J. E. Nesbitt, "Combustion Vessel Laboratory Development Focusing on Optical Diagnostic Subsystem Integration through the Dynamic Characteriztion of Fuel Sprays," Michigan Technological University, 2008.

[12] D. L. Siebers, "Ignition Delay Characteristics of Alternative Diesel Fuels: Implications on Cetane Number," SAE, vol. 10, no. 01, 1985.

[13] R. P. Durrett, D. C. Oren and C. R. Ferguson, "A Multidimensional Data Set for Diesel Combustion Model Validation: I - Initial Conditions, Pressure History and Spray Shapes," in International fuels and lubricants meeting and exposition, Toronto, Canada, 1987.

[14] D. C. Oren, S. Wahiduzzaman and C. R. Ferguson, "A Diesel Combustion Bomb: Proof of Concept," SAE, vol. 841358, 1984.

[15] Stanford Research Systems, "DG645 Digital Delay Generator," Stanford Research Systems, Inc., 2008.

[16] Photron Limited, "FASTCAM SA1.1/FASTCAM SA1.1 RV Hardware Manual, Revision 1.07E". 
[17] LIGHTSPEED Technologies, "The DRAGON series High Power LED Light Sources".

[18] M. Tang, Email Correspondence, 2016.

[19] N. Otsu, "A Threshold Selection Method from Gray-Level Histograms," IEEE, vol. 9, no. 1, pp. 62-66, 1979.

[20] J. S. Lim, Two-Dimensional Signal and Image Processing, Prentice Hall, 1990.

[21] J. B. Heywood, Internal Combustion Engine Fundamentals, New York: McGrawHill, 1988.

[22] J. D. Naber, D. L. Siebers and S. S. Julio, "Effects of Natural Gas Composition on Ignition Delay Under Diesel Conditions," Lawrence Livermore National Laboratory, Irvine, 1994.

[23] G. Lequien, S. Skeen, J. Manin, L. Pickett and O. Andersson, "Ignition Quality Effects on Lift-Off Stabilization of Synthetic Fuels," SAE International, 2015. 


\section{Appendix}

This section includes all supplemental information and documentation not placed in the main body of the report

\subsection{Optical Filter Characteristics}

Optical filter characteristics for the filters used to reduce the broadband emittance of the soot oxidation in the combustion tests are shown in Figure 10-1 and Figure 10-2.

Combined, they have a significant transmission reduction outside of the visible spectrum.

The peak transmission occurs near the green LED wavelength of $530 \mathrm{~nm}$. Combined they have very low transmission $(<1 \%)$ above $700 \mathrm{~nm}$ until nearly $1200 \mathrm{~nm}$ which is well into the IR and above the transmission of the optics in the camera. $1200 \mathrm{~nm}$ corresponded to the peak in black-body radiation for a temperature of $2500 \mathrm{~K}$.

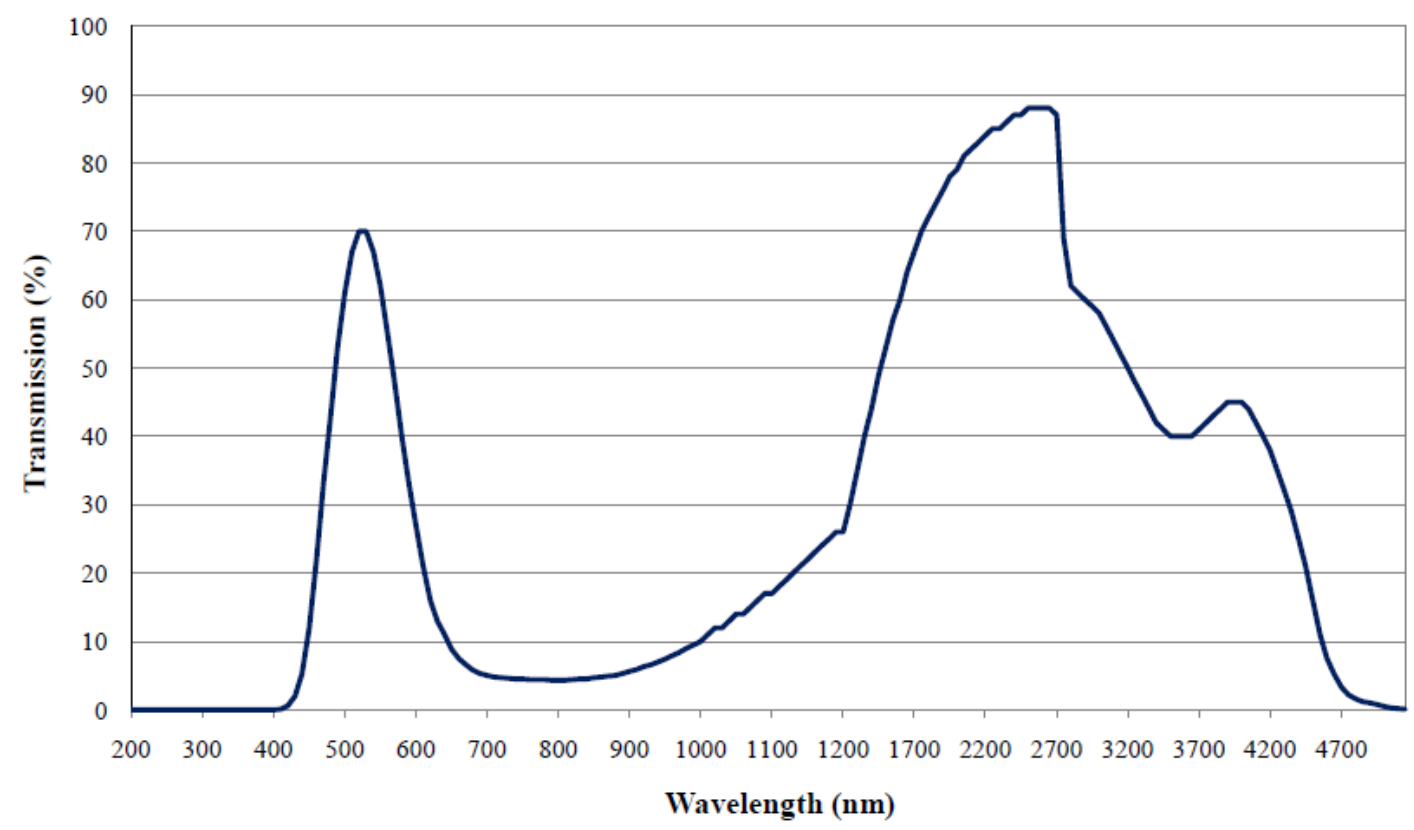

Figure 10-1: Edmund Optics, VG-9 filter transmission (From Edmund Scientific, 2014) 


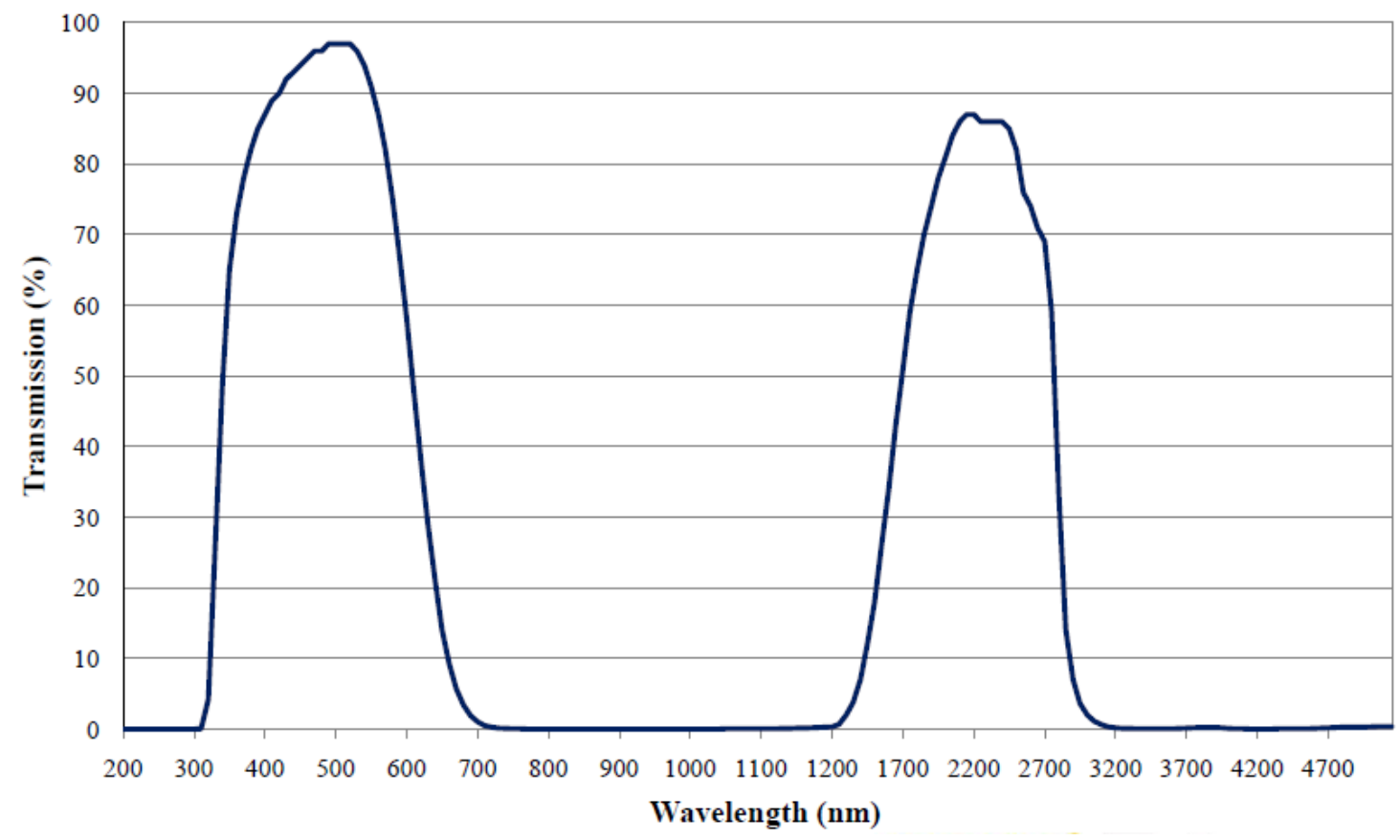

Figure 10-2: Edmund Optics, BG-39 filter transmission (From Edmund Scientific, 2014) 
10.2 Combusting Test Matrix, JP-8 and LCJP-8

Table 10-1: Combusting Test Matrix, $7.3 \mathrm{~kg} / \mathrm{m}^{3}$ Ambient Density

\begin{tabular}{|c|c|c|c|c|c|}
\hline $\begin{array}{c}\text { Fuel } \\
\text { Temperature } \\
\left({ }^{\circ} \mathrm{C}\right)\end{array}$ & $\begin{array}{c}\text { Injection } \\
\text { Pressure } \\
\text { (bar) }\end{array}$ & $\begin{array}{l}\text { Ambient } \\
\text { Density } \\
\left(\mathrm{kg} / \mathrm{m}^{3}\right)\end{array}$ & $\begin{array}{c}\text { Ambient } \\
\text { Temperature } \\
\text { (K) }\end{array}$ & $\begin{array}{c}\text { Charge } \\
\text { Gas \% } \\
\mathrm{O}_{2}\end{array}$ & Fuel \\
\hline \multirow{9}{*}{63} & 500 & \multirow{18}{*}{7.3} & \multirow{3}{*}{600} & \multirow{18}{*}{21} & \multirow{18}{*}{$\begin{array}{c}\text { LCJP-8 } \\
\text { and } \\
\text { JP-8 }\end{array}$} \\
\hline & 1000 & & & & \\
\hline & 1500 & & & & \\
\hline & 500 & & \multirow{3}{*}{700} & & \\
\hline & 1000 & & & & \\
\hline & 1500 & & & & \\
\hline & 500 & & \multirow{3}{*}{800} & & \\
\hline & 1000 & & & & \\
\hline & 1500 & & & & \\
\hline \multirow{9}{*}{93} & 500 & & \multirow{3}{*}{600} & & \\
\hline & 1000 & & & & \\
\hline & 1500 & & & & \\
\hline & 500 & & \multirow{3}{*}{700} & & \\
\hline & 1000 & & & & \\
\hline & 1500 & & & & \\
\hline & 500 & & \multirow{3}{*}{800} & & \\
\hline & 1000 & & & & \\
\hline & 1500 & & & & \\
\hline
\end{tabular}


Table 10-2: Combusting Test Matrix, 14.8 kg/m³ Ambient Density

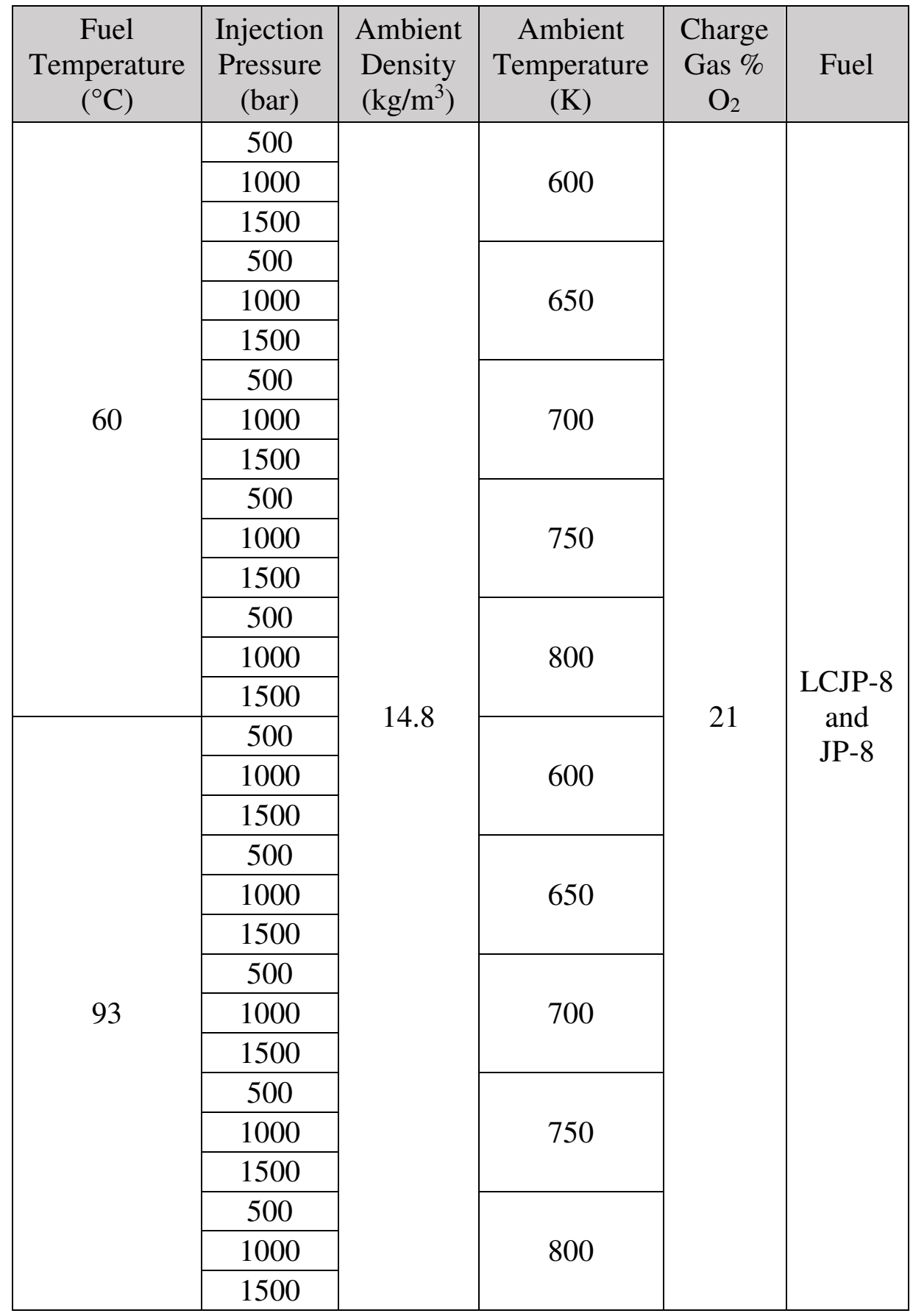


Table 10-3: Combusting Test Matrix, $18.0 \mathrm{~kg} / \mathrm{m}^{3}$ Ambient Density

\begin{tabular}{|c|c|c|c|c|c|}
\hline $\begin{array}{c}\text { Fuel } \\
\text { Temperature } \\
\left({ }^{\circ} \mathrm{C}\right)\end{array}$ & $\begin{array}{c}\text { Injection } \\
\text { Pressure } \\
\text { (bar) }\end{array}$ & $\begin{array}{l}\text { Ambient } \\
\text { Density } \\
\left(\mathrm{kg} / \mathrm{m}^{3}\right)\end{array}$ & $\begin{array}{c}\text { Ambient } \\
\text { Temperature } \\
\text { (K) }\end{array}$ & $\begin{array}{c}\text { Charge } \\
\text { Gas \% } \\
\mathrm{O}_{2}\end{array}$ & Fuel \\
\hline \multirow{9}{*}{60} & 500 & \multirow{18}{*}{18.0} & \multirow{3}{*}{600} & \multirow{18}{*}{21} & \multirow{18}{*}{$\begin{array}{c}\text { LCJP-8 } \\
\text { and } \\
\text { JP-8 }\end{array}$} \\
\hline & 1000 & & & & \\
\hline & 1500 & & & & \\
\hline & 500 & & \multirow{3}{*}{700} & & \\
\hline & 1000 & & & & \\
\hline & 1500 & & & & \\
\hline & 500 & & \multirow{3}{*}{800} & & \\
\hline & 1000 & & & & \\
\hline & 1500 & & & & \\
\hline \multirow{9}{*}{93} & 500 & & \multirow{3}{*}{600} & & \\
\hline & 1000 & & & & \\
\hline & 1500 & & & & \\
\hline & 500 & & \multirow{3}{*}{700} & & \\
\hline & 1000 & & & & \\
\hline & 1500 & & & & \\
\hline & 500 & & \multirow{3}{*}{800} & & \\
\hline & 1000 & & & & \\
\hline & 1500 & & & & \\
\hline
\end{tabular}


Table 10-4: Combusting Test Matrix, 24.0 kg/m³ Ambient Density

\begin{tabular}{|c|c|c|c|c|c|}
\hline $\begin{array}{c}\text { Fuel } \\
\text { Temperature } \\
\left({ }^{\circ} \mathrm{C}\right)\end{array}$ & $\begin{array}{c}\text { Injection } \\
\text { Pressure } \\
\text { (bar) }\end{array}$ & $\begin{array}{l}\text { Ambient } \\
\text { Density } \\
\left(\mathrm{kg} / \mathrm{m}^{3}\right)\end{array}$ & $\begin{array}{c}\text { Ambient } \\
\text { Temperature } \\
(\mathrm{K})\end{array}$ & $\begin{array}{c}\text { Charge } \\
\text { Gas \% } \\
\mathrm{O}_{2}\end{array}$ & Fuel \\
\hline \multirow{18}{*}{60} & 500 & \multirow{34}{*}{24.0} & \multirow{3}{*}{800} & \multirow{34}{*}{21} & \multirow{34}{*}{$\begin{array}{c}\text { LCJP-8 } \\
\text { and } \\
\text { JP-8 }\end{array}$} \\
\hline & 1000 & & & & \\
\hline & 1500 & & & & \\
\hline & 500 & & \multirow{3}{*}{850} & & \\
\hline & 1000 & & & & \\
\hline & 1500 & & & & \\
\hline & 500 & & \multirow{3}{*}{900} & & \\
\hline & 1000 & & & & \\
\hline & 1500 & & & & \\
\hline & 500 & & \multirow{3}{*}{950} & & \\
\hline & 1000 & & & & \\
\hline & 1500 & & & & \\
\hline & 500 & & \multirow{3}{*}{1000} & & \\
\hline & 1000 & & & & \\
\hline & 1500 & & & & \\
\hline & 500 & & & & \\
\hline & 1000 & & 1100 & & \\
\hline & 1500 & & & & \\
\hline \multirow{16}{*}{93} & 500 & & \multirow{3}{*}{800} & & \\
\hline & 1000 & & & & \\
\hline & 1500 & & & & \\
\hline & 500 & & \multirow{3}{*}{850} & & \\
\hline & 1000 & & & & \\
\hline & 1500 & & & & \\
\hline & 500 & & \multirow{3}{*}{900} & & \\
\hline & 1000 & & & & \\
\hline & 1500 & & & & \\
\hline & 500 & & \multirow{3}{*}{950} & & \\
\hline & 1000 & & & & \\
\hline & 1500 & & & & \\
\hline & 500 & & \multirow{3}{*}{1000} & & \\
\hline & 1000 & & & & \\
\hline & 1500 & & & & \\
\hline & 500 & & 1100 & & \\
\hline
\end{tabular}




\begin{tabular}{|l|l|l|l|l|l|}
\hline & 1000 & & & & \\
\cline { 2 - 3 } & 1500 & & & & \\
\hline
\end{tabular}

Table 10-5: Combusting Test Matrix, $30.2 \mathrm{~kg} / \mathrm{m}^{3}$ Ambient Density

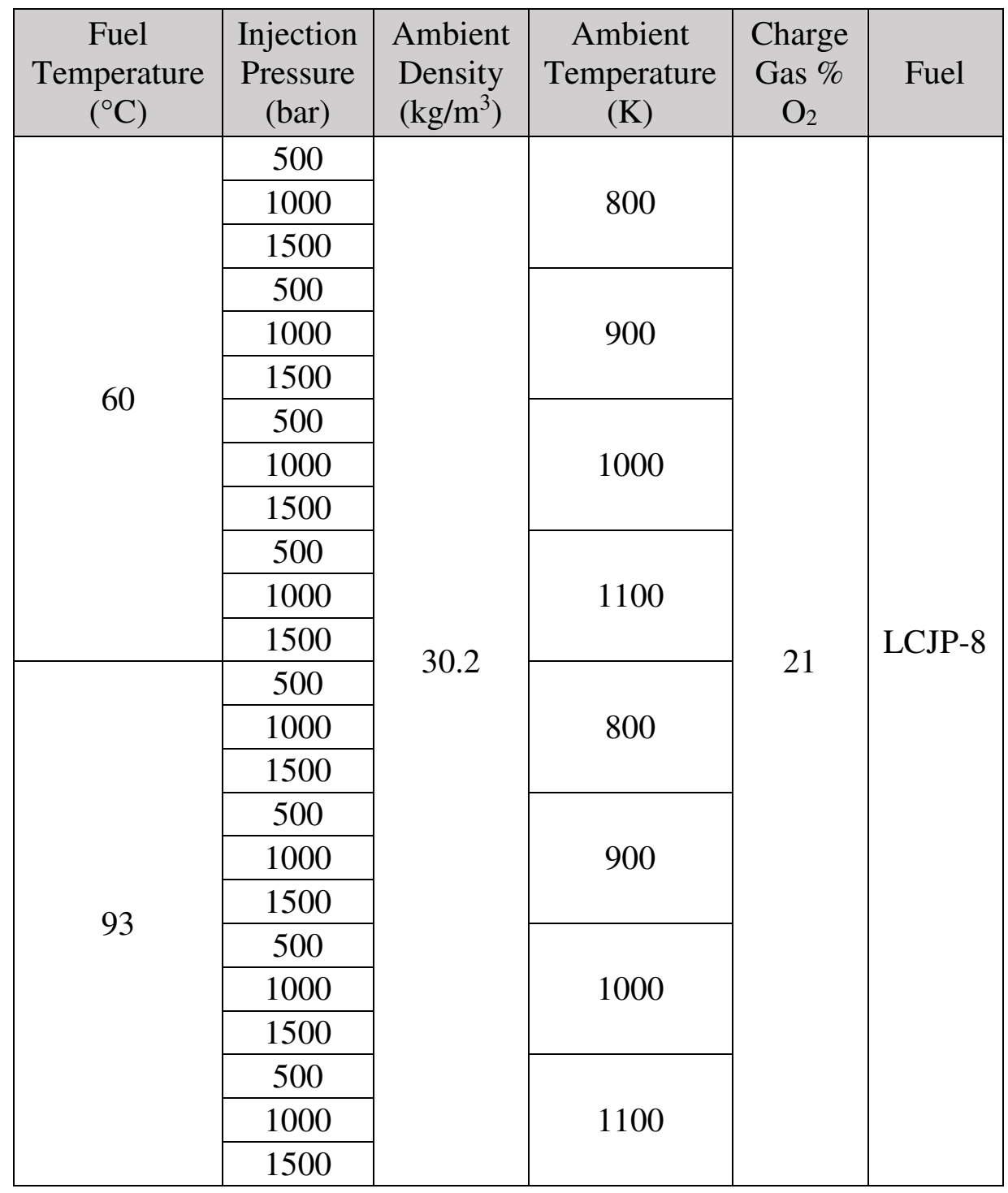




\subsection{Test Matrix for the Statistical Testing of JP-8}

Table 10-6: Statistical Testing of JP-8 at Varying Fuel Temperatures

\begin{tabular}{|c|c|c|c|c|c|c|}
\hline $\begin{array}{c}\text { Fuel } \\
\text { Temperature } \\
\left({ }^{\circ} \mathrm{C}\right)\end{array}$ & $\begin{array}{c}\text { Injection } \\
\text { Pressure } \\
\text { (bar) }\end{array}$ & $\begin{array}{l}\text { Ambient } \\
\text { Density } \\
\left(\mathrm{kg} / \mathrm{m}^{3}\right)\end{array}$ & $\begin{array}{l}\text { Ambient } \\
\text { Temperature } \\
\text { (K) }\end{array}$ & $\begin{array}{c}\text { Charge } \\
\text { Gas \% } \\
\mathrm{O}_{2}\end{array}$ & Fuel & $\begin{array}{l}\text { Number } \\
\text { of tests } \\
\text { at each } \\
\text { condition }\end{array}$ \\
\hline \multirow{4}{*}{93} & \multirow{8}{*}{1000} & \multirow{8}{*}{24} & 800 & \multirow{8}{*}{21} & \multirow{8}{*}{ JP-8 } & \multirow{4}{*}{5} \\
\hline & & & 900 & & & \\
\hline & & & 1000 & & & \\
\hline & & & 1100 & & & \\
\hline \multirow{4}{*}{177} & & & 800 & & & \multirow{4}{*}{3} \\
\hline & & & 900 & & & \\
\hline & & & 1000 & & & \\
\hline & & & 1100 & & & \\
\hline
\end{tabular}




\subsection{Combusting Test Matrix, JP-8 Surrogate}

Table 10-7: Combusting Test Matrix, JP-8 Surrogate

\begin{tabular}{|c|c|c|c|c|c|}
\hline $\begin{array}{c}\text { Fuel } \\
\text { Temperature } \\
\left({ }^{\circ} \mathrm{C}\right)\end{array}$ & $\begin{array}{l}\text { Injection } \\
\text { Pressure } \\
\text { (bar) }\end{array}$ & $\begin{array}{l}\text { Ambient } \\
\text { Density } \\
\left(\mathrm{kg} / \mathrm{m}^{3}\right)\end{array}$ & $\begin{array}{l}\text { Ambient } \\
\text { Temperature } \\
\text { (K) }\end{array}$ & $\begin{array}{c}\text { Charge } \\
\text { Gas \% } \\
\mathrm{O}_{2}\end{array}$ & Fuel \\
\hline \multirow{7}{*}{93} & \multirow{7}{*}{1000} & \multirow{3}{*}{14.8} & 600 & \multirow{7}{*}{21} & \multirow{7}{*}{$\begin{array}{c}\text { JP-8 } \\
\text { Surrogate }\end{array}$} \\
\hline & & & 700 & & \\
\hline & & & 800 & & \\
\hline & & \multirow{4}{*}{24.0} & 800 & & \\
\hline & & & 900 & & \\
\hline & & & 1000 & & \\
\hline & & & 1100 & & \\
\hline
\end{tabular}




\subsection{Non-combusting Spray Test Matrix}

Table 10-8: Non-combusting Spray Test Matrix

\begin{tabular}{|c|c|c|c|c|c|}
\hline $\begin{array}{c}\text { Fuel } \\
\text { Temperature } \\
\left({ }^{\circ} \mathrm{C}\right)\end{array}$ & $\begin{array}{l}\text { Injection } \\
\text { Pressure } \\
\text { (bar) }\end{array}$ & $\begin{array}{l}\text { Ambient } \\
\text { Density } \\
\left(\mathrm{kg} / \mathrm{m}^{3}\right)\end{array}$ & $\begin{array}{l}\text { Ambient } \\
\text { Temperature } \\
(\mathrm{K})\end{array}$ & $\begin{array}{c}\text { Charge } \\
\text { Gas \% } \\
\mathrm{O}_{2}\end{array}$ & Fuel \\
\hline \multirow{7}{*}{93} & \multirow{7}{*}{1000} & \multirow{3}{*}{14.8} & 600 & \multirow{7}{*}{0} & \multirow{7}{*}{$\begin{array}{c}\text { LCJP-8, } \\
\text { JP-8 and } \\
\text { JP-8 } \\
\text { Surrogate }\end{array}$} \\
\hline & & & 700 & & \\
\hline & & & 800 & & \\
\hline & & \multirow{4}{*}{24} & 800 & & \\
\hline & & & 900 & & \\
\hline & & & 1000 & & \\
\hline & & & 1100 & & \\
\hline
\end{tabular}

